\title{
PREDICTION OF COOLANT TEMPERATURE FIELD \\ IN A BREEDER REACTOR \\ INCLUDING INTERASSEMBLY HEAT TRANSFER
}

by

Brian Cheng-jean Chen

Ne11 E. Todreas

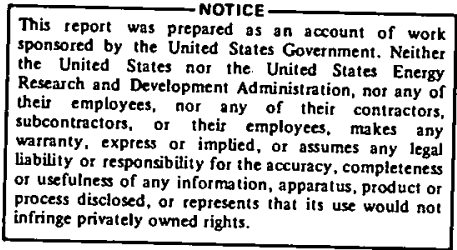

May, 1975

DEPARTMENT OF NUCLEAR ENGINEERING

MASSACHUSETTS INSTITUTE OF TECHNOLOGY

Cambridge, Massachusetts

02139

ERDA Research and Development

Contract AT $(11-1)-2245$

U.S. Energy Research and Development Administration

\section{$<$}




\section{DISCLAIMER}

This report was prepared as an account of work sponsored by an agency of the United States Government. Neither the United States Government nor any agency Thereof, nor any of their employees, makes any warranty, express or implied, or assumes any legal liability or responsibility for the accuracy, completeness, or usefulness of any information, apparatus, product, or process disclosed, or represents that its use would not infringe privately owned rights. Reference herein to any specific commercial product, process, or service by trade name, trademark, manufacturer, or otherwise does not necessarily constitute or imply its endorsement, recommendation, or favoring by the United States Government or any agency thereof. The views and opinions of authors expressed herein do not necessarily state or reflect those of the United States Government or any agency thereof. 


\section{DISCLAIMER}

Portions of this document may be illegible in electronic image products. Images are produced from the best available original document. 
ABSTRACT

A general procedure for investigating the effect of the interassembly heat transfer on the temperature field of a breeder reactor is provided. Th1s procedure ut1lizes a simple multiassembly code, SUPERENERGY, and a set of normalized assembly maps derived from this code. We applied this procedure to the Clinch River Breeder Reactor to study the effect of including various concentric rings of coupled assemblies on the temperature prediction of the central assembly. We found insignificant perturbation from the inclusion of second ring assemblies and important perturbation from the inclusion of first ring assemblies. 


\section{ACKNOWLEDGMENTS}

We would like to express our appreclation to Frank Carre for his assistance and participation in the programming. We also value the discussions with Dr. Lothar Wolf and Dr. Ehsan Khan. We thank Dr. Mario Carelli at the advanced reactors division of Westinghouse Electric Corporation for the data he provided on the Clinch River Breeder Reactor. 
TABLE OF CONTENTS

Page

Abstract 2

Acknowledgments 3

Table of Contents 4

List of Figures 6

List of Tables 8

1. Introduction, 10

2. Physical Model 12

3. Computational Method 16

4. Normalized Assembly Studies 20

4.1 Single Assembly Studies 22

4.2 Multiassembly Studies 23

5. Prediction of Interassembly Heat Transfer
Between Blanket Assemblies

5.1 Prediction of Assembly Temperature Flelds Considering the Six (First Ring) Surrounding Assemblies

5.2 Prediction of Assembly Temperature Fields Considering the Nineteen (First and Second Ring) Surrounding Assemblies 30

6. Computational Strategies for LMFBR Cores 33

6.1 Classification of Combinations of Assemblies with Different Flow Rates 33

6.2 Strategies in Selecting the Number of
Assemblies for Coupling 
Page

7. Example of Heat Penetration from Different Levels of Insulation

8. Conclusion and Discussion 37

Nomenclature $\quad 40$

List of References 43

Figures 44

Tables $\quad 82$

Appendix 1 SUPERENERGY Manual 1-1

Appendix 2 Listing of Code SUPERENERGY 2-1

Appendix 3 A Sample Problem 3-1 
LIST OF FIGURES

\begin{tabular}{|c|c|c|c|}
\hline & & : & Page \\
\hline Figure & 1 & Subchannels in an Assembly & 44 \\
\hline F1gure & 2 & $\begin{array}{l}\text { Regions of Assembly with Different } \\
\text { Flow Rates }\end{array}$ & 45 \\
\hline Figure & 3 & $\begin{array}{l}\text { Numbering Scheme for the Nelghboring } \\
\text { Subchannels }\end{array}$ & 46 \\
\hline Figure & 4 & $\begin{array}{l}\text { Fuel and Blanket Assemblies Orificing } \\
\text { Scheme and Nominal Flow Rates at Plant } \\
\text { Thermal and Hydraulic Design Condlions }\end{array}$ & 47 \\
\hline Figure & 5 & $\begin{array}{l}\text { Subchannel Numbering Scheme for Fuel } \\
\text { Assembly }\end{array}$ & 48 \\
\hline Figure & 6 & $\begin{array}{l}\text { Subchannel Numbering Scheme for } \\
\text { Blanket Assembly }\end{array}$ & 49 \\
\hline Figure & 7 & $\begin{array}{l}\text { Temperature Prediction for Zone } 1 \\
\text { Assembly }\end{array}$ & 50 \\
\hline Figure & 8 & $\begin{array}{l}\text { Temperature Prediction for Zone } 2 \\
\text { Assembly }\end{array}$ & 51 \\
\hline Figure & 9 & $\begin{array}{l}\text { Temperature Prediction for Zone } 3 \\
\text { Assembly }\end{array}$ & 52 \\
\hline Figure & 10 & $\begin{array}{l}\text { Temperature Prediction for Zone } 4 \\
\text { Assembly }\end{array}$ & 53 \\
\hline Figure & 11 & $\begin{array}{l}\text { Temperature Prediction for Zone } 5 \\
\text { Assembly }\end{array}$ & 54 \\
\hline F1gure & 12 & $\begin{array}{l}\text { Temperature Prediction for Zone } 6 \\
\text { Assembly }\end{array}$ & 55 \\
\hline Figure & 13 & $\begin{array}{l}\text { Temperature Prediction for Zone } 7 \\
\text { Assembly }\end{array}$ & 56 \\
\hline Figure & 14 & $\begin{array}{l}\text { Temperature Prediction for Zone } 8 \\
\text { Assembly }\end{array}$ & 57 \\
\hline Figure & 15 & $\begin{array}{l}\text { Temperature Prediction for Zone } 9 \\
\text { Assembly }\end{array}$ & 58 \\
\hline & & (continued) & \\
\hline
\end{tabular}




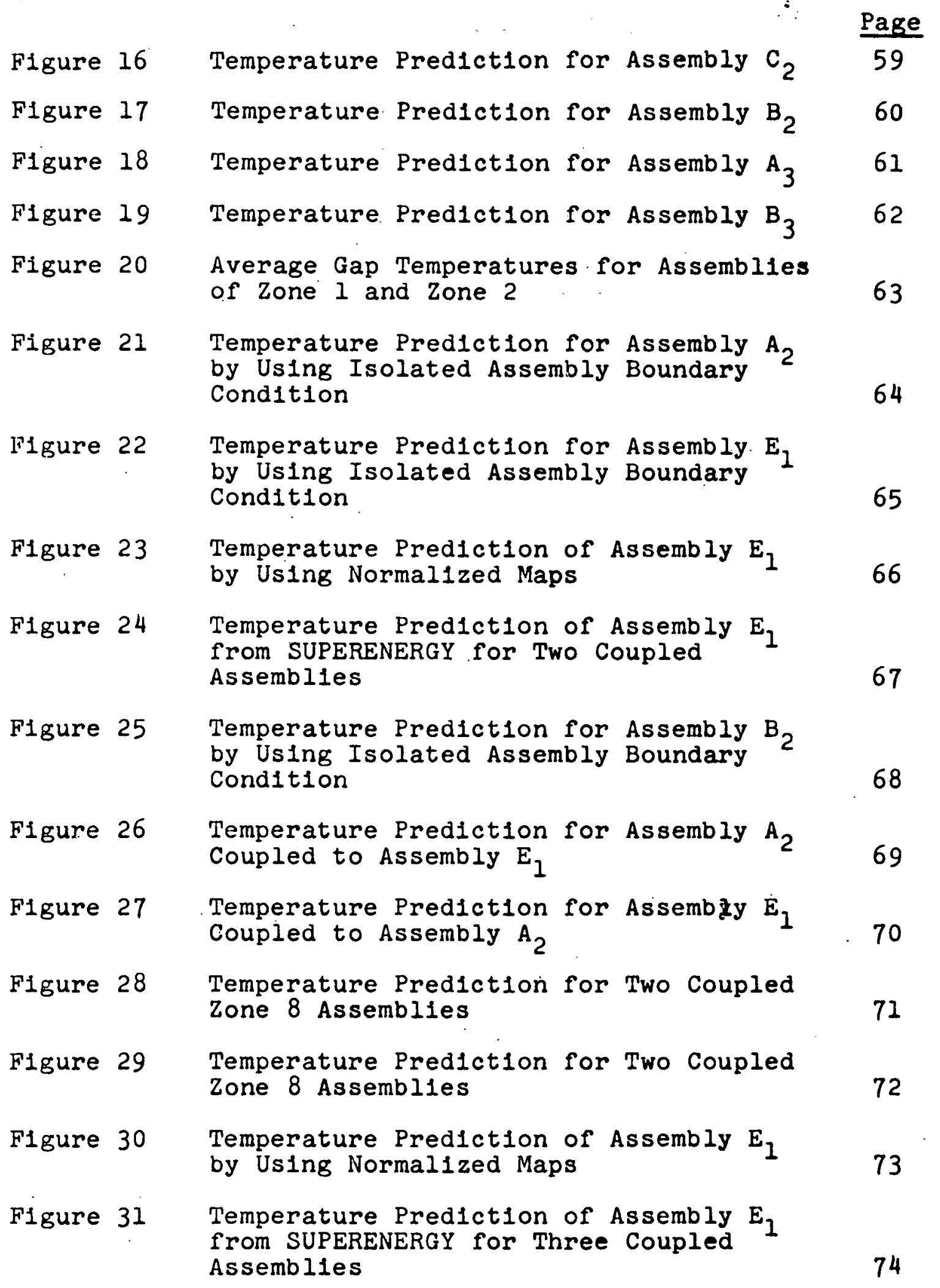


$\underline{\text { Page }}$

Figure 32 Classification of Heat Penetration:

Paths

Figure 33 Temperature Prediction Lor Assembly $E_{1}$ by Using Isolated Wall Boundary

Condition

F1gure 34 Temperature Prediction for Assembly $\mathrm{E}_{1}$ by Using Isolated Assembly Boundary Condition

F1gure 35 Temperature Prediction for Assembly $E_{1}$ by Coupling Surrounding First Ring

Six Assembiles

F1gure 36 Temperature Prediction for Assembly $E_{1}$ by Coupling Surrounding Sixteen First and SEcond Rings Assemblies

Figure $37 \quad$ Fuel Rods Numbering Scheme for 19 Pin As sembly

Figure 38 Numbering of Assemblies with Their Data Packs

\section{LIST OF TABLES}

Table 1 Geometric Characteristics of Demo

Page

Plant Assemblies

82

Table 2 Computer Space and Time Required

for SUPERENERGY 
Chapter 1

1. Introduction

Considerable amount of effort has been devoted over the last decade to the development of subchannel codes for predicting the coolant temperatures of a reactor. A few of the well-known codes are COBRA [1], THI-3D[2], THINC [3], HAMBO [4]. They use sophisticated physical modeling processes to simulate the cross flows between the subchannels. They couple the momentum equations with energy equations by solving the velocity distributions from the momentum equations and then by using these velocities in the energy equations. They also use iterative procedures for the finite difference equations to obtain convergent solutions. Because of these characterlstics, most of these codes require large storage and long running time so that they are most useful for analysis of a single assembly. Hence interassembly heat trasnfer effects have not been extensively investigated to date. These interassembly heat transfer effects are specially significant for the blanket region of a breeder reactor because of the severe radial heat flux gradients which consequently will cause severe temperature gradients in this blanket region. These temperature gradients enhanced by the irradiation swelling can cause significant bowing and deformation of the assembly. It is unrealistic to neglect interassembly heat transfer and thereby obtain 
an over-conservative design of a breeder reactor. Therefore It is desirable to understand and to know quantitatively how the inclusion of the interassembly heat transfer affects the temperature distribution. In studying this question in breeder reactors w1th wire wrapped fuel assemblies we adopt the methodology of the ENERGY Code [5] to analyze the performance of each subassembly. The physical model of simulating the cross flow caused by the wire wrap of the fuel. pin by an effective eddy diffusitivity is employed. The velocities in the interior region and the wall region of an assembly are obtained from the unfform theoretical flow split velocities $[5,6]$. These approximations enable the momentum equations to be decoupled from the energy equations. We shall also use the marching scheme instead of an iterative procedure for the finite difference equations. These simplifications enable us to reduce greatly the storage space and the running time required for computation.

As we shall see in the following sections, heat penetration from the neighboring assemblies to a central assembly can be represented by two-dimensional maps which are independent of the heat generation in the central assembly itself. By utilizing these maps, an estimate of the temperature increase or decrease due to interassembly heat transfer can be obtained 
without running a multiassembly code at all. Furthermore, a simple multiassembly code SUPERENERGY, is developed to accurately assess temperature flelds for cases where interassembly heat transfer is significant or to simply and convenfently calculate the temperature fleld for many assemblies in one run. The results of this multiassembly code will be compared with the flelds estimated from the utilization of two-dimensional maps.

In Chapter 2 a short description of the breeder reactor core and a brief introduction of the physical modeling process, developed on the code ENERGY and generalized on the code SUPERENERGY, w1ll be presented. In Chapter 3, the computational method will be discussed. Chapter 4 presents the parametric study obtained by using this code and the physical basis for obtaining and interpreting those two-dimensional maps. Chapter 5 discusses various computational strategles for coupling the assemblies. Chapter 6 compares the prediction from the parametric study with the prediction from the SUPERENERGY code. Chapter 7 gives an example of heat penetration on a central assembly due to different levels of insulated boundary conditions. Chapter 8 summarizes the finding of this study. 
Chapter 2

2. Physical Model

The hexagonal assembly of a breeder reactor consists of wire wrapped bundles of fuel pins inside a duct wall. There are gaps between the duct walls of different assemblies. For reasons of symmetry we divide the gaps in the middle, as shown by the dashed line in Figure 1 , and call the pins, the duct, and the gap assoclated with the duct all together as an assembly. If the temperature gradient across the gap vanishes, we call the assembly as an isolated assembly and the boundary condition as an isolated assembly boundary condition. If the temperature gradient across the duct vanishes, we call the boundary condition as an isolated wall boundary condition. The subchannels are defined as the region bounded by the lines jolning the centers of the pin rods. The assembly can be divided into four regions as shown in Figure 2. Region I 1s the interior region where the wire wrap mixing effect can be modeled by an effective eddy diffusitivity, $\varepsilon_{H}$. Region II is composed of the edge subchannels which can be modeled by an average circumferential swirl flow, $v_{\theta}$, due to the unidirectional wire wrap in the edge subchannels. Region III is the duct wall and region IV is the gap. 
The governing differential equations for the various regions in steady state are next written.

For region $I$, the differential equation is

$$
\rho \mathrm{C}_{\mathrm{p}} \overrightarrow{\mathrm{v}}_{1} \cdot \nabla \mathrm{T}=\left(\mathrm{k}+\rho \mathrm{C}_{\mathrm{p}} \varepsilon_{1}\right) \nabla^{2} \mathrm{~T}+\mathrm{Q}
$$

under the assumptions that the fluid is incompressible and viscous effects are negligible, where $Q$ is the heat generation rate. The flow velocity for this region is along the core length direction. For region II, the differential equation is

$$
\rho C_{p}\left(\vec{v}_{\theta}+\vec{v}_{2}\right) \cdot \nabla T=\left(k+\rho C_{p} \varepsilon_{2}\right) \nabla^{2} T+Q
$$

where $\vec{v}_{\theta}$ is the circumferential velocity along the wall, $\vec{v}_{2}$ is the longitudinal velocity along the length of the core and $\varepsilon_{\mathrm{H}_{2}}$ is the effective eddy diffusitivity for region II which is in general different from $\varepsilon_{\mathrm{H}_{I}}$ of region $I$. In region III, the differential equation can be written as

$$
\nabla^{2} \mathrm{~T}=0
$$

where we have assumed negligible heat generation in the wall. In region IV, the differential equation is

$$
\rho C_{p} \vec{v}_{4} \cdot \nabla T=k \nabla^{2} T
$$


where we have assumed that this is a laminar flow region, the boundary conditions for joining various regions are

$$
\begin{aligned}
T_{\text {region } I} & =T_{\text {region } I I} \\
V T \cdot \hat{n}_{\text {region } I} & =\nabla T \cdot \hat{n}_{\text {region } I I}
\end{aligned}
$$

at the boundary between region I and II,

$$
\begin{aligned}
\eta_{\text {region II }} & =\mathrm{T}_{\text {region }} \text { III } \\
h \nabla T \cdot \hat{n}_{\text {region II }} & =k^{\prime} \nabla T \cdot \hat{n}_{\text {region III }}
\end{aligned}
$$

at the boundary between region II and III,

$$
\begin{aligned}
\text { II region III } & =T_{\text {region } I V} \\
k V T \cdot \hat{n}_{\text {region III }} & =h^{\prime} \nabla T \cdot \hat{n}_{\text {region IV }}
\end{aligned}
$$

at the boundary between region III and IV, and

$$
\begin{aligned}
T_{\text {region IV }} & ={ }^{\prime} \text { region } I V ' \\
k \nabla T \cdot \hat{n}_{\text {region } I V} & =k \nabla T \cdot \hat{n}_{\text {region IV }}
\end{aligned}
$$

at the boundary between region IV's of nelghboring assemblies. In order to find the heat transfer coefficlents between regions II and III and regions III and IV, we 
should use the correlation given by Lyon-Martineli1[7],

$$
\text { Nu }=7+0.025 \mathrm{Pe}^{0.8}
$$

where $\mathrm{Pe}$ is the Peclet number defined as

$$
\mathrm{Pe} \equiv \operatorname{RePr} \equiv \frac{\mathrm{D}^{v \rho C} \mathrm{p}}{k} .
$$

The hydraulic diameters and the velocities in the above equations are computed for the wall subchannels adfacent to the duct. 


\section{Chapter 3}

\section{Computational Method}

With the above physical picture in mind, it is easy to write down the finite difference equations for these differential equations. An equivalent method for writing down the finite difference equations is to draw a control volume for each individual subchannel and to balance the energy within the control volume. The result of this energy balance for region $I$ is

$$
\begin{aligned}
T_{(1,0)}^{j+1}= & T_{(1,0)}^{j}+\frac{Q_{1} \Delta z}{\rho C_{p} v_{1}}+\frac{(p-d) \Delta z}{A_{1}} \frac{\left(k+\rho C_{p} \varepsilon_{H}\right)}{\rho C_{p} v_{1}} \cdot \\
& {\left[\frac{T_{(1,1)}^{j}+T_{(1,2)}^{j}-2 T_{(1,0)}^{j}}{n_{1}}+\frac{T_{(1,3)}^{j}-T_{(1,0)}^{j}}{\eta_{2}}\right] }
\end{aligned}
$$

where the superscripts for $T$ refer to the axlal level, the first subscripts refer to the numberlng of the subchannel, and the second subscripts refer to the neighbors. Zero for the second subscripts means the subchannel 1tself. We should refer to Figure 3 for the numbering of the neighbors. For those interior subchannels whose neighbors are all interior subchannels, $n_{2}$ in Eq.(11) should be replaced by $n_{1}$.

For region II, the difference equation is 
17

$$
\begin{aligned}
T_{(1,0)}^{j+1}= & T_{(1,0)}^{j}+\frac{Q_{1} \Delta z}{\rho C_{p} v_{2}}+\frac{b \Delta z}{2 A_{2}} \cdot \frac{v_{\theta}}{v_{2}} \cdot\left[T_{(1,2)}^{j}-T_{(1,3)}^{j}\right] \\
& +\frac{(p-d) \Delta z}{A_{2}} \cdot \frac{\left(k+\rho C_{p} \varepsilon_{H_{2}}\right)}{\rho C_{p} v_{2}} \cdot \frac{\left[T_{(1,1)}^{j}-T_{(1,0)}^{j}\right]}{n_{2}} \\
& +\frac{g_{\Delta z}}{A_{2}} \cdot \frac{\left(k+\rho C_{p} \varepsilon_{2}\right)}{\rho C_{p} v_{2}} \cdot\left[\frac{T_{(1,2)}^{j} T_{(1,0)}^{j}}{n_{A}}\right. \\
& \left.+\frac{T_{(1,3)}^{j}-T_{(i, 0)}^{j}}{\eta_{B}}\right]+\frac{p \Delta z}{A_{2}} \cdot \frac{1}{\rho C_{p} v_{2}} \\
& \cdot\left[\frac{T_{(i, 4)}^{j}-T_{(1,0)}^{j}}{R_{1}}\right]
\end{aligned}
$$

for the wall channel, where $n_{A}$ or $n_{B}$ equals to $n_{4}$ when the wall subchannel has a corner subchannel as a neighbor.

Otherwise they are equal to $n_{3}$. We have similar expression for the corner subchannels in this region with $A_{2}$ replaced by $\mathrm{A}_{3}$.

For region III, the equation for the wall channel is

$$
\begin{aligned}
T_{(i, 0)}^{j+1}= & 2 T_{(1,0)}^{j}-T_{(i, 0)}^{j-1}-\frac{s_{1}(\Delta z)^{2}}{A_{4}} \cdot\left[\frac{T_{(1,2)}^{j}-T_{(1,0)}^{j}}{n_{C}}\right. \\
& \left.+\frac{T_{(1,3)}^{j}-T_{(i, 0)}^{j}}{n_{D}}\right]+\frac{(\Delta z)^{2}}{k^{\prime} s_{1}} \cdot\left[\frac{T_{(1,1)}^{j}-T_{(1,0)}^{j}}{R_{1}}\right. \\
& \left.+\frac{T_{(i, 4)}^{j}-T_{(1,0)}^{j}}{R_{2}}\right] .
\end{aligned}
$$


where $n_{C}$ or $n_{D}$ takes on the value of $n_{5}$ when the nelghboring subchannel is a corner subchannel. 'Otherwise they take the value of $n_{3}$. We have similar expression for the corner channels.

For region IV, the difference equation for the wall channel is

$$
\begin{aligned}
& \mathrm{T}_{(1,0)}^{j+1}=\mathrm{T}_{(1,0)}^{j}+\frac{\mathrm{p} \Delta \mathrm{z}}{\mathrm{\rho C} \mathrm{v}_{4} \mathrm{~A}_{4}} \cdot\left[\frac{\mathrm{T}_{(1,1)-\mathrm{T}_{(1,0)}^{j}}^{j}}{\mathrm{R}_{2}}\right. \\
& \left.+2 k \cdot \frac{T_{(1,4)}^{j}-T_{(1,0)}^{j}}{s_{2}}\right]+\frac{k s_{2} \Delta z}{2 p C_{p} v_{4} A_{4}} \\
& \text { - }\left[\frac{T_{(1,2)}^{j}-T_{(1,0)}^{j}}{\eta_{E}}+\frac{T_{(1,3)}^{j}-T_{(1,0)}^{j}}{\eta_{F}}\right] \text {, }
\end{aligned}
$$

where $n_{E}$ or $n_{F}$ equals to $n_{6}$ when the wall channel has a corner channel as a nelghbor. Otherw1se, they are equal to $n_{3}$. A similar expression can be obtained for the corner channels.

In the actual code calculation, we make the following simplifications :

1) The conduction heat transfer in the axial direction is neglected since it is negligible compared to the convective heat transfer by the axlal flow in regions $I$, II, and IV. 
2.) ine conduction heat transfer in the axial and the azimuthal directions are small when compared to the heat conduction in the radial direction for the duct region III. This is due to the facts that the wall is thin ( $(.11 "$ In thickness) and the conductivity of the wall is much lower than the conductivity of the liquid sodium. And hence most of heat redistribution in the azimuthal direction will go through. the ilquid sodium instead of the duct. We therefore approximate the temperature distributions in the axial and the azimuthal directions by linear functions in this region III.

These approximations enable use of a simple marching scheme for solving the finite difference equations. That is, once temperatures in a given level are known, the temperatures in the next level are calculable uniquely without any iteration. 


\section{Chapter 4}

4. Jormalized Assembly Studies

Before using the code to study the penetration of an imposed heat flux into an assembly, an invariance characteristic of this penetration will be demonstrated. Let us write down a general energy transport equation which is val1d for all the regions as

$$
\rho C_{p} \vec{v} \cdot \nabla T=\left(k+\rho C_{p} \varepsilon_{H}\right) \nabla^{2} T+Q
$$

The boundary conditions are isolated assembly boundary conditions for all the faces except one face where we 1mpose a heat flux entering the assembly through the gap. Mathematically, this boundary condition can be expressed as

$$
\nabla T \cdot \hat{n}_{1}=\left\{\begin{array}{l}
0 \text { for } 1=2,3,4,5,6 \\
F \text { for } 1=1,
\end{array}\right.
$$

where $\hat{n}_{1}$ is the unit vector normal to the 1 th face of the assembly. There are six faces for a hexagonal assembly labeled in counter clockwise sequence one through six starting with the northeast face. We can write $T$ as a summation of functions $\mathrm{T}_{1}$ and $\mathrm{T}_{2}$ which satisfy the following equations, 


$$
\rho C_{p} \vec{v} \cdot \nabla \mathrm{T}_{1}=\left(k+\rho C_{p} \varepsilon_{H}\right) \nabla^{2} \mathrm{~T}_{1}+\mathrm{Q}
$$

and

$$
\rho C_{p} \vec{v} \cdot \nabla T_{2}=\left(k+\rho C_{p} \varepsilon_{H}\right) \nabla^{2} T_{2}
$$

The boundary condition for $\mathrm{T}_{1}$ is an 1solated assembly boundary condition. The boundary condition for $\mathrm{T}_{2}$ is the same as that for $T$. They are

$$
\nabla T_{1} \cdot \hat{n}_{1}=0 \cdot \text { for } 1=1,2,3,4,5,6
$$

and

$$
\nabla T_{2} \cdot \hat{n}_{1}=\left\{\begin{array}{l}
0 \text { for } 1=2,3,4,5,6 \\
F \text { for } 1=1 .
\end{array}\right.
$$

The value $\mathrm{T}-\mathrm{T}_{1}=\mathrm{T}_{2}$ is the increment of temperature due to the externally imposed heat flux. This increment is independent of the internal heat generation and depends only on the velocity, hence on the flow rate, and the geometry of the assembly as well as the physical properties of the coolant as seen easily from Eq. (18). The rotational invariance of the geometry implies rotational invariance of the maps for these temperature increments. The dependence on the flow rate implies that the same maps will result for the assemblies with the same flow rates. These characteristics enable us to investigate only a few of the typical assemblies in the reactor and from these results 
to understand the heat penetration effect for all the assemblies in the reactor core. Although the above areument holds for a single assembly, the same proof w1ll hold for multiassemblies as well. Therefore the temperature increment maps for multiassemblies have the same characteristics. However, we would have less rotational invariance because the surrounding assemblies may not have the same flow rates.

By using the difference equations (II)-(14) with zero heat generation, we can obtain a set of maps for temperature increments due to a given external heat flux. We present such results in the next two subsections.

4.1 Single Assembly Studies We take the Clinch River Breeder Reactor as an example for our study. A sector of the core with the orificing scheme and the nominal flow rates at plant thermal and hydraulic design conditions is shown in Fig. 4. Geometric characteristics of the assemblies are given in 'l'able 1. The numbering of the subchannels and their actual positions in the fuel and the blanket assemblies are shown in Figs. 5 and 6 . The maps for the temperature increments are given in Figures 7 through 15. There are five different oriflcing zones for fuel assemblies and four different orificing zones for blanket assemblies. 
We Impose a heat flux on the north face of each of the various assemblies. The heat flux has a uniform profile in the azimuthal direction and a linear profile in the axial direction. In our example, we use $20^{\circ} \mathrm{F}$ temperature difference between adjacent gaps at the top of the assemblies and $0^{\circ} \mathrm{F}$ temperature difference at the inlet end of the assemblies. This is equivalent to a heat flux of $1.73 \times 10^{5} \mathrm{BTU} / \mathrm{hr}-\mathrm{ft}^{2}$ at the top of the assembly and a heat flux of $0 \mathrm{BTU} / \mathrm{hr}-\mathrm{ft}^{2}$ at the bottom of the assembly. The total heat entering into the 64 inch long assembly is $0.86 \times 10^{5} \mathrm{BrU} / \mathrm{hr}$. The input mixing parameters are those recommended by Khan, Ref. [5], 1.e. $\varepsilon^{*}=0.01$ and $C=.08$ for the fuel assemblies, and $\varepsilon^{*}=.007$ and $c=.40$ for the blanket assemblies. The flow rate Inside the gap associated with an assembly (1.e. within the dotted line in Fig. 1) is $600 \mathrm{lbm} / \mathrm{hr}$ in our example. We clearly see from these figures, the higher the axial flow rate, the less the heat penetrates. The swirl flow Inside the duct wall carries the heat flux in the swirl direction and therefore enhances the heat penetration in the swirl direction. This is especially clear for the blanket assemblies where the swirl flow is strong.

4.2 Multiassembly Studies We shall define all the assemblies adjacent to 
the central assembly as the first ring assemblies. All the assemblies adjacent to the first ring assemblies except the central assembly and the first ring assemblies themselves are called the second ring assemblles. From the previous single assembly study, it can be concluded that the effect of the heat penetration through the first ring assemblies on the central assembly is extremely small when the first ring assemblies are fuel assemblies. This is due to the facts that the axfal flow rates of the fuel assemblies are very high and their swirl flow rates are low. Hence the only necessary multiassembly studies are for the blanket assemblies.

The case of interest is a limiting one in which a central assembly is surrounded by six other assemblies each with an externally 1mposed heat flux from 1ts outer nelghbors and each with the lowest possible flow rate. This situation can be designated the second ring heat penetration effect and it can be examined in a normalized fashion, because of superposition principles, by considering the effect of an externally Imposed heat flux on only one face of a first ring assembly. In our example, the assemblies all will have the flow rates of the ninth orificing zone. We pick the seven assemblies as $\mathrm{B}_{2}, \mathrm{~A}_{3}$, $C_{2}, C_{1}, B_{1}, A_{2}, B_{3}$ in Fig. 4 and let the external heat flux go through the fourth face of the assembly $C_{1}$, 
then the temperature rise in assemblies $A_{2}, B_{3}, A_{3}$ are extremely small for an imposed heat flux of the same characteristics as in the single assembly studies having a linear axial profile and a maximum value of $1.73 \times 10^{5}$ $3 T U / h r f^{2}$. This fact simplified the code calculation by allowing reduction of the number of coupled assemblies from seven to four. The worst four coupled assemblies in our actual example are assemblies $C_{2}, B_{2}, A_{3}, B_{3}$ because of their low flow rates. The worst heat penetration case is the case of an imposed heat flux on the fourth face of the assembly $\mathrm{C}_{2}$. Results are given in Fig. 16-19 for. assemblies $\mathrm{C}_{2}, \mathrm{~B}_{2}, \mathrm{~A}_{3}$, and $\mathrm{B}_{3}$ respectively, which show that this heat flux causes a maximum of on $1 y=12^{\circ} \mathrm{F}$ in one of the Eap subchannels in assembly $\mathrm{A}_{3}$. This small amount of temperature rise penetrates only the peripheral channels of assembly $\mathrm{A}_{3}$. 


\section{Chapter 5}

5. Prediction of Interassembly Heat Transfer Between Blanket Assemblies

Such predictions for multiassembly arrays are possible by two methods

1) Utilization of normalized assembly temperature maps together with calculations of the desired assembly treated as an 1solated assembly.

2) Direct calculation of the coupled multiassembly array .

5.1 Prediction of Assembly Temperature Fields Considering the Six (First Ring) Surrounding Assemblies

To predict the temperature distributions by the first method, we can use SUPERENERGY for each assembly individually with isolated assembly boundary condition. Utilizing these temperature distributions and the results of the simple, normalized assembly maps discussed in Chapter 4, we can predict the temperature distributions for the assemblies in a coupled conflguration by using the expressions derived in the following section. We define the average gap temperatures at the bundle exit for assembly 1 and assembly 2 as $T_{1}$ and $T_{2}$ before the assemblies are coupled, and as $\mathrm{T}_{1}^{\prime}$ and $\mathrm{T}_{2}^{\prime}$ after the assemblies are coupled, as shown in F1gs.20(a) and 20 (b) respectively. From the normallzed assembly maps, we can 
represent the average axial temperature changes for assembly 1 and assembly 2 as $\Delta t_{A 1}$ and $\Delta t_{A 2}$ for a given temperature cradient, $\Delta t_{R}$, across the gaps between assemblies 1 and 2 , as shown in Fig. 20(c). From eqs. (13) and (20), we can see that a linear proportionality exists between the temperature gradient across the gap and the average axial temperature rise in the assembly since the gap temperature gradient is directly proportional to F. By using this linear proportionality, we can write down two expressions relating the temperatures before the assembly coupling (Figure 20a) to the temperatures after the assembly coupling (Figure 20b) as

and

$$
\frac{T_{1}^{\prime}-T_{1}}{\Delta t_{A 1}}=\frac{r_{1}^{\prime}-T_{2}^{\prime}}{\Delta t_{R}}
$$

$$
\frac{r_{2}^{\prime}-T_{2}}{\Delta t_{A 2}}=\frac{T_{1}^{\prime}-T_{2}^{\prime}}{\Delta t_{R}}
$$

We can solve these two algebraic equations for $T_{1}^{\prime}$ and $T_{2}^{\prime}$ as

$$
\begin{aligned}
& T_{1}^{\prime}=\frac{T_{1}\left(\Delta t_{R}+\Delta t_{A 2}\right)-T_{2} \Delta t_{A 1}}{\Delta t_{R}+\Delta t_{A 2}-\Delta t_{A I}} \\
& { }^{\prime}{ }^{\prime}{ }_{2}^{\prime}=\frac{T_{1} \Delta t_{A 2}+T_{2}\left(\Delta t_{R}-\Delta t_{A 1}\right)}{\Delta t_{R}+\Delta t_{A 2}-\Delta t_{A 1}},
\end{aligned}
$$

and the difference as 


$$
T_{1}^{\prime}-T_{2}^{\prime}=\frac{\left(T_{1}-T_{2}\right) \Delta t_{R}}{\Delta t_{R}+\Delta t_{A 2}-\Delta t_{A 1}}
$$

We evaluate $T_{1}^{\prime}-T_{2}^{\prime}$ in eq. (25) by utilizing the SUPERENERGY temperature predictions for assemblies 1 and 2 treated with isolated assembly boundary conditions (for $\mathrm{T}_{1}$ and $\mathrm{T}_{2}$ ), and normalized assembly maps for assemblies 1 and 2 (for $\Delta t_{R}, \Delta t_{A 1}, \Delta t_{A 2}$ ). We can predict the distribution of the temperature changes in assembly $I$ due to this assembly coupling as

$$
\Delta \mathrm{T}_{\mathrm{I}_{1}}=\frac{\mathrm{T}_{1}^{\prime}-\mathrm{T}_{2}^{\prime}}{\Delta \mathrm{t}_{\mathrm{R}}} \Delta \mathrm{t}_{\mathrm{Al}_{1}}
$$

where 1 refers to the various subchannels and $t_{A l_{1}}$ is obtained for each channel from the normalized assembly maps. Combining Eq.(25) and Eq.(26) gives the final result,

$$
\Delta T_{I_{1}}=\frac{T_{1}-T_{2}}{\Delta T_{R}+\Delta t_{A 2}-\Delta t_{A 1}} \cdot t_{A I_{1}}
$$

We apply this prediction procedure to assemblies $A_{2}$ and $E_{1}$ of Fig. 4. Temperature distribution for assemblies $A_{2}$ and $E_{1}$ by using isolated assembly boundary conditions are given in Figs. (21) and (22) respectively. Results using this prediction for the temperature changes in assembly $\mathrm{E}_{1}$ are shown in F1g. (23). The coupled two assembly code prediction (method 2) for assembly $E_{1}$ coupled to assembly $A_{2}$ is shown in Fig. (24). The depth of penetration of interassembly effects is well 
predicted. Within the region where subchannel temperatures are affected by interassembly heat transfer, differences of several degrees exist with the largest deviations occurring in the third face of assembly $E_{1}$. These are due to the approximation of using an average constant heat flux for the whole face of the assembly and the deviation of axial profile of the heat flux addition from the assumed linear profile.

To consider the effect of each of the six surrounding assemblies on a central assembly, we can invoke the principle of superposition to add all the temperature rises together. However care must be taken in computing the average temperature gradients for varlous faces of the assembly. When computing the difference between the average temperatures of the adjacent faces of the central assembly and first ring assemblies, the perturbations on the central assembly face temperatures due to previous coupling steps should be considered. Physically, we can picture this procedure as the following. We first bring one assembly in contact with the central assembly, and then we bring the second assembly in contact with the previous two and so on until all of them are in contact with each other. The final steady state is the same as if we bring all of them in contact at the same time. 
5.2 Prediction of Assembly Temperature Fields

Considering the Nineteen (First and Second Ring)

Surrounding Assemblies

As we have illustrated in the previous twoassembly example, the normalized maps are extremely simple and convenient tools for estimating the heat penetration without coupled assembly code predictions when the number of coupled assemblies are small. The maps are also useful tools to estimate the importance of the heat penetration from the second ring assemblies to the central assembly. In this estimation, we can use either the single assembly normalized maps successively or the multiassembly normalized map once. To illustrate this point, we shall use the assemblies $C_{2}, B_{2}, A_{3}$, and $B_{3}$ in Figure 4 as our example. We want to see the importance of heat penetration from assembly $\mathrm{C}_{1}$ to assembly $\mathrm{A}_{3}$. From single assembly runs, we compute the difference of the average gap temperatures between assembly $C_{1}$ and assembly $C_{2}$, 1.e. $T_{1}-T_{2}$, Figure (22a). Let us suppose it is $100^{\circ} \mathrm{F}$. By using this difference and the single assembly normalized maps corresponding to assemblies $C_{2}$ and $C_{1}$, 1.e. zone 8 , Figure 14 and zone 7 , Figure 13 respectively, we can proceed as described in Section 5.1 to predict the temperature changes in assembly $\mathrm{C}_{2}$. The average gap temperature rise in the sixth face of assembly $\mathrm{C}_{2}$ due to $100^{\circ} \mathrm{F}$ difference between the faces of 
assembly $C_{1}$ and $C_{2} 1$ s, per eq. $(27), \frac{100}{20+142+130} \times 23=7.9^{\circ} \mathrm{F}$, where we have used

$$
\begin{aligned}
& \left.\Delta t_{A 2}\right|_{\text {Bundle } C_{2}}=\sum_{1} \Delta t_{A_{1}}=\frac{152+150+140+125}{4}=142 \quad \text { (28a) } \\
& \left.\Delta t_{A 1}\right|_{\text {Bundle } C_{1}}=\sum_{1} \Delta t_{A 1_{1}}=\frac{135+136+130+119}{4}=130 \quad(28 \mathrm{~b}) \\
& \left.\Delta t_{A_{1}}\right|_{\begin{array}{l}
\text { face } 6 \\
\text { Bundle } C_{2}
\end{array}}=\left.\sum_{1} \Delta t_{A_{1}}\right|_{\begin{array}{l}
\text { face } 6 \\
\text { Bundle }
\end{array}} c_{2}
\end{aligned}
$$

By using this average temperature rise and the single assembly mormalized map for zone 9, we can further predict the temperature rise in the assembly $\mathrm{A}_{3}$. For example, the fifth face of assembly $A_{3}$ will have an average temperature rise of $\frac{7.9}{20+165+142} \times 41.5=1^{\circ} \mathrm{F}$ from Eq. (27), where

$$
\begin{aligned}
& \left.\Delta t_{A 2}\right|_{\text {Bundle } A_{3}}=\sum_{1} \Delta t_{A_{1}{ }_{1}}=\frac{187+178+161+136}{4}=165 \\
& \left.\Delta t_{A 1}\right|_{\text {Bundle } C_{2}}=\sum_{1} \Delta t_{A 1_{1}}=\frac{152+150+140+125}{4}=142 \\
& \left.\Delta t_{A_{1}}\right|_{\begin{array}{l}
\text { face 5 } \\
\text { fundle } A_{3}
\end{array}}=\left.\sum_{1} \Delta t_{A_{1}}\right|_{\begin{array}{l}
\text { face } 5 \\
\text { Bundle }
\end{array}} A_{3}
\end{aligned}
$$


We can also use the multiassembly normalized map, Figure (16)-(19), to predict the average temperature rise in the fifth face of assembly $\mathrm{A}_{3}$. The expression we should use to compute the subchannel temperature changes in Assembly $A_{3}$ is again Eq. (27) with $\Delta t_{A l}$ taken as the 1 th subchannel axial temperature change in the normalized map for assembly $\mathrm{A}_{3}(1 . e . \mathrm{Fig}$. 18). The result of this calculation is $\frac{100}{20+142+130} \times 0=0$ : F, where $\Delta t_{A}$ 's are given by $\mathrm{Eq}$. (28). Both of these type 1 methods predict insignificant temperature changes in assembly $A_{3}$ as we expected. WE have not applied method 2 to the calculation. of these assemblies by using a hypothetical $\mathrm{T}_{1}-\mathrm{T}_{2}=100^{\circ} \mathrm{F}$. Rather method 2 has been applied as well as method 1 (using a multiassembly normalized map) to asemblies $B_{2}$, $A_{2}$ and $E_{1}$ operating at the Clinch River Design conditions (Ref. [8]) as described below. Temperature distribution

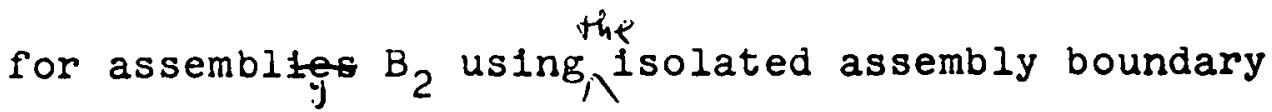
condition is shown in FIg. (25). Temperature distributions for assemblies $A_{2}$ and $E_{1}$ coupled to each other are shown in Figs. (26) and (27) respectively. Normalized assembly map for two coupled zone 8 assemblies is shown in Figs. (28) and (29). Results using this prediction for the temperature changes in assembly $E_{1}$ are shown in Fig. (30). The three-coupled assembly code prediction (method 2) for assembly $E_{I}$ is shown in FIg. (31). The second ring heat penetration effects on the central assembly is insignificant as can be seen from the comparison of these two figures. 


\section{Chapter 6}

6. COMPUTATIONAL STRATEGIES FOR LMFBR CORES

6.1 Classification of combinations of assemblies with different flow rates.

As we have stated before, the external heat flux can hardly penetrate a fuel assembly due to the high flow rate in the fuel assembly. The fuel assembly also has low swirl flow. The small amount of heat penetrating into the assembly will not be carried around to the other faces of the assembly. Both of these characterlstics do not exist for a blanket assembly. Hence the relative position of a face to the position of the face with heat addition or subtraction is very important for a blanket assembly. We shall restrict our classifications of these relative positions to the blanket assemblies only.

As we have pointed out earlter, the only assemblies which are important in a seven assembly study are those adjacent to the heat addition assembly. There are four of them. The heat penetration from different paths are shown in F1g.(25). They can be categorized into three classes. For a given constant heat flux into the assembly $D$, the effect of the heat penetration depends on the path length and the flow rates of the assemblies $D, E$ and $A$. For given flow rates, the heat penetrates the most for 
the shortest heat path which is path 3 in F1g. (25). For a given heat path, the heat penetrates the most for the combination of lowest flow rates. By using these criterla, It is easy to determine which is the most important heat penetration from' the second ring assemblies once code calculations have been made for all the assemblies using the isolated assembly boundary conditions. If the most lmportant heat penetration from the second ring assemblies will not affect the central assembly significantly, then we can neglect all the rest of the second ring effects. The same procedure applies for the whole reactor. In such circumstances it is necessary to couple only seven assemblies in predicting the temperature distribution for the central assembly.

6.2 Strategies in selecting the number of assemblies for coupling.

We listed in Table 2 the storage space and the computation time the code requires for various bundle sizes and various numbers of coupled assemblies.

It is clear that the analytically simplest way of predicting the temperatures is to run the code for as many assemblies coupled as the computer allows. At the other extreme, single assembly results fox each assembly when used with normalized maps are sufficient to compute temperatures including interassembly heat transfer effects. 
A compromise procedure for typical LMFBR's is to confirm that sufficiently accurate central assembly temperature predictions can be obtalned considering only the first ring assemblies. This confirmation requires the use of normalized multiassembly maps. The whole reactor can then be analysed by a series of sevencoupled assembly calculations treating each assembly in the core in turn as a central assembly. 


\begin{abstract}
Chapter 7
EXAMPLE OF HEAT PENETRATION FROM DIFFERENT

LEVELS OF INSULATED BOUNDARY CONDITIONS
\end{abstract}

To demonstrate the effect of interassembly heat transfer we have calculated temperatures of blanket assembly $E_{1}$. with the following successively accurate assumptions.

1. Isolated wall boundary condition (figure 26)

2. Isolated assembly boundary condition with $600 \mathrm{lb} / \mathrm{hr}$ gap flow ( f1gure 27)

3. Including surrounding first ring assemblies (figure 28)

4. Including surrounding first and second ring assemblies (figure 29)

Appendix 3 lists the SUPERENERGY calculation of case 4. All operating conditions for cases 1,2 and 3 are the same as those listed for case 4 .

From these results, the following conclusions can be made. Serlous error will result if one uses the 1solated wall boundary conditions to predict the temperature distribution for all the assemblies in a reactor. The prêdiction from seven coupled assemblies calculation will give adequate accuracy in the temperature distribution for the central assembly. 
Chapter 8

8. CONCLUSION AND DISCUSSION

We have developed a code SUPERENERGY to study the effects of the interassembly heat transfer on the temperature distribution in a breeder reactor. We classified the effects according to the rings of the assemblies surrounding the central assembly. In our example of the Clinch River Breeder Reactor, we found that the first ring effects are 1mportant and the second ring effects are negligible. Although we did the study using a gap flow rate of $600 \mathrm{lb} / \mathrm{hr}$, we also studied changes in the normalized assembly maps due to different gap flow rates varying from $600 \mathrm{lb} / \mathrm{hr}$ to $5 \mathrm{lb} / \mathrm{hr}$. We found the changes small and the above conclusions valld even for the small gap flow rate of $5 \mathrm{lb} / \mathrm{hr}$. We also have presented general procedures for obtaining various ring effects for any breeder reactor with hexagonal assemblies.

In summary, we can see changes of temperature corresponding to different levels of heat insulation for the assembly. There is significant amount of changes in the coolant temperatures for the interfor subchannels of blanket assemblies when we allow heat transfer through the duct into the gap coolant instead of insulating the wall. In terms of boundary conditions, this is equivalent to replacing the 1 solated wall boundary 
condition by the isolated assembly boundary condition. In our example, of Chapter 7 , this change can be $21^{\circ} \mathrm{F}$. Furthermore, if we allow the heat to transfer between gaps of different assemblies, we can see another significant change in the coolant temperatures as well as the duct wall temperatures. In our example this change can be $\sim 70^{\circ} \mathrm{F}$. When we increase, the number of coupled rings about a central assembly from one to two the changes in temperatures become smaller very quickly. For reactors with extremely small flow rates both in the gaps and Inside the assemblies, the number of rings we have to couple in order to get an accurate prediction might be large. In order to determine this number of rings, one should do the normalized maps study as described in section 5. Once the necessary number of rings for coupling has been determined, the code SUPERENERGY can be run with this number of rings for each assembly. The whole reactor core can be covered by successive calculations. Interassembly heat transfer plays an 1mportant role in the heat redistribution of a breeder reactor. The present code assumes average constant physical properties for the coolant throughout the core. Hence it does not take the buoyancy effects and the recirculation phenomena of the coolant into consideration. Because of the steady state assumption, the code can deal neither with transient states nor with accident conditions. Future development 
in extending the capability of this code to cover both above cases will be imperative and beneflclal. However, investigation has been made on the importance of buoyancy effects on the Clinch River Breeder Reactor. It is found that the buoyancy effect is negliglble even in the blanket assemblies with the lowest flow rate of 15310 , lb/hr. The Grashof number corresponding to this flow rate is $G^{*}=0.00237$, which 1s well below the critical Grashof number, $G r_{C}^{*}=0.025$, where the buoyancy effects are becoming significant [5]. 


\section{NOMENCLATURE}

$\mathrm{A}_{1}$

$\mathrm{A}_{2}$

$\mathrm{A}_{3}$

$\mathrm{A}_{4}$

$A_{5}$

C

$\mathrm{C}_{\mathrm{p}}$

d

$\mathrm{g}$

h

$h^{\prime}$

$k$

$k^{\prime}$

$\ell$

$\mathrm{p}$

$Q_{1}$

$\mathrm{R}_{1}$
$=$ flow area of the interior subchannel

= flow area of the wall subchannel

= flow area of the corner subchannel

= flow area of the gap wall subchannel

= flow area of the gap corner subchannel

$=$ ratio of swirl velocity to average axial

velocity for the porous body model

= constant pressure heat capacity

$=$ rod diameter

$=$ distance between the surface of the rod next to the wall and the surface of the wall

$=$ heat transfer coefficlent between the wall channels and the duct wall

$=$ heat transfer coefflcient between the gap channels and the duct wall

$=$ conductivity for the coolant

$=$ conductivity for the duct wall

$=$ lead

$=\operatorname{rod} \mathrm{pitch}$

= heat generation rate per unit volume for subchannel 1

= total resistance between the edge subchannel and the duct subchannel 


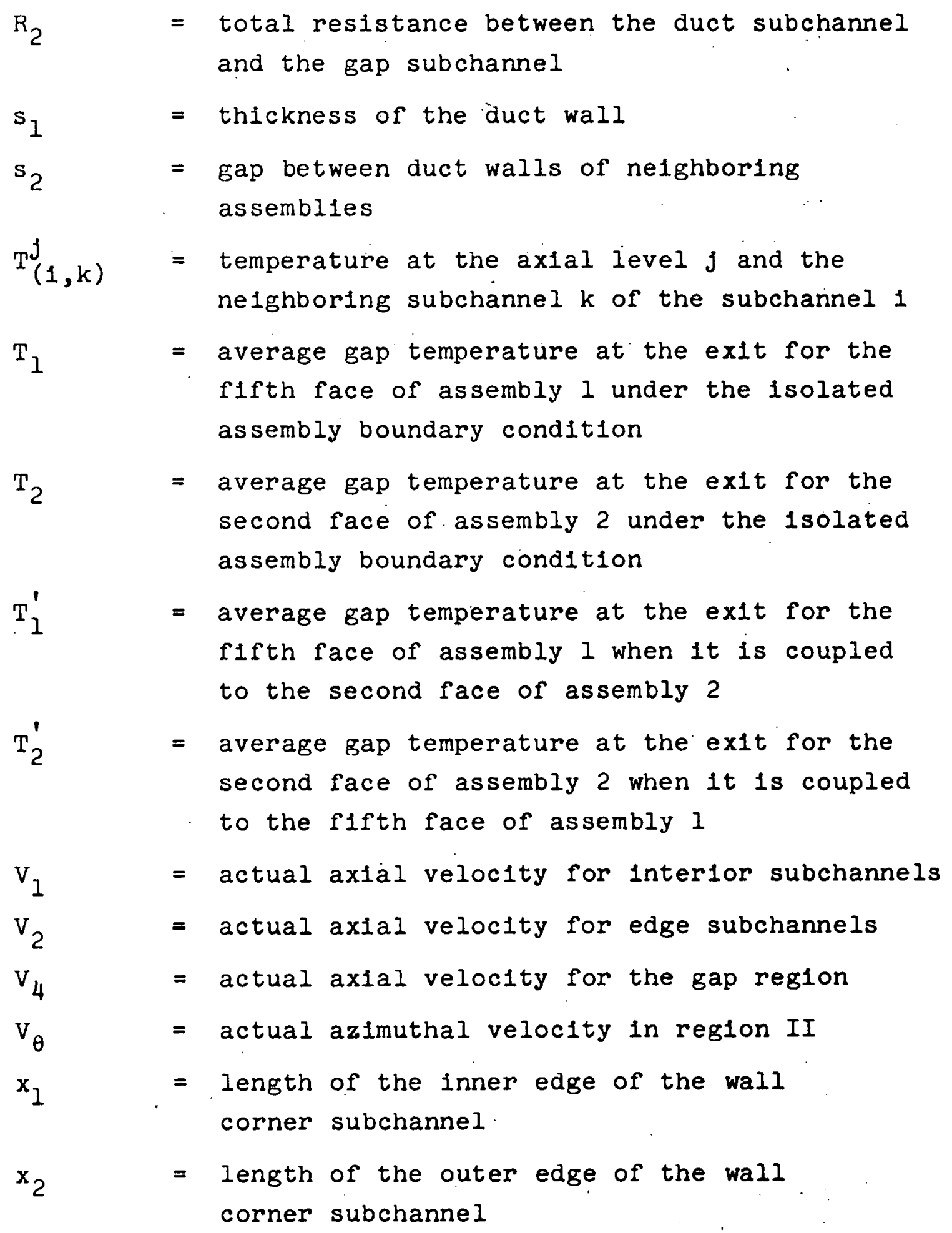




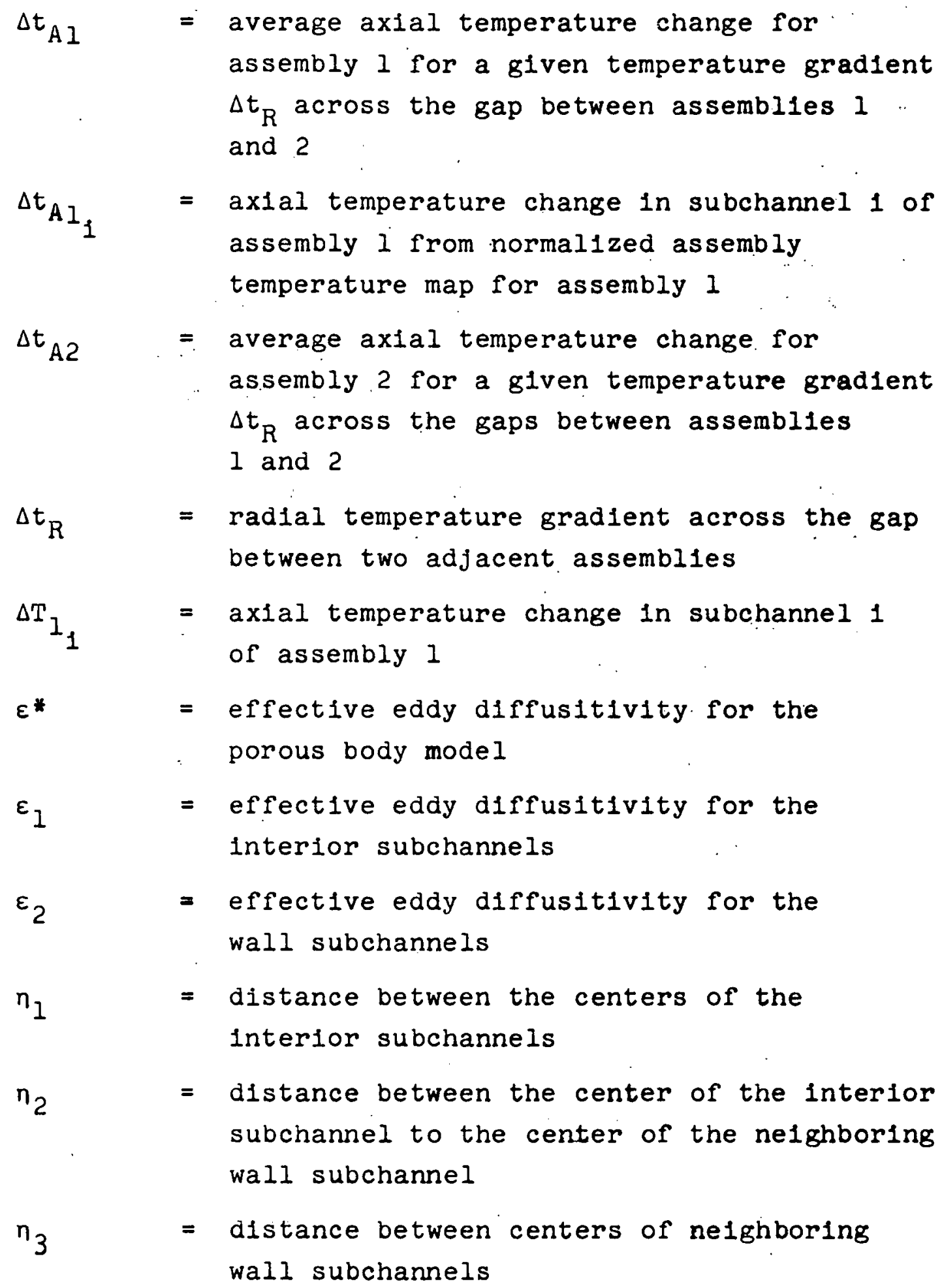




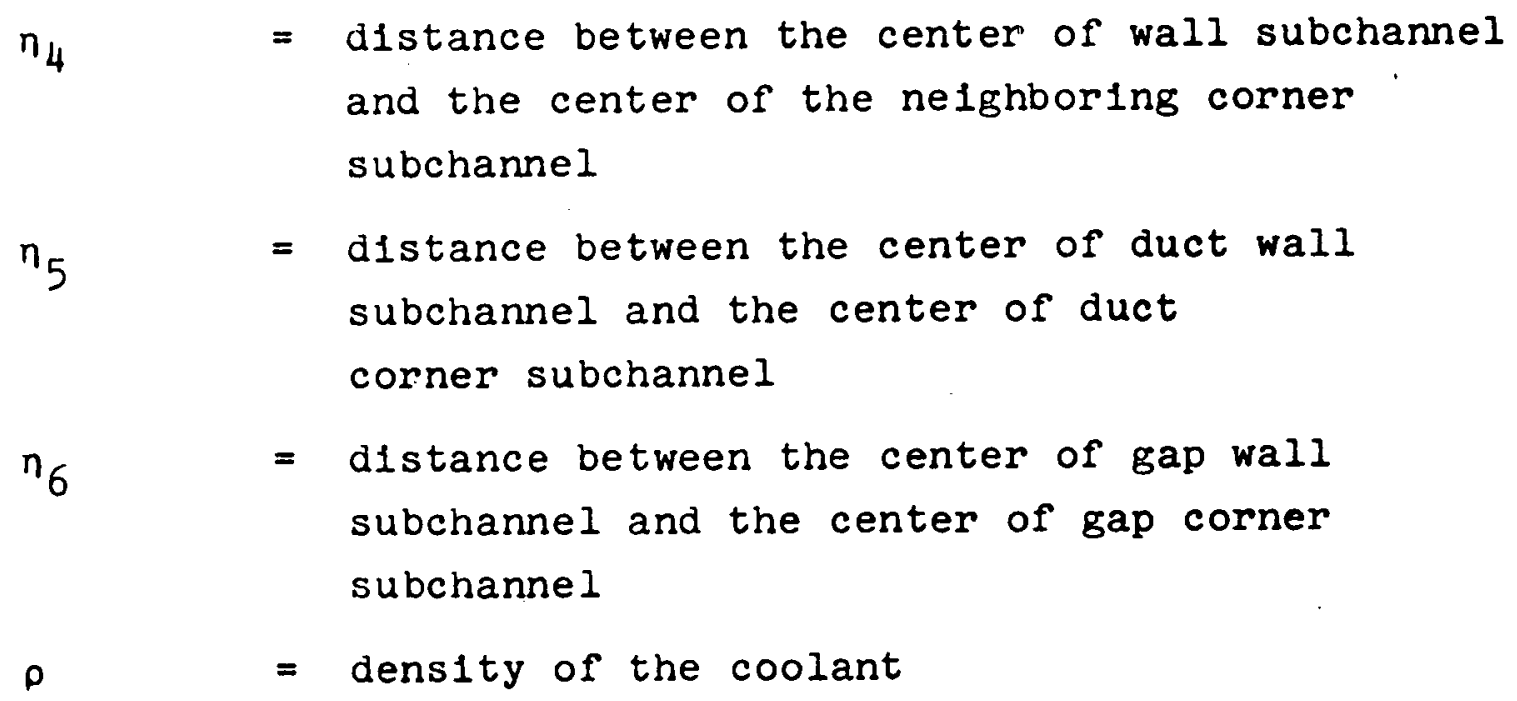


REFERENCES

1. D.S. Rowe, "COBRA IIIC - A DIgital Computer Program for Steady State and Transient Thermal Hydraulic Analysis Rod Bundle Nuclear Fuel Element," BNWL1695, March 1975.

2. W.T. Sha and R.C. Schmitt, "THI-3D- A Computer Program for Steady State Thermal-Hydraulic Multichannel Analys1s," ANL-8112, July 1974.

3. H. Chelemer, J. Weisman, I.S. Tong, "Subchannel Analysis," Nuc. Eng. Des. Vol. 27, 3 (1972)

4. R.W. Bowring, "HAMBO: A Computer Programme for the Subchannel Analysis of the Hydraulic and Burn Out Characteristics of Rod Clusters,"

Part-I General Description, AEEW-R 524 (1967).

Part-II The Equation, AEEW-R 582 (1968).

5. E. Khan, "A Porous Body Model for Predicting Temperature Distributions in Wire Wrapped Fuel and Blanket Assemblies of a Liquid Metal Fast Breeder Reactor," M.I.T. Ph.D. Thesis, Jan. 1975

6. W. Baumann, "MISTRAL-II; Thermohydraul1scher Mischströmungsalgor1thmus für Stabbündel," KFK1605, Jun1 1972 .

7. R.N. Lyon (ed.) Liquid Metals Handbook, Sponsored by Committee on the Basic Properties of Liquid Metals, Offlce of Naval REsearch, Department of the Navy, in Collaboration with U.S. Atomic Energy Commission and Bureau of ShIps, Department of the Navy, June, 1952.

8. Private Communication w1th M.D. Carelli at the Advanced Reactors Division, Westinghouse Electric Corporation. 
SUBCHANNELS IN AN ASSEMBLY

1. Interior Subchannel

2. Wall subchannel

3. Corner subchanneI

4. Duct wall subchannel
5. Duct corner subchannel

6. Gap wall subchannel

7. Gap corner subchannel

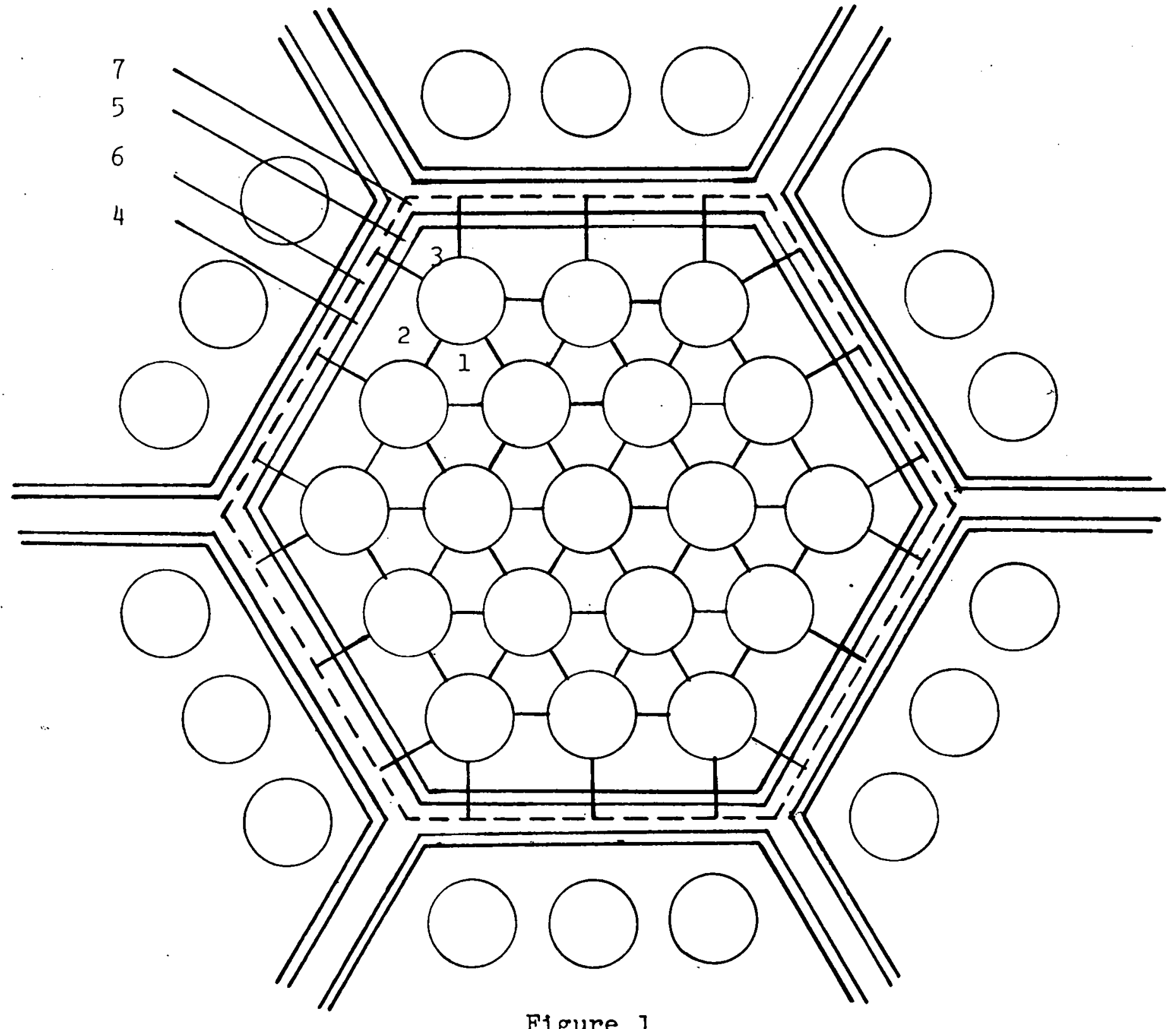

Figure I 
REGIOIS OF ASSEMBLY WITH DIFFERENT FLOW RATES

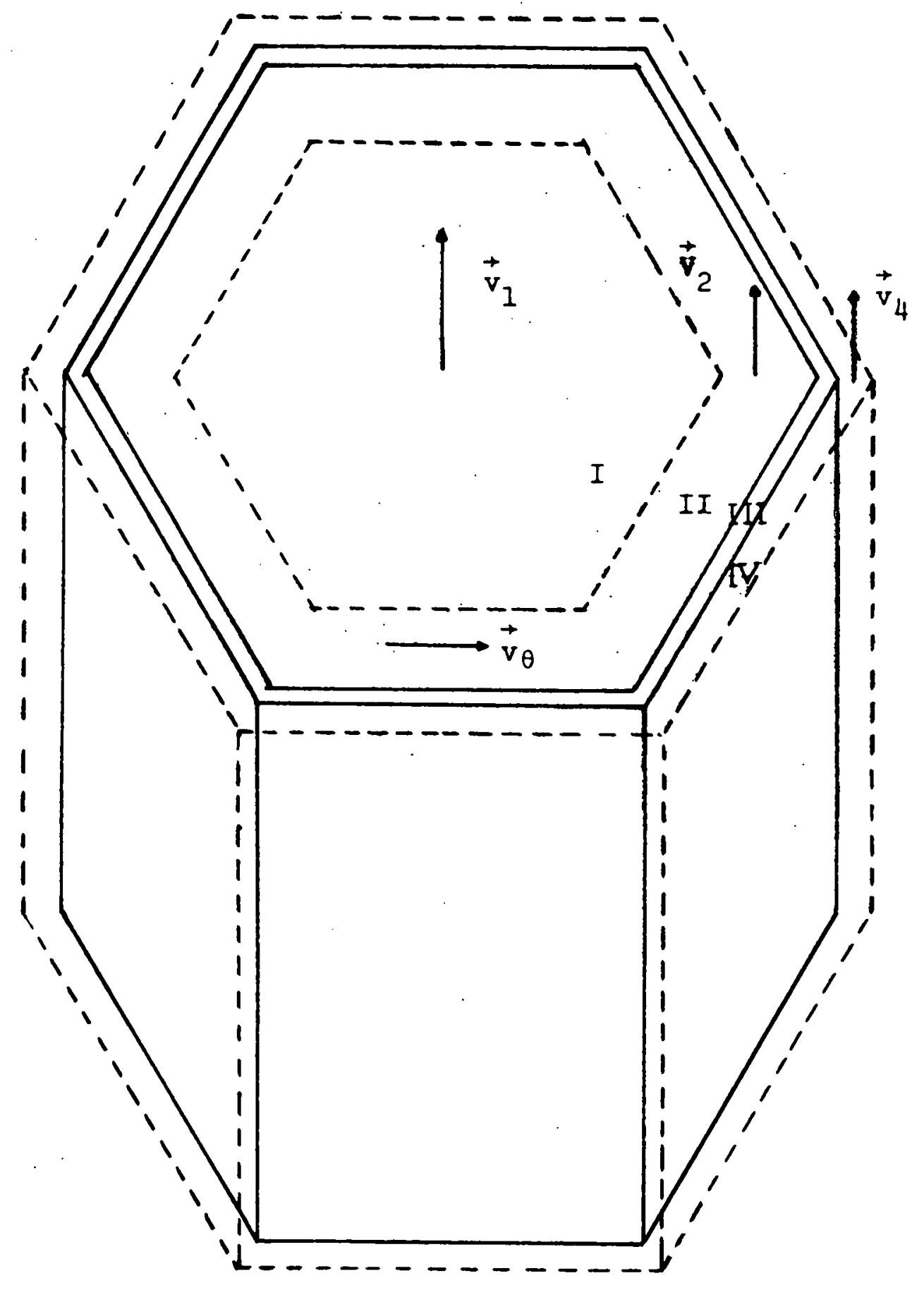

F1gure 2 
NUMBERI NG SCHEME FOR THE NEIGHBORI NG SUBCHA NNEL S.
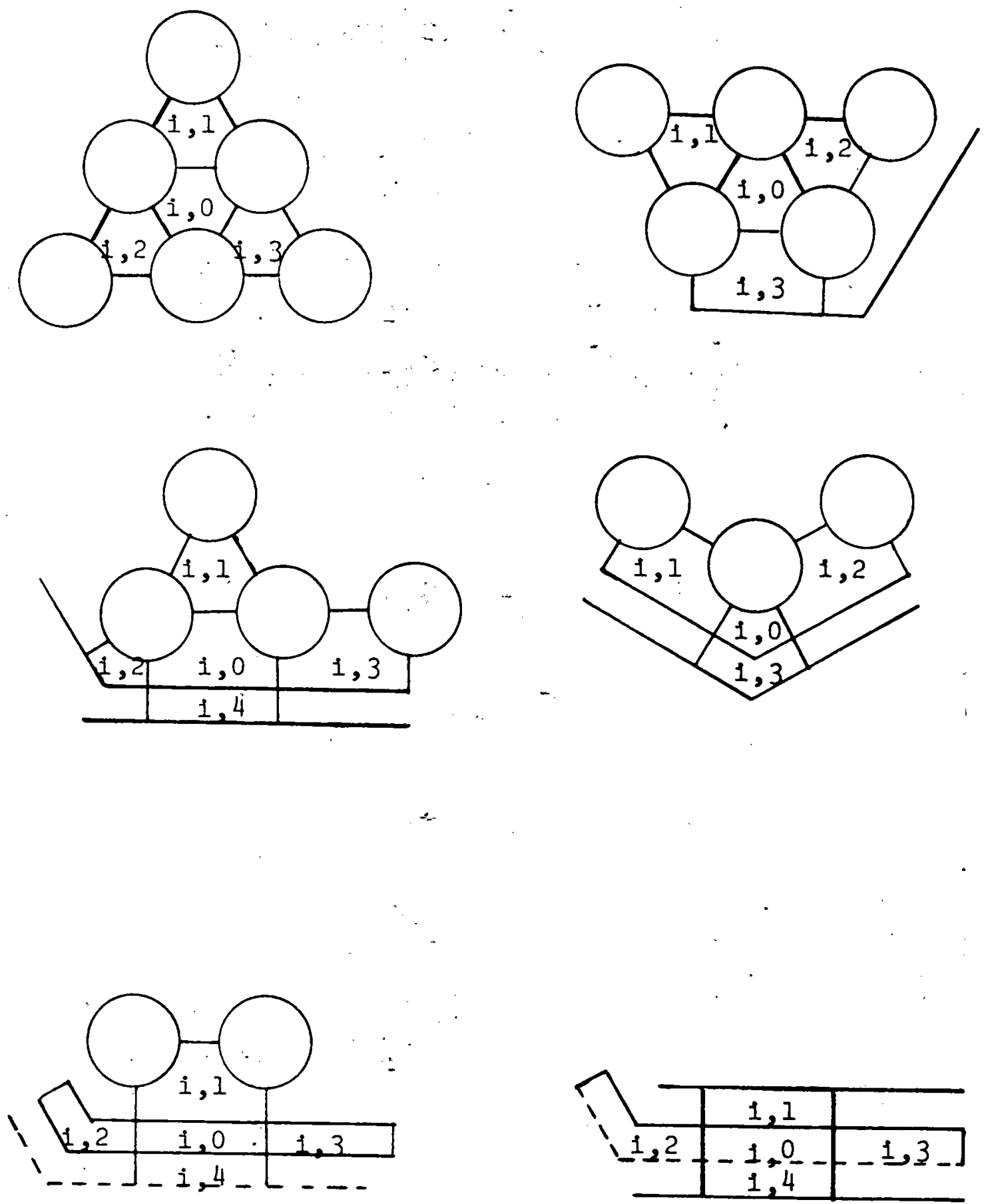

Figure 3 


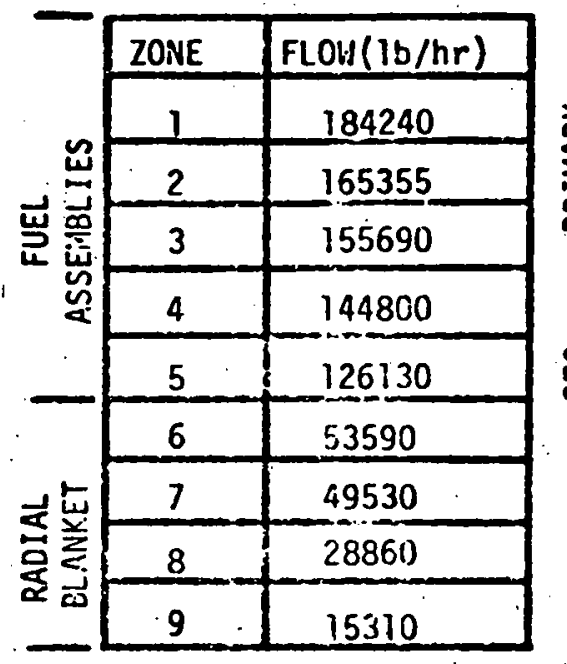

\begin{tabular}{|c|c|}
\hline CONTROL ASS'Y. & FLOW $(1 t / h r)$ \\
\hline Central & 40140 \\
\hline Row 4 & 33915 \\
\hline Row 7 Corner & 33915 \\
\hline Row 7 Flat & 401.40 \\
\hline Row 4 & (upf 150 ow) \\
\hline
\end{tabular}

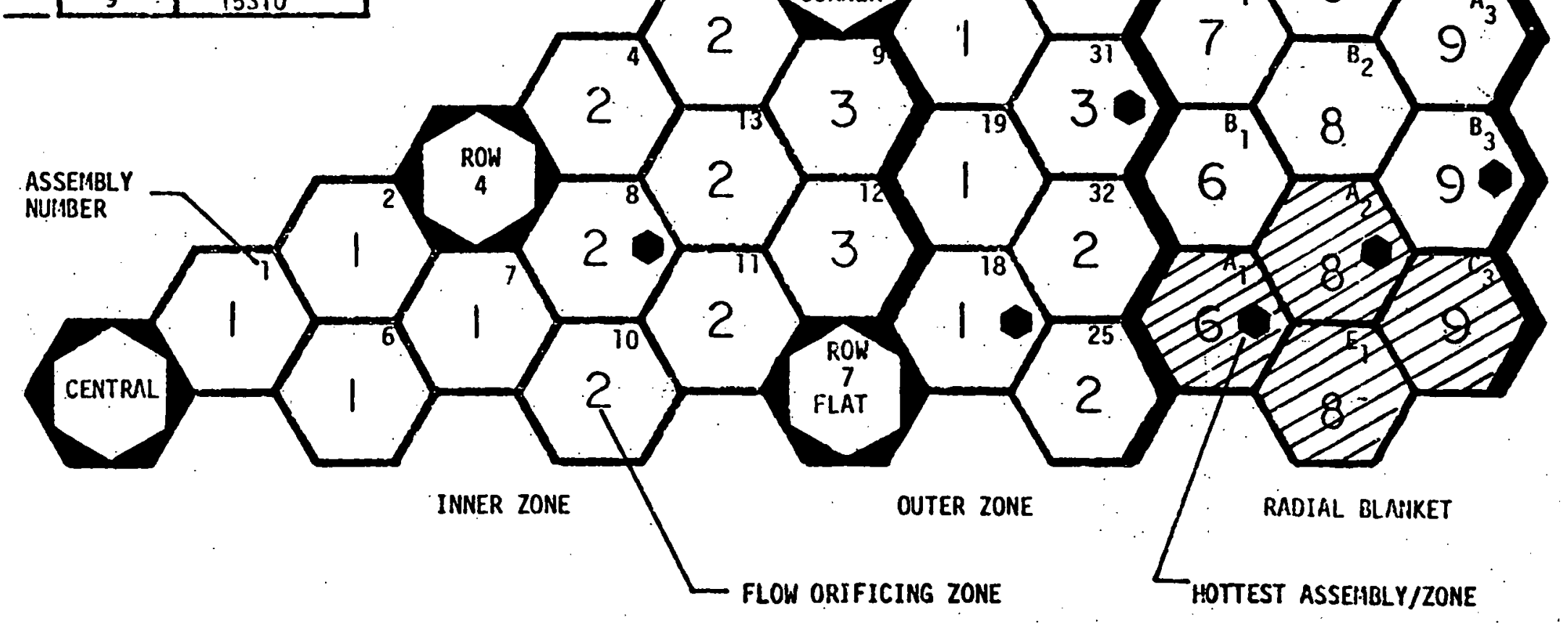

F1gure 4 
SUBCHANNLL NUMBERING SCHEME FOR FUEL ASSEMBLY

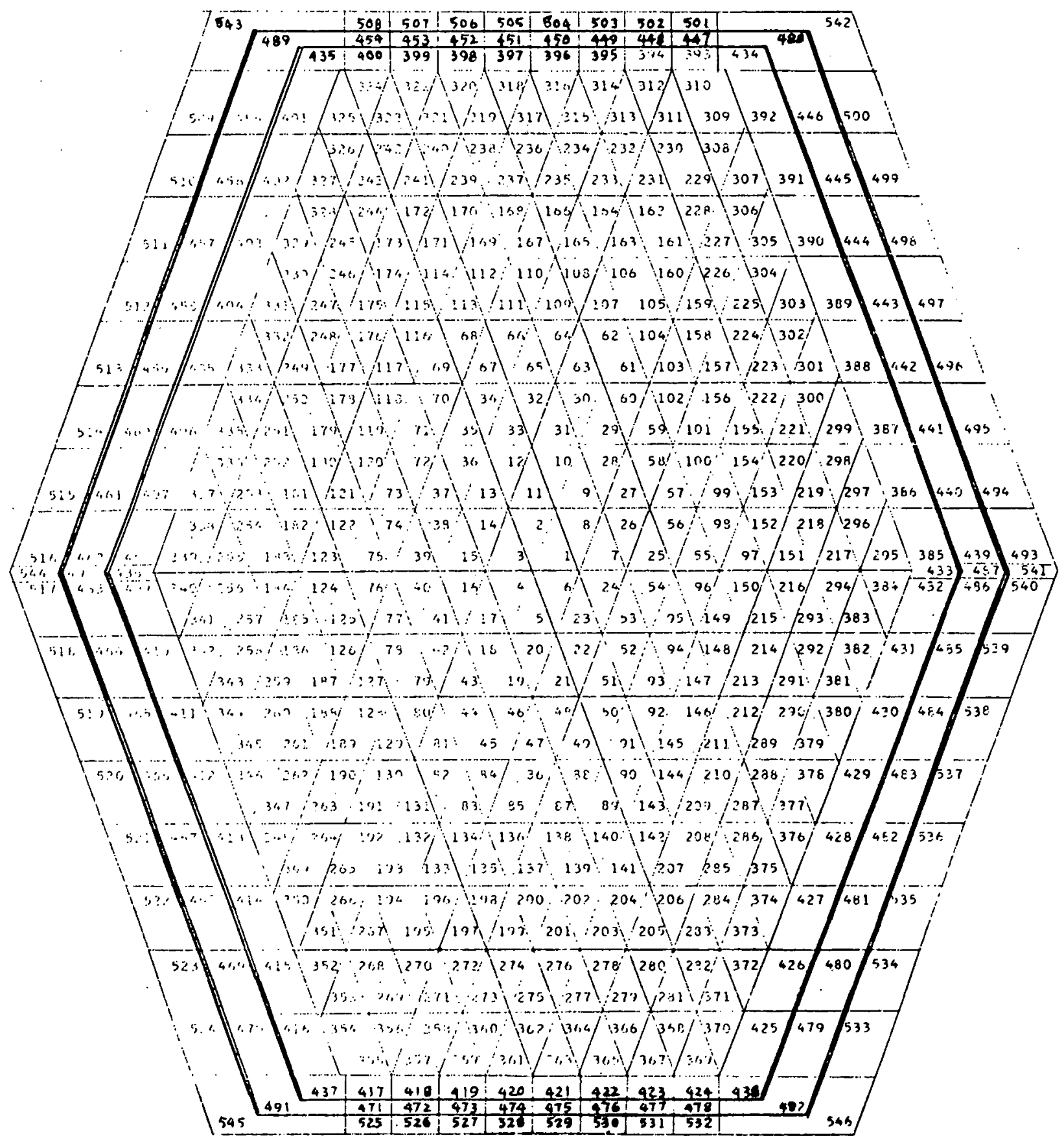

Figure 5 
SUBCIIANNEL INUMBERING SCHEME FOR BLANKET ASSEMBLY

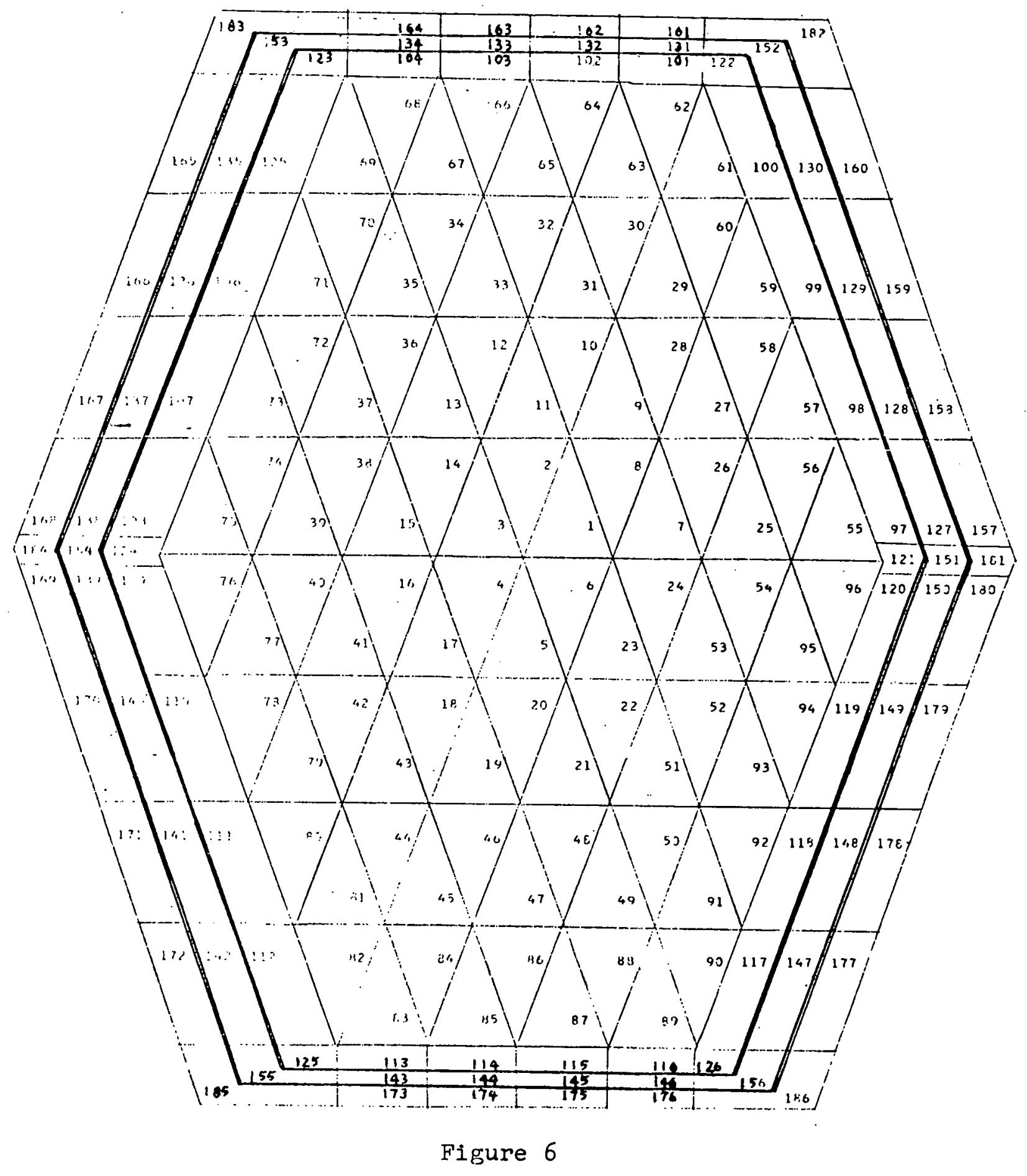


TEMPERATURE PREDICTION FOR ZONE I ASSEMBLY

Geometry: Fuel (Table 1)

Bundle flow rate $(\mathrm{lb} / \mathrm{hr}) 184240$ Gap flow rate (lb/hr)

bundle Reynolds ilo.

Gap Reynolds No. $6.92 \times 10^{4}$ $2.94 \times 10^{3}$
Heat Generated: Heat Entered:

Input Parameters (Ref.[5]): $\varepsilon^{*}=0.01$ $\mathrm{C}=0.08$

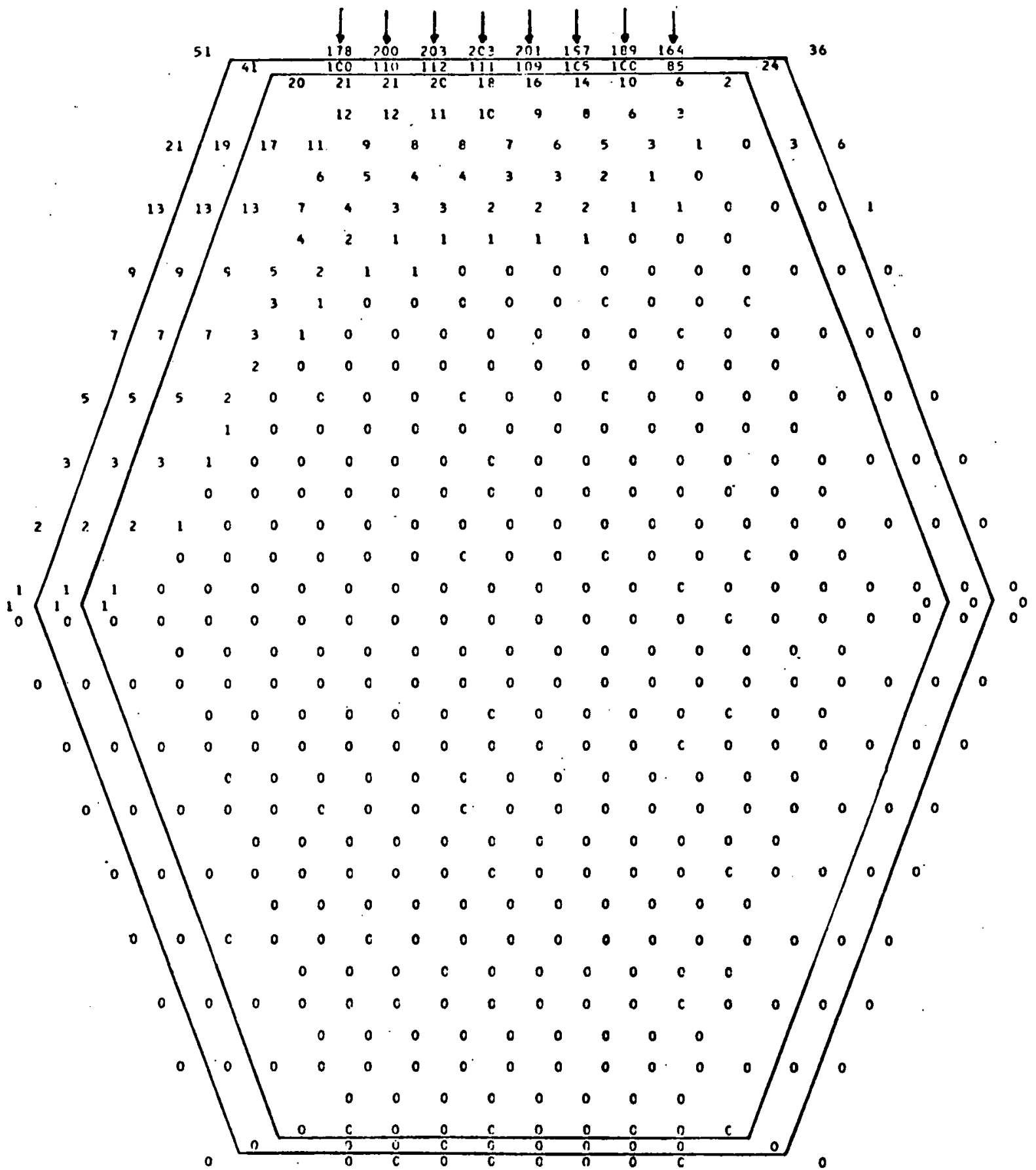

Figure 7 
TEMPERATURE PREDICTION FOR ZONE 2 ASSEMBLY

Geometry: Fuel (Table 1) Heat Generated:

$0 \mathrm{Kw}$

Bundle flow rate (lb/hr) 165355

Heat Entered:

$25.3 \mathrm{KW}$

Gap flow rate (lb/hr)

600

Bundle Reynolds No.

$6.21 \times 10^{4}$

Input Parameters (Ref.[5]):

Gap Reynolds No. $\quad 2.94 \times 10^{3}$

$$
\varepsilon^{*}=0.01
$$

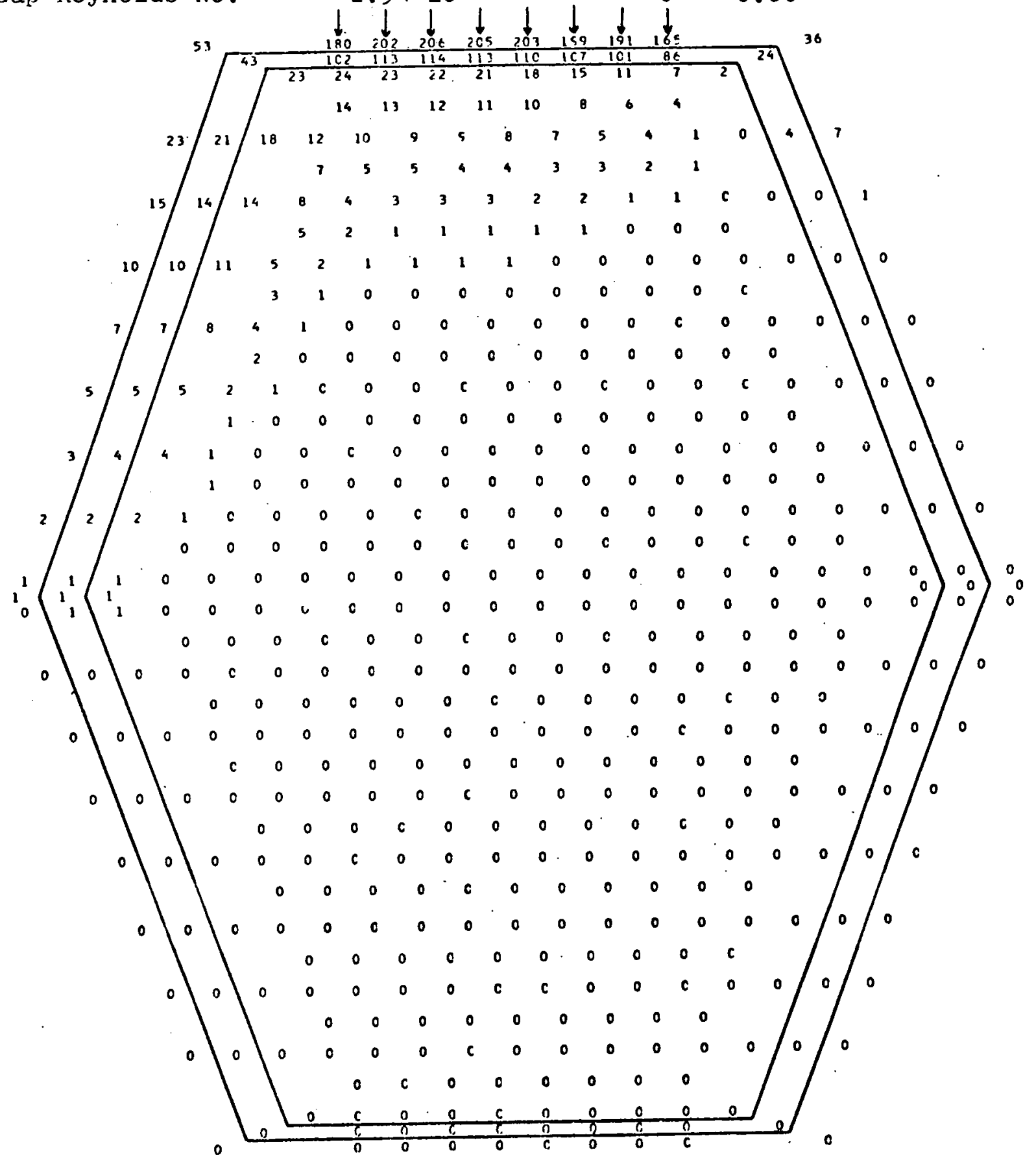

Figure 8 
TEMPERATURE PREDICTION FOR ZONE 3 ASSEMBLY

Geometry: Fuel (Table 1) Heat Generated:

$0 \mathrm{KW}$ Bundle flow rate $(\mathrm{lb} / \mathrm{hr}) 155690$

Heat Entered:

$25.3 \mathrm{KW}$

Gap flow rate (lb/hr)

Bundle Reynolds No.

Gap Reynolds No.
600 $5.85 \times 10^{4}$

$2.94 \times 10^{3}$
Input Parameters (Ref.[5]):

$$
\varepsilon^{*}=0.01
$$$$
C=0.08 \text {. }
$$

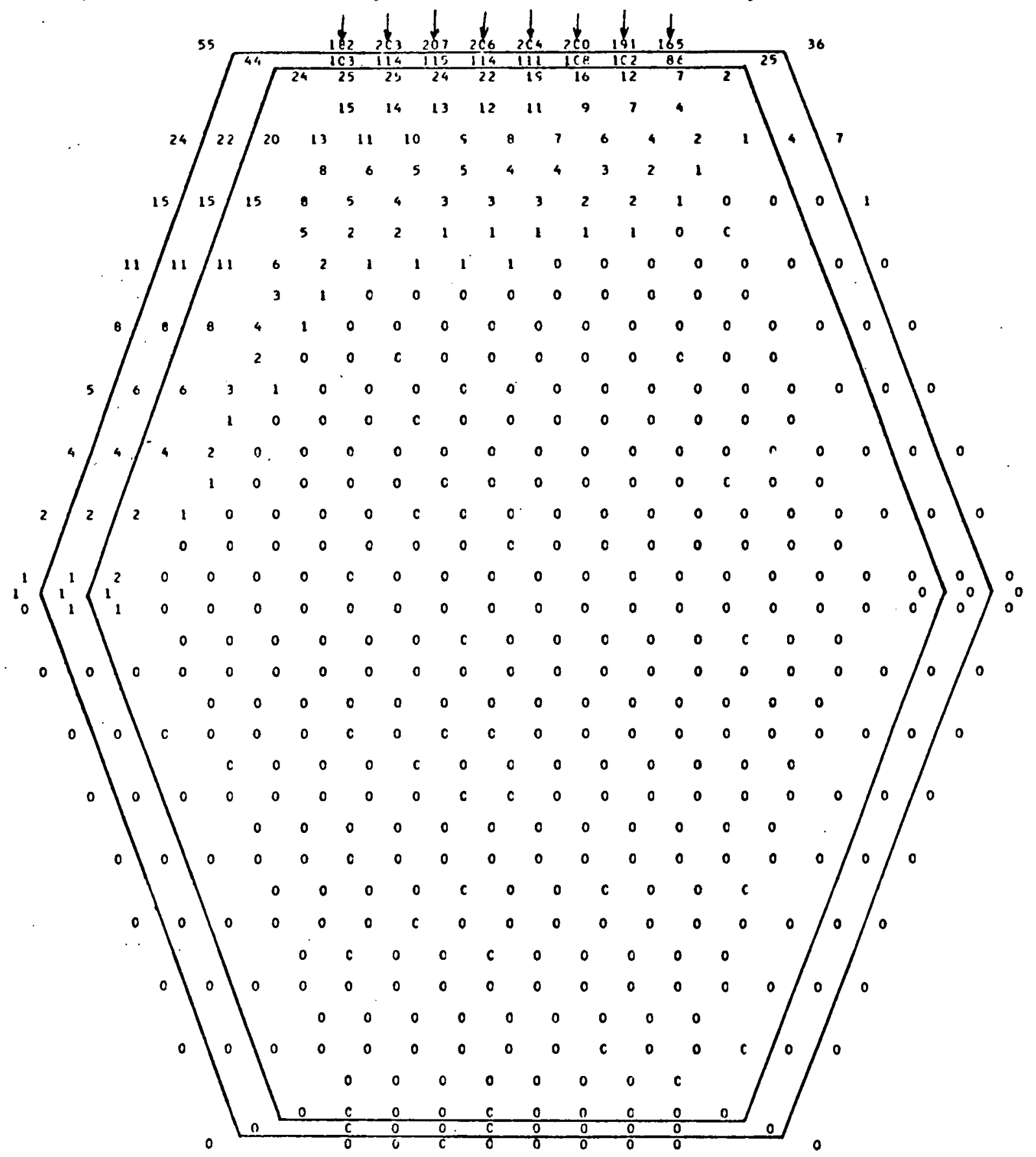

F1gure 9 
TEMPERATURE PREDICTION FOR ZONE 4 ASSEMBLY

Geonetry: Fuel (Table 1)

Bundle flow rate $(\mathrm{lb} / \mathrm{hr}) 144800$

Gap flow rate $(\mathrm{lb} / \mathrm{hr}$ )

Bundle Reynolds No.

Gap Reynolds No.
Heat Generated: $0 \mathrm{KW}$

Heat Entered: $25.3 \mathrm{Kw}$

Input Parameters (Ref.[5]):

$\varepsilon^{*}=0.01$

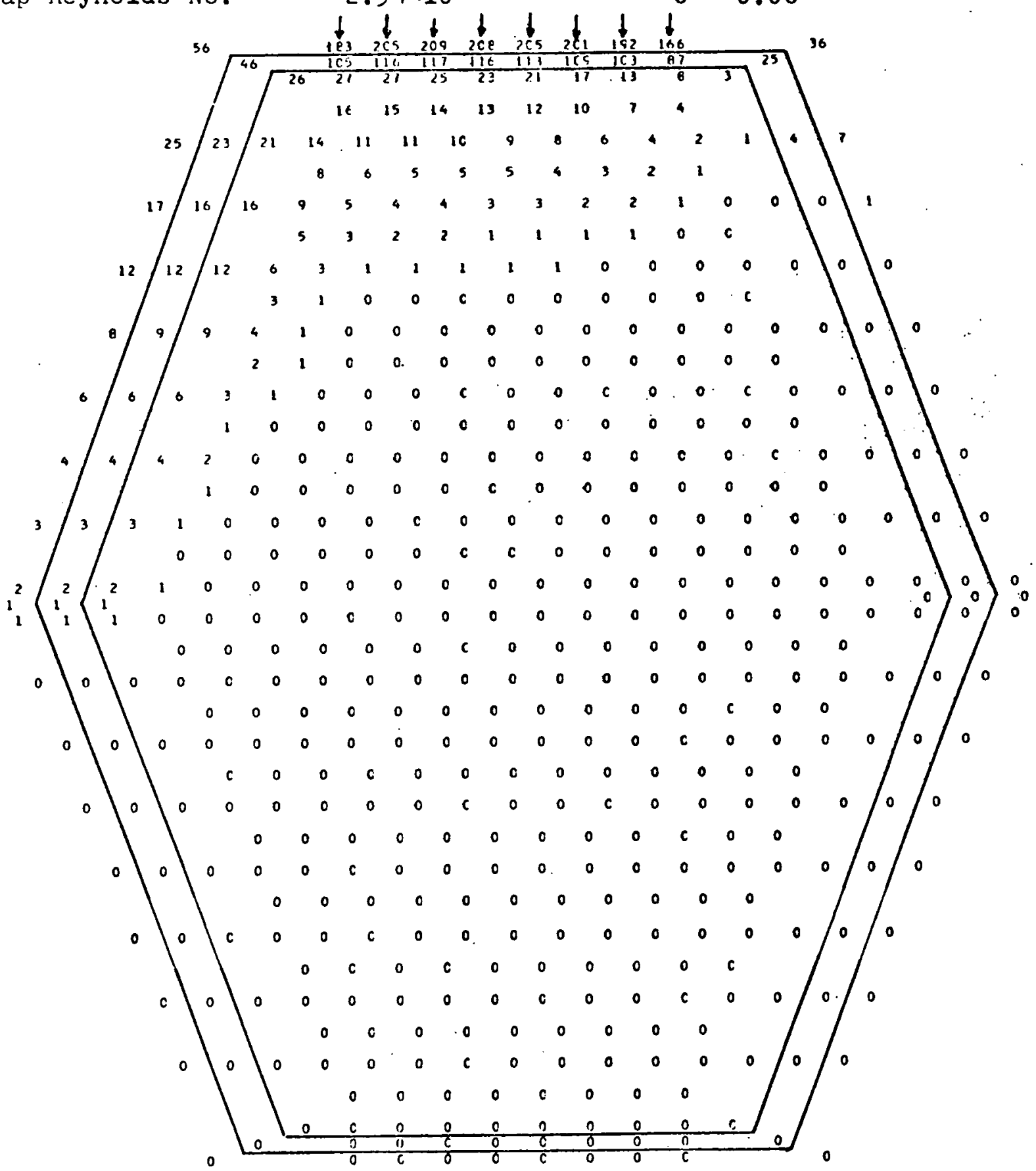

Figure 10 
TEMPERATURE PREDICTION FOR ZONE 5 ASSEMBLY

Geometry: Fuel (Table 1)

Bundle flow rate $(1 \mathrm{~b} / \mathrm{hr}) 126130$ Gap flow rate $(1 \mathrm{~b} / \mathrm{hr})$ Bundle Reynolds No. $4.74 \times 10^{4}$ Gap Reynolds No. $2.94 \times 10^{3}$
Heat Generated:

Heat Entered:

Input Parameters (Ref.[5]):

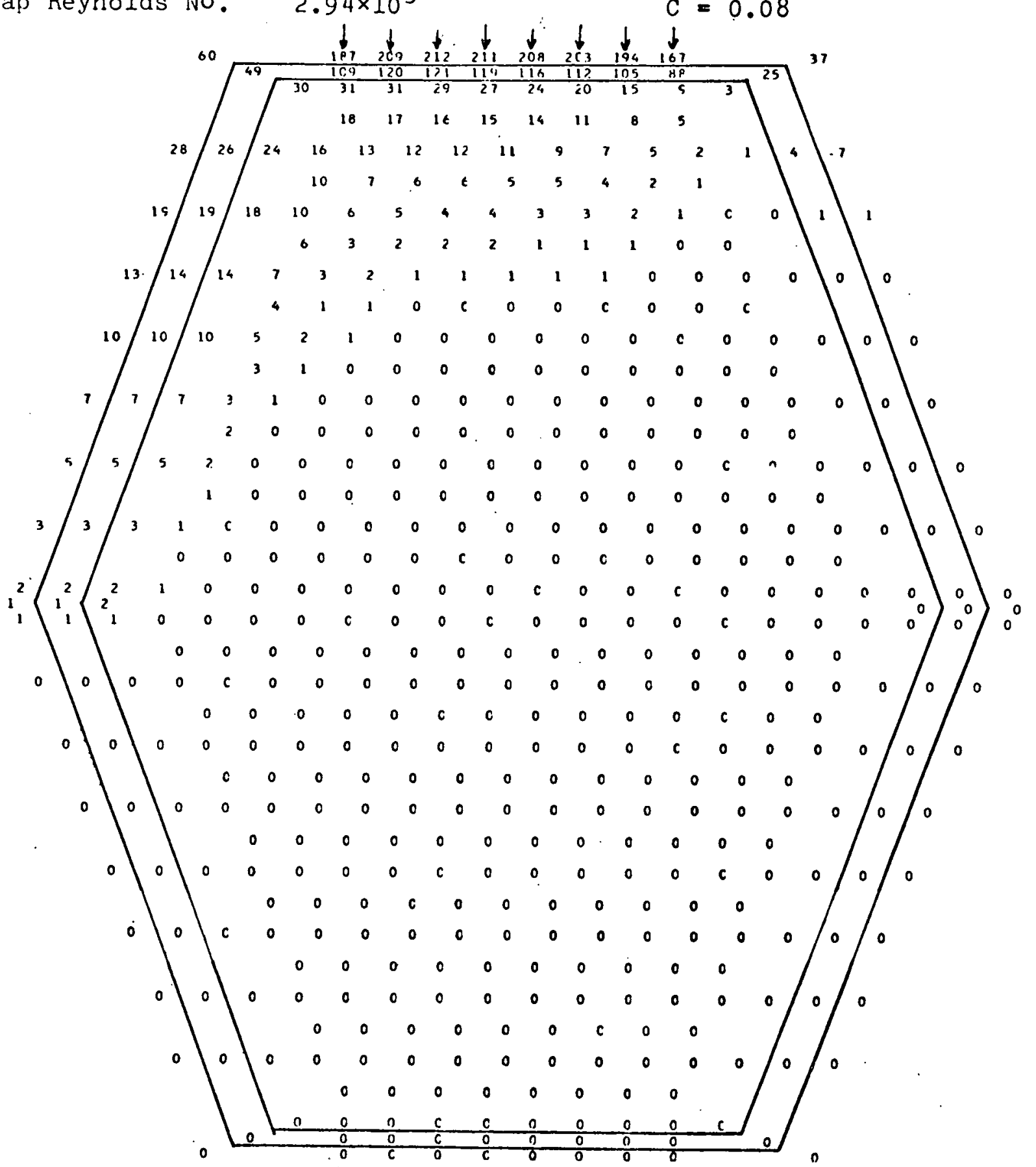

Figure 11 
TEMPERATURE PREDICTION FOR ZONE 6 ASSEMBLY

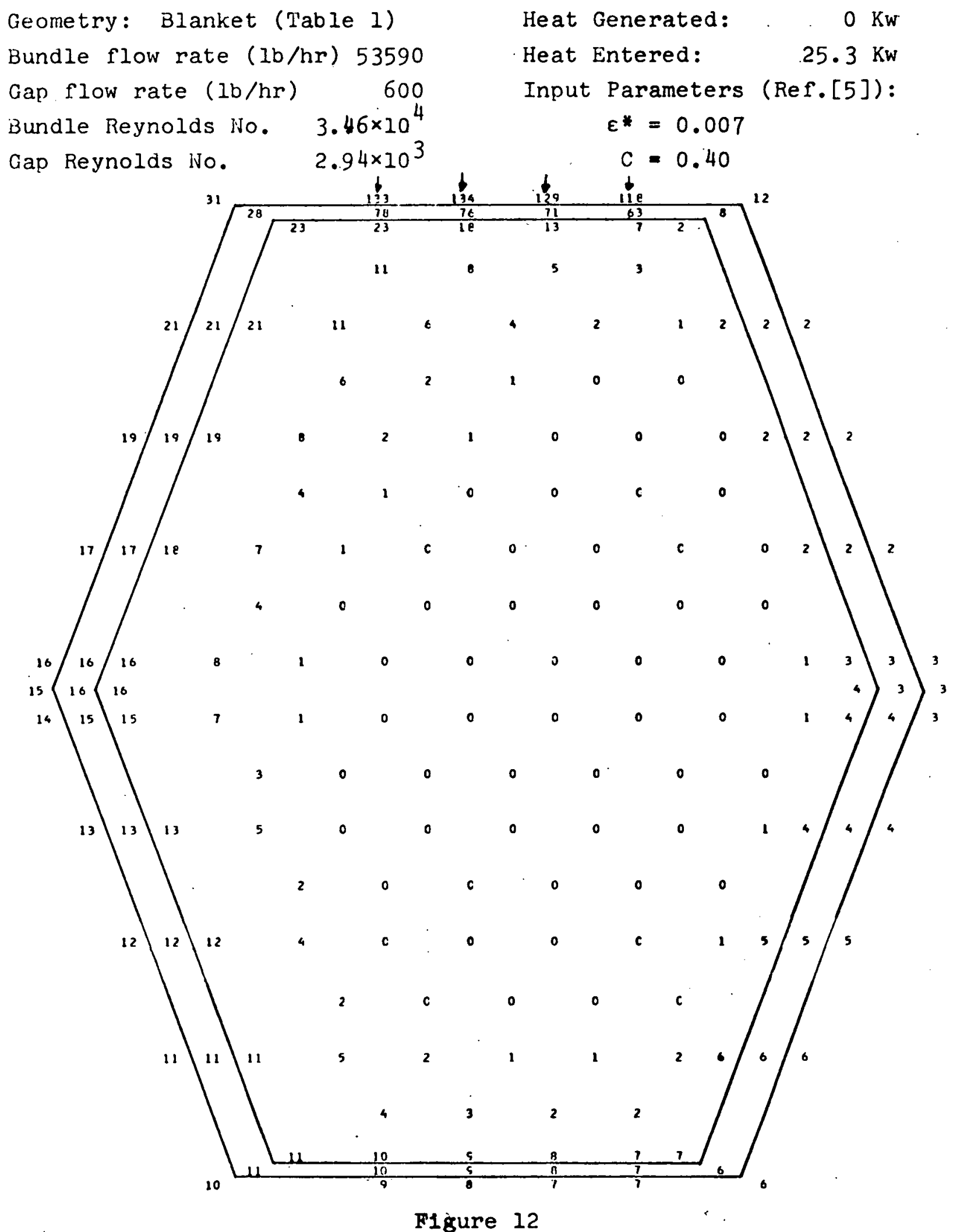


TEIMPERATURE PREDICTION FOR ZONE 7 ASSEMBLY
Lieometry: Blanket (Table 1)
Heat Generated:
$0 \mathrm{Kw}$
Bundle flow rate $(\mathrm{lb} / \mathrm{hr}) 49530$
Gap flow rate ( $1 \mathrm{~b} / \mathrm{hr}) \quad 600$
Bundle Reynolds NO. $3.20 \times 10^{4}$
Gap Reynolds No.
Heat Entered:
$25.3 \mathrm{Kw}$
Input Parameters (Ref.[5]):

$$
\begin{aligned}
\varepsilon * & =0.007 \\
C & =0.40
\end{aligned}
$$

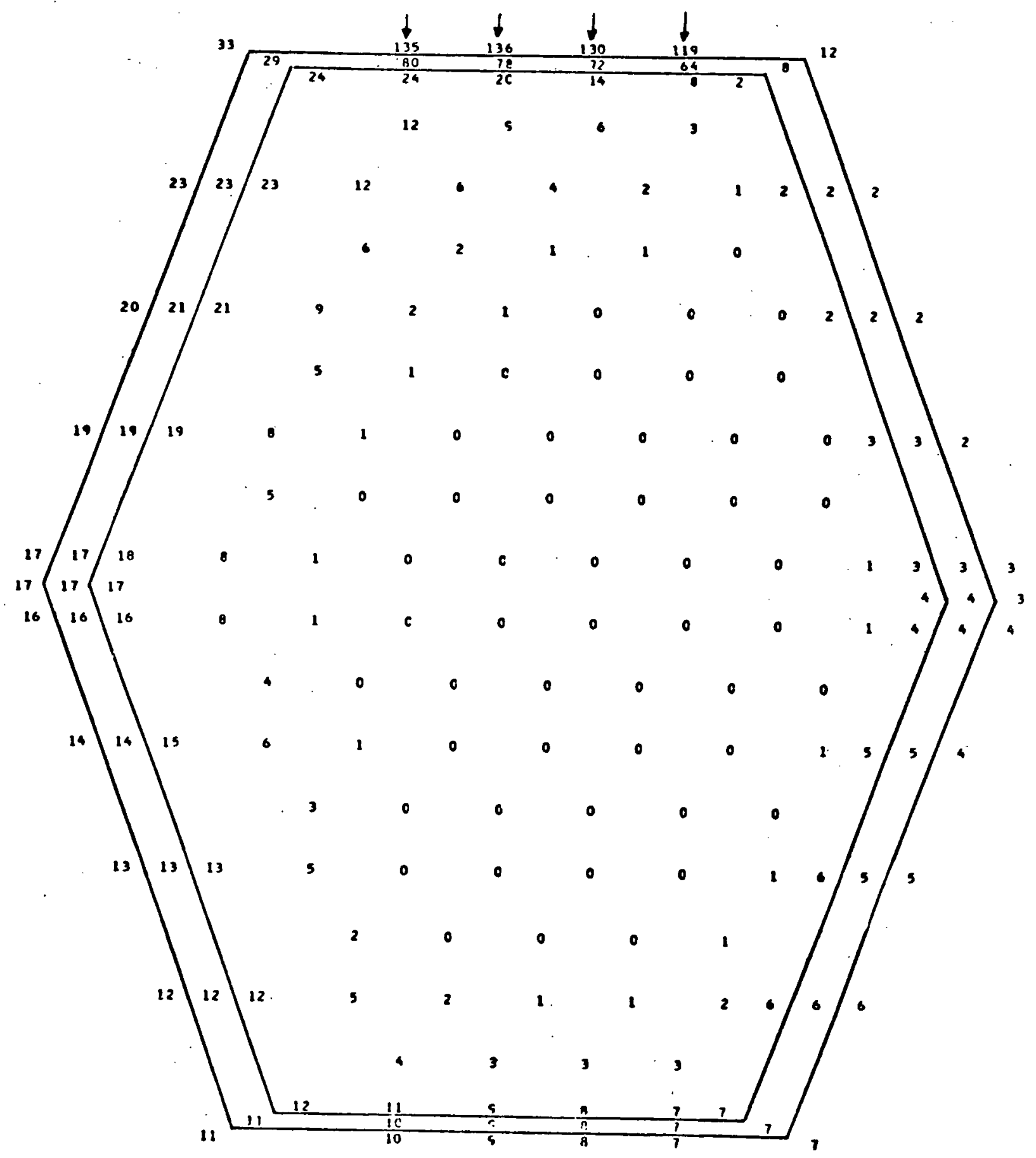

PIgure 13 
TEMPERATURE PREDICTION FOR ZONE 8 ASSEMBLY

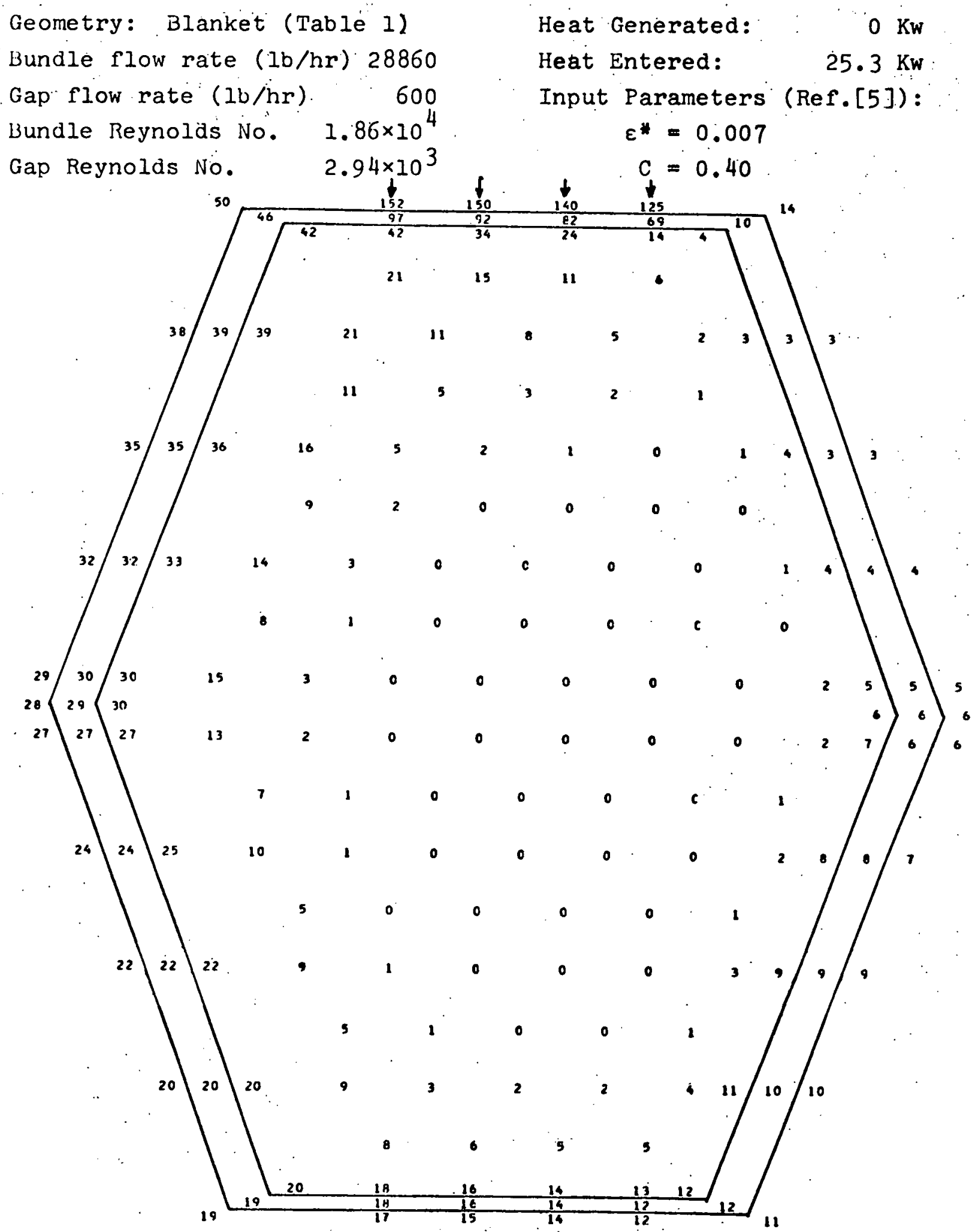

Figure 14 
TEMPERATURE PREDICTION FOR ZONE 9 ASSEMBLY

Geometry: Blanket (Table 1)

Bundle flow rate $(\mathrm{lb} / \mathrm{hr}) 15310$

Gap flow rate $(\mathrm{lb} / \mathrm{hr}) \quad 600$

iundile Reynolds No. $9.88 \times 10^{3}$

Gap Reynolds No. $2.94 \times 10^{3}$
Heat Generated:

Heat Entered:

Input Parameters (Ref.[5]):

$$
\begin{aligned}
\varepsilon^{*} & =0.007 \\
c & =0.40
\end{aligned}
$$

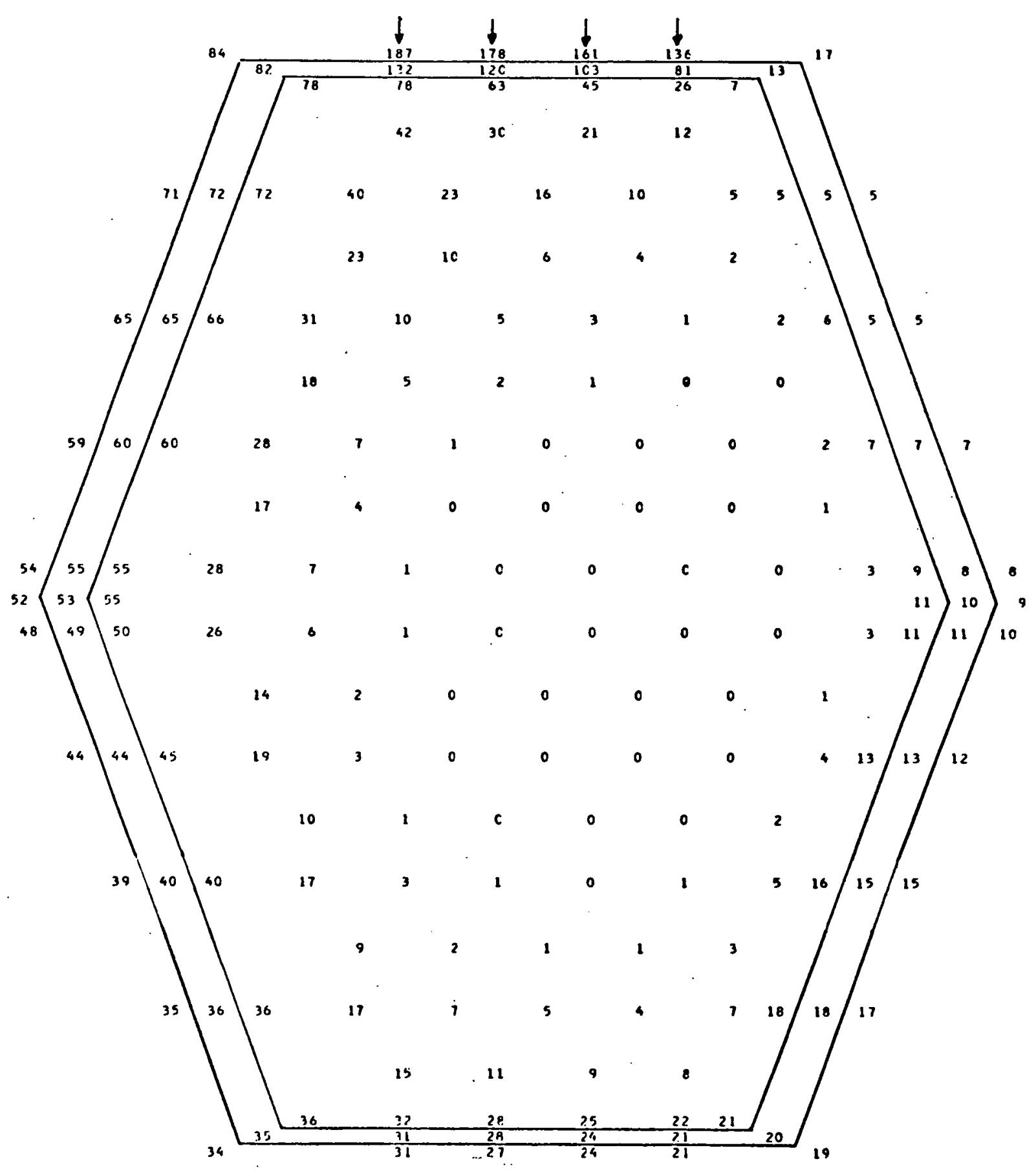

Figure 15 
TEMPERATURE PREDICTION FOR ASSEMBLY $\mathrm{C}_{2}$
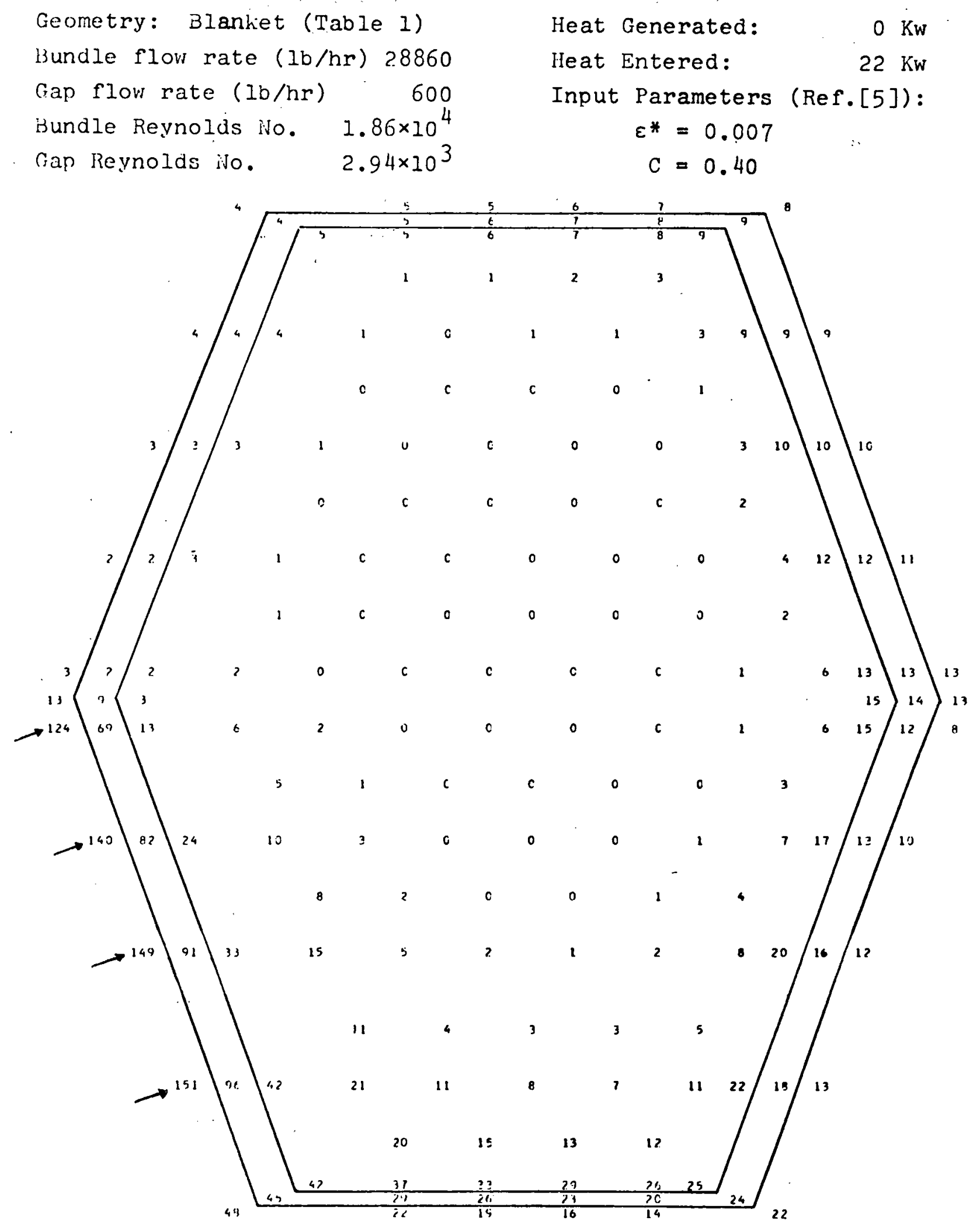

F1gure 16 
TEMPERATURE PREDICTION FOR ASSEMBLY $\mathrm{B}_{2}$

Geometry: Blanket (Table 1)

Bundle flow rate $(\mathrm{lb} / \mathrm{hr}) 28860$ Gap flow rate $(\mathrm{lb} / \mathrm{hr}$ ) Bundle Reynolds No. $1.86 \times 10^{4}$ Gap Reynolds ilo. $\quad 2.94 \times 10^{3}$
Heat Generated: $\quad 0 \mathrm{Kw}$

Heat Entered

$2 \mathrm{KW}$

Input Parameters (Ref.[5]):

$$
\begin{aligned}
\varepsilon^{*} & =0.007 \\
C & =0.40
\end{aligned}
$$

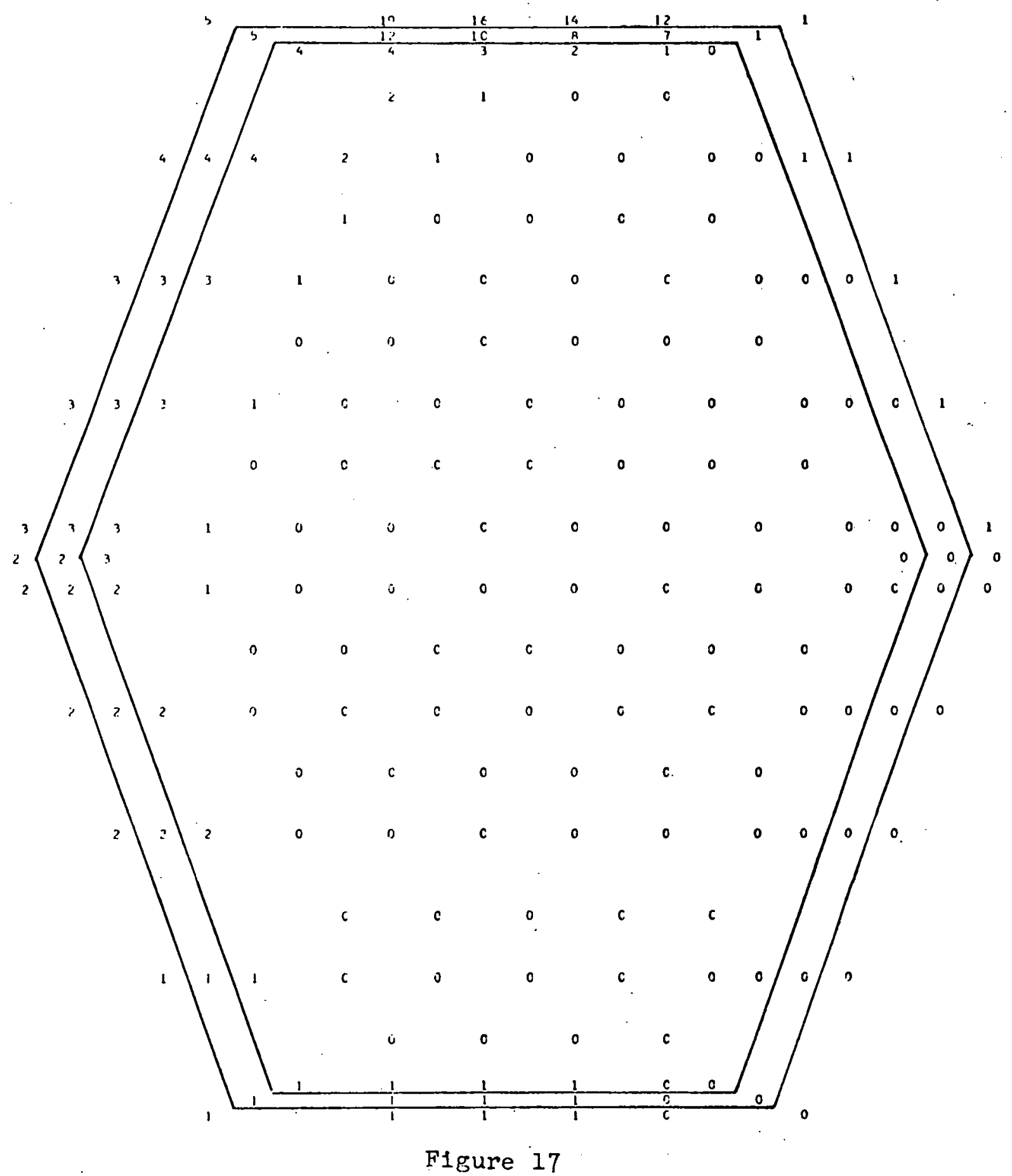


IEMPERATURE PREDICTION FOR ASSEMBLY $\mathrm{A}_{3}$

Geometry: Blanket ('rable 1)

Bundle flow rate. ( $\mathrm{lb} / \mathrm{hr}) 15310$ Gap flow rate $(1 \mathrm{~b} / \mathrm{hr}) \cdot 600$ Bundle Reynolds No. $9.88 \times 10^{3}$ Gap Reynolds No. $\quad 2.94 \times 10^{3}$
Heat Generated: $0 \mathrm{KW}$

Heat Entered: $\quad I \mathrm{Kw}$

Input Parameters (Ref.[5]):

$$
\begin{aligned}
\varepsilon^{*} & =0.007 \\
C & =0.40
\end{aligned}
$$

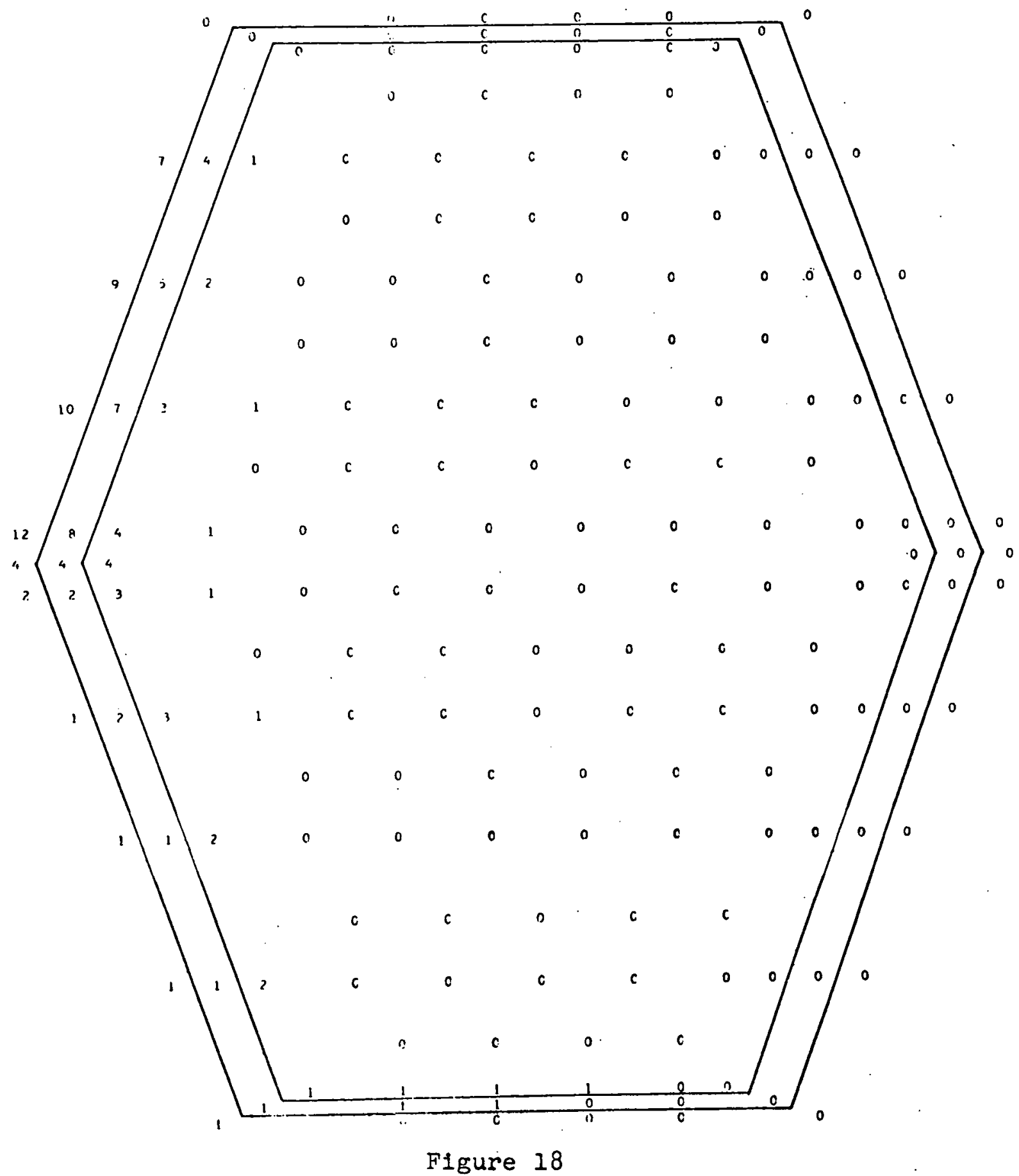


TEMPERATURE PREDICTION FOR ASSEMBLY B 3

Geometry: Blanket (Table 1)

Bundle flow rate $(\mathrm{lb} / \mathrm{hr})=15310$

Gap flow rate $(1 \mathrm{~b} / \mathrm{hr}) \quad 600$

Bundle Reynolds iNo. $\quad 9.88 \times 10^{3}$

Gap Reynolds INo. $\quad 2.94 \times 10^{3}$
Heat Generated:

$0 \mathrm{KW}$

Heat Entered:

$0 \mathrm{KW}$

Input Parameters, (Ref.[5]):

$$
\begin{aligned}
\varepsilon^{*} & =0.007 \\
C & =0.40
\end{aligned}
$$

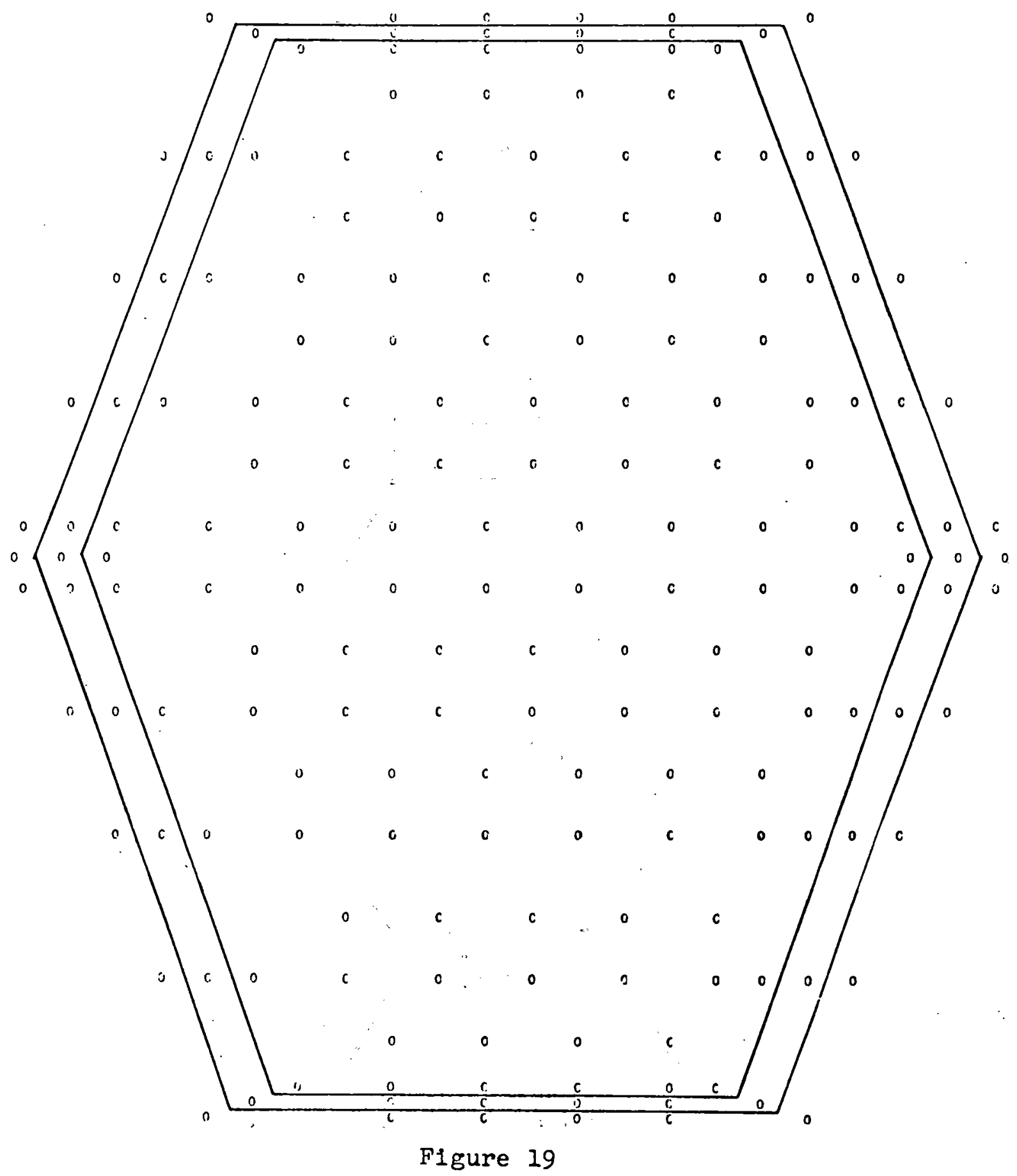


AVERAGE GAP TEMPERATURES FOR ASSEMBLIES OF ZONE I AND ZONE 2

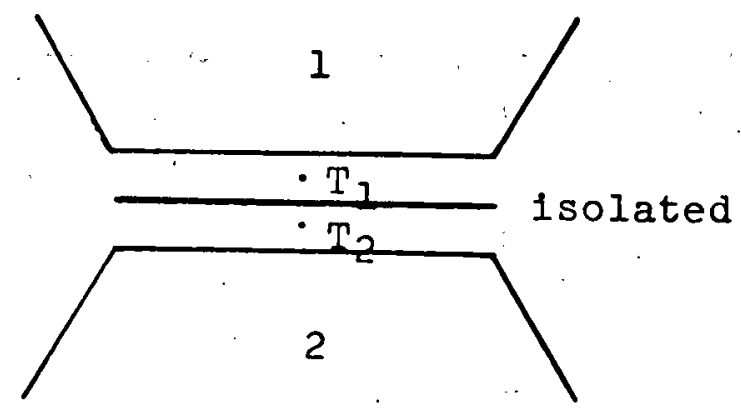

(a)

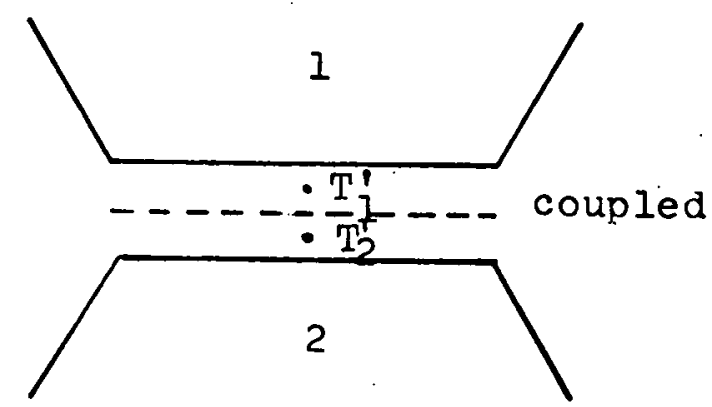

(b)

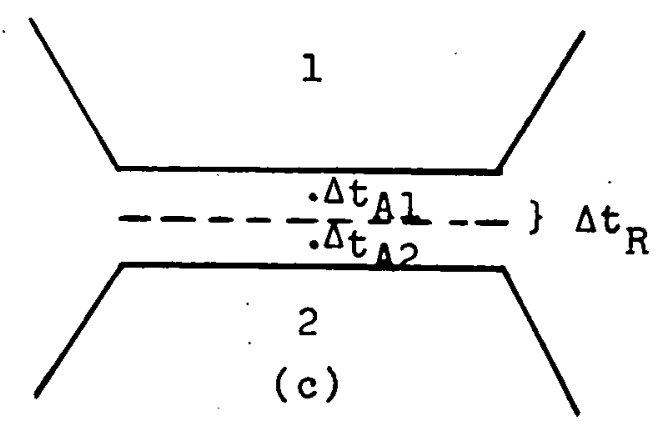

Figure 20 
Geometry: Blanket (Table 1; Bundle flow rate ( $\mathrm{lb} / \mathrm{hr}) 28860$ Gap flow rate $(\mathrm{Ib} / \mathrm{hr}) \quad 600$ Bundle Reynolds No. $\quad 1.86 \times 10^{4}$ Gap Reynolds No.
Heat Generated: Heat Entered:

Input Parameters (Ref.[5]):

$$
\begin{aligned}
\varepsilon^{*} & =0.007 \\
C & =0.40
\end{aligned}
$$

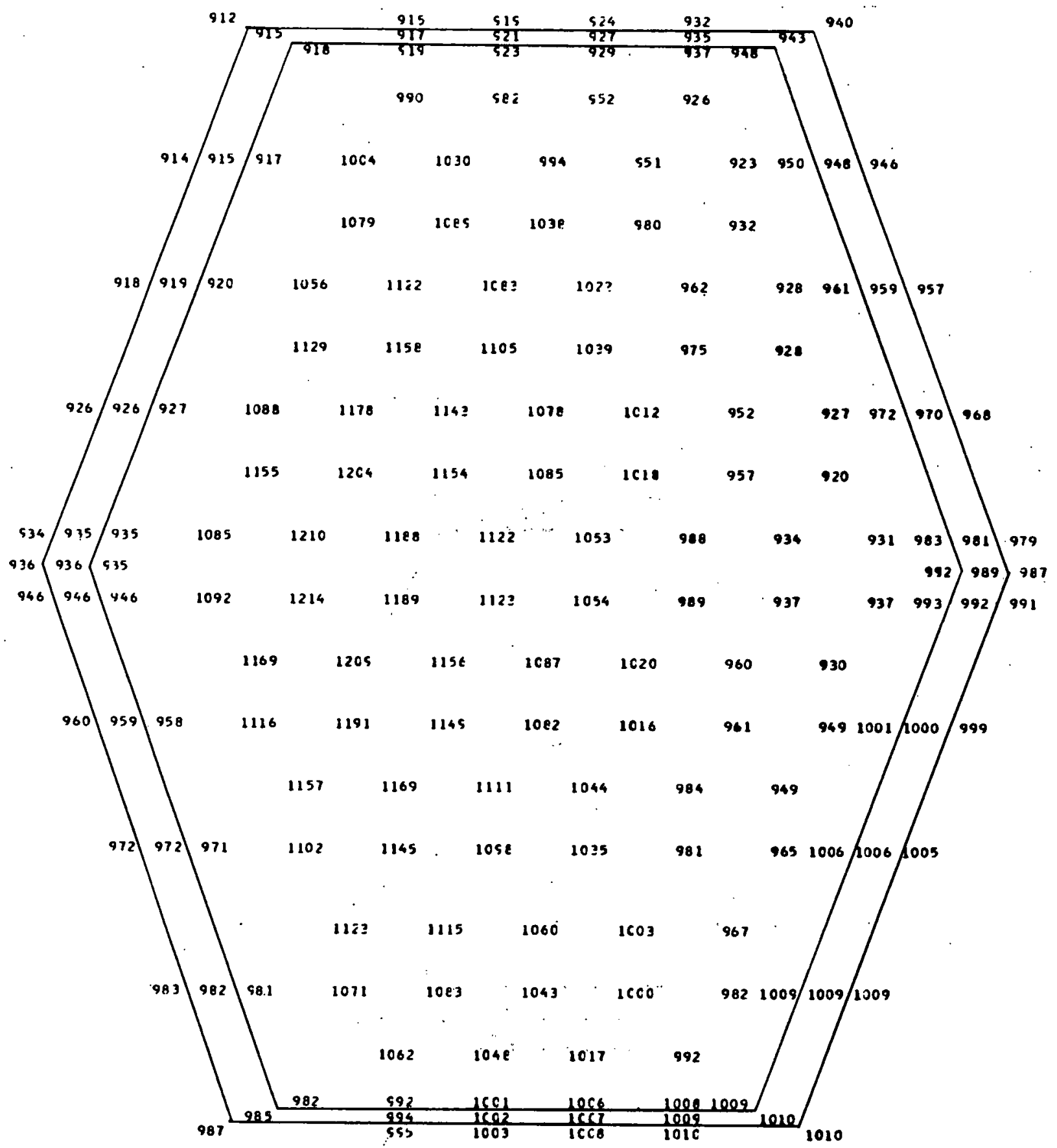

F1gure 21 
TY TEMPERATURE PREDICTION FOR ASSEMBLY E

BY USING ISOLATED ASSEMBLY BOUNDARY CONDI\&ION

Geometry: Blanket (Table 1)

Bundle flow rate $(\mathrm{lb} / \mathrm{hr}) 28860$

Gap flow. rate $(1 \mathrm{~b} / \mathrm{hr})$

Bundle Reynolds No.

Gap Rey nolds No.
Heat Generated:

Heat Entered;

Input Parameters (Ref. [5]):

$$
\varepsilon * 0.007
$$$$
c=0.40
$$

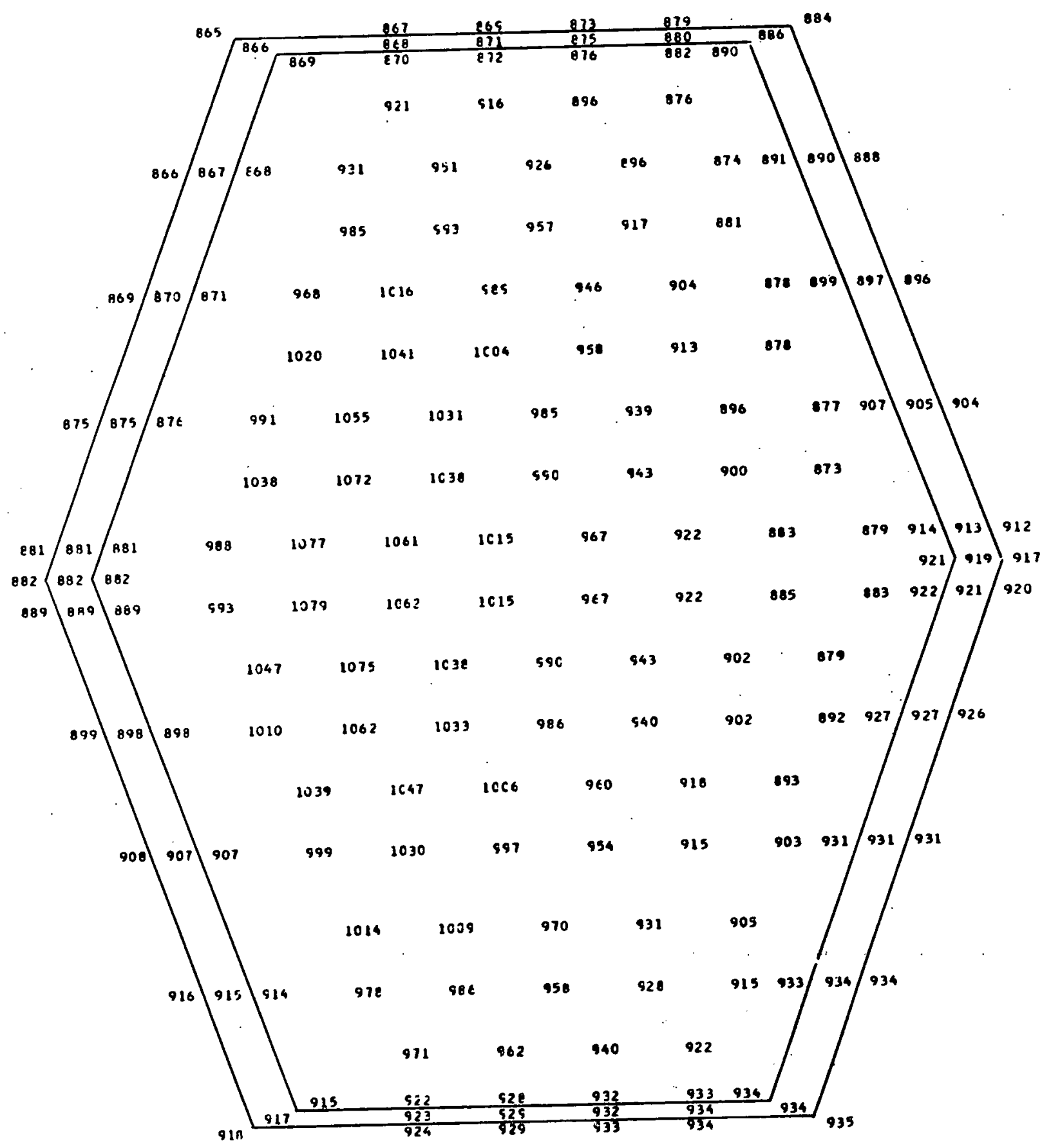

F1gure 22 
TIO DRTYRE PREDICTION OF ASSEPBLY E ${ }_{1}$ BY USING NORMALIZED MAPS
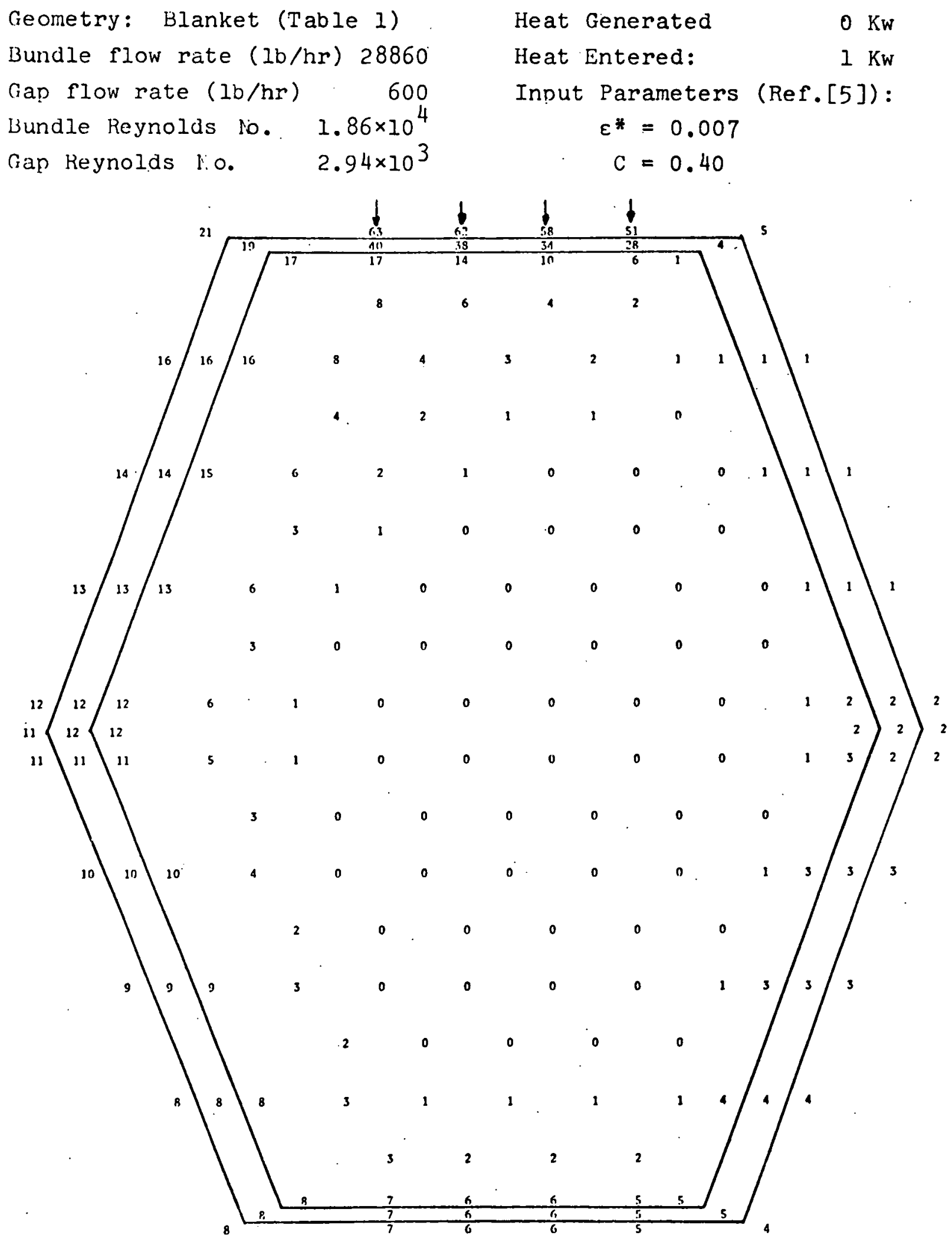

Figure 23 
TEMPERATURE PREDICTION OF ASSEMBLY $\mathrm{E}_{\overline{1}}$

FROM SUPERENERGY FOR TWO COUPLED ASSEMBLIES

Geometry: ilanket (Table 1) iundle flow rate $(\mathrm{lb} / \mathrm{hr}) 28860$ Gap flow rate $(1 \mathrm{~b} / \mathrm{hr})$ isunale Reynolds No: $1.86 \times 10^{4}$ Gap Reyholds No. $2.94 \times 10^{3}$
Heat Generated

Heat Entered: $0^{\circ} \mathrm{KW}$

$1 \mathrm{KW}$

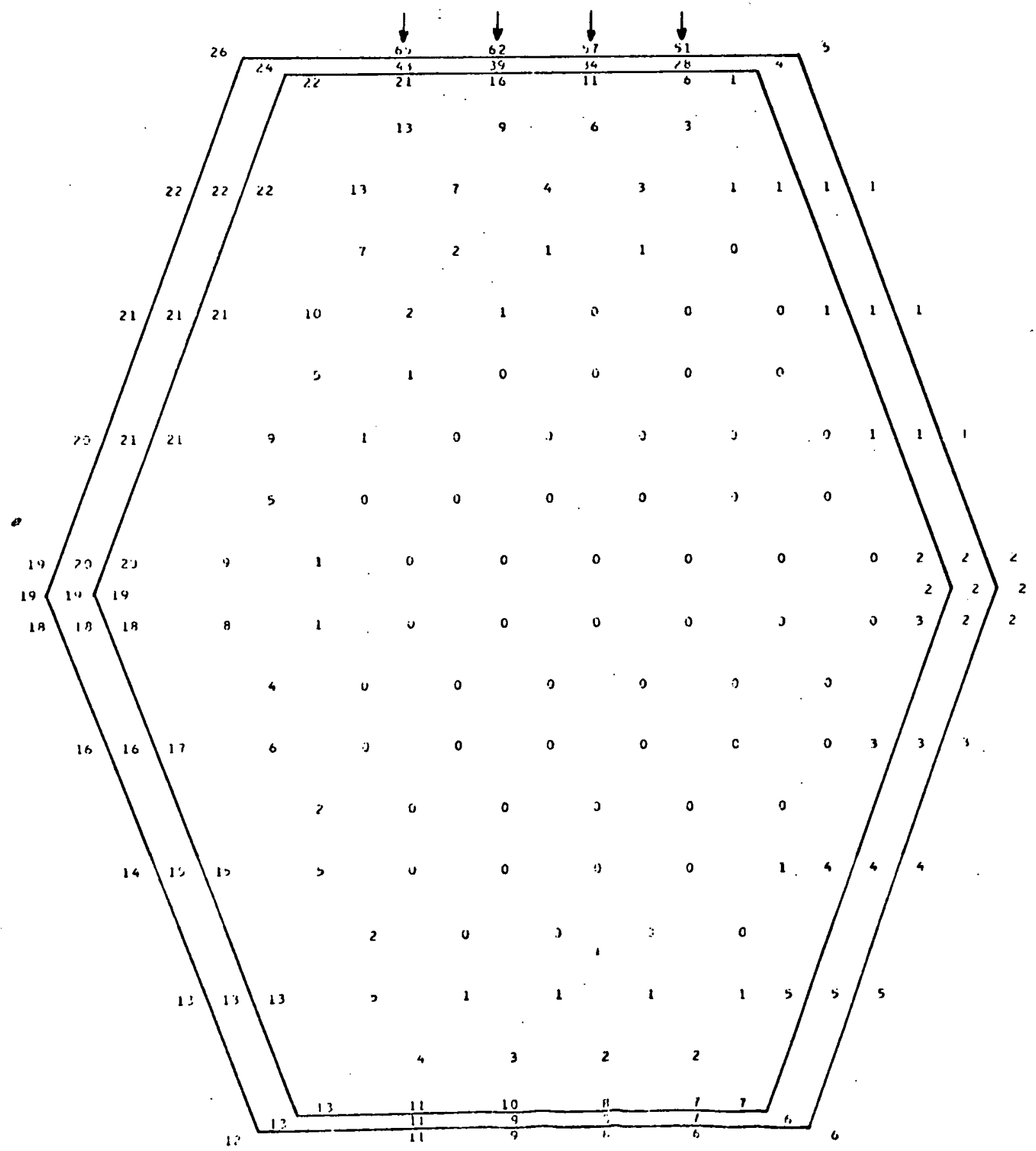

F1gure 24 
TEMPERATURE PREDICTION FOR ASSEMBLY $\mathrm{B}_{2}$ EY USING ISOLATED ASSEMBLY BOUNDARY CONDITION

Geometry: Blanket (Table 1)

Bundle flow rate $(\mathrm{lb} / \mathrm{hr}) 28860$

Gap flow rate $(1 \mathrm{~b} / \mathrm{hr})$

Bundle Reynolds No. $1.86 \times 10^{4}$

Gap Reynolds NO.
Heat Generated:

Heat Entered:

Input Parameters (Ref.[5]):

$$
\begin{aligned}
\varepsilon^{*} & =0.007 \\
C & =0.40
\end{aligned}
$$

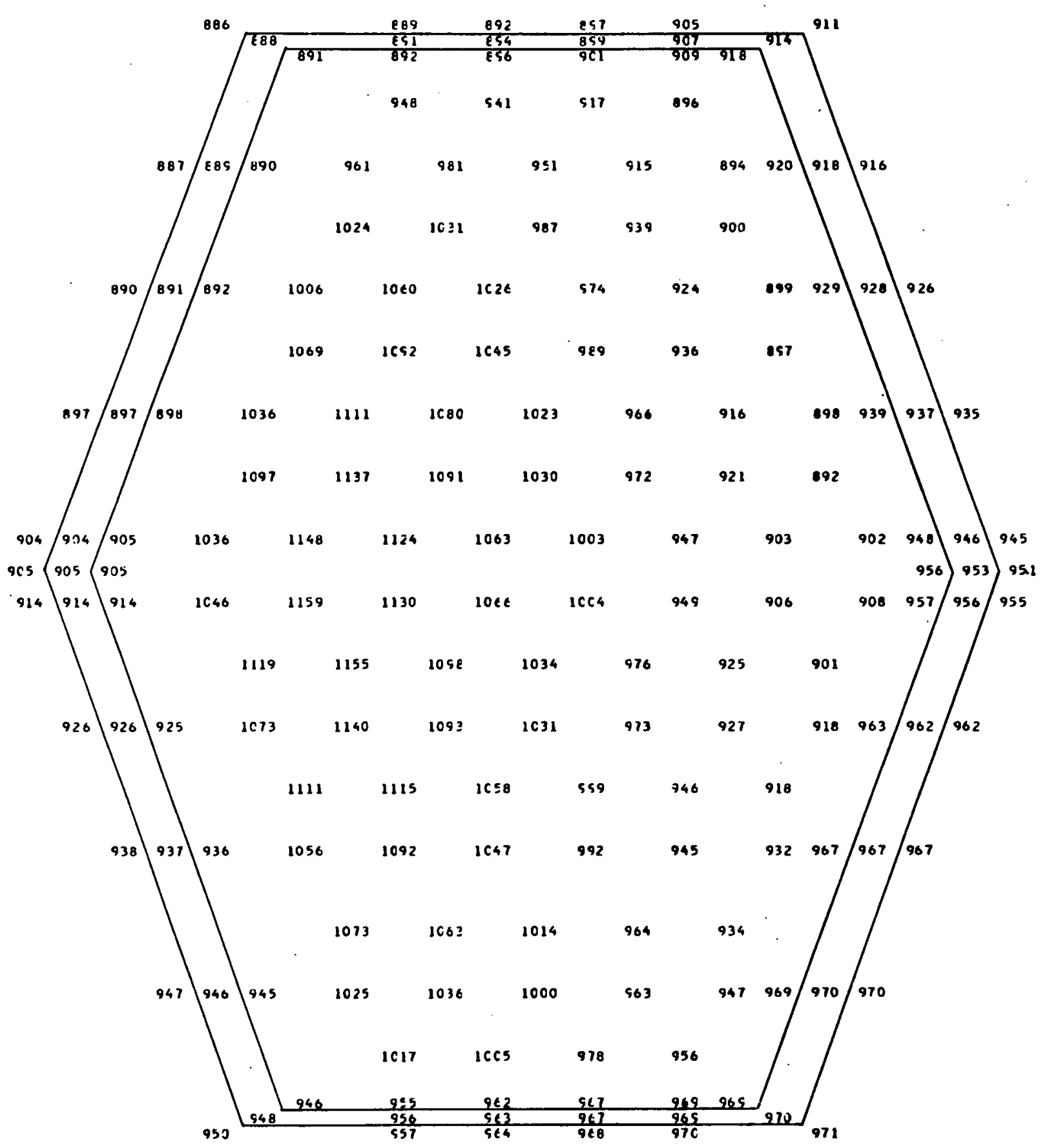

F1g̀ure 25 
TEMPERATURE PREDICTION FOR ASSEMBLY A2

COUPJED TO ASSEMBLY $\mathrm{E}_{1}$

Geometry: Blanket (Table 1)

Bundle flow rate $(\mathrm{lb} / \mathrm{hr}) 28860$

Gap flow. rate $(1 \mathrm{~b} / \mathrm{hr})$

Bundle Reynolds No: $1.86 \times 10^{4}$

Gap Reynolds No.
Heat Generated: $\quad 756.6 \mathrm{Kw}$

Heat Entered: $\quad-14 \quad \mathrm{KW}$

Input Parameters (Ref.[5]):

$$
\begin{aligned}
\varepsilon^{*} & =0.007 \\
c & =0.40
\end{aligned}
$$

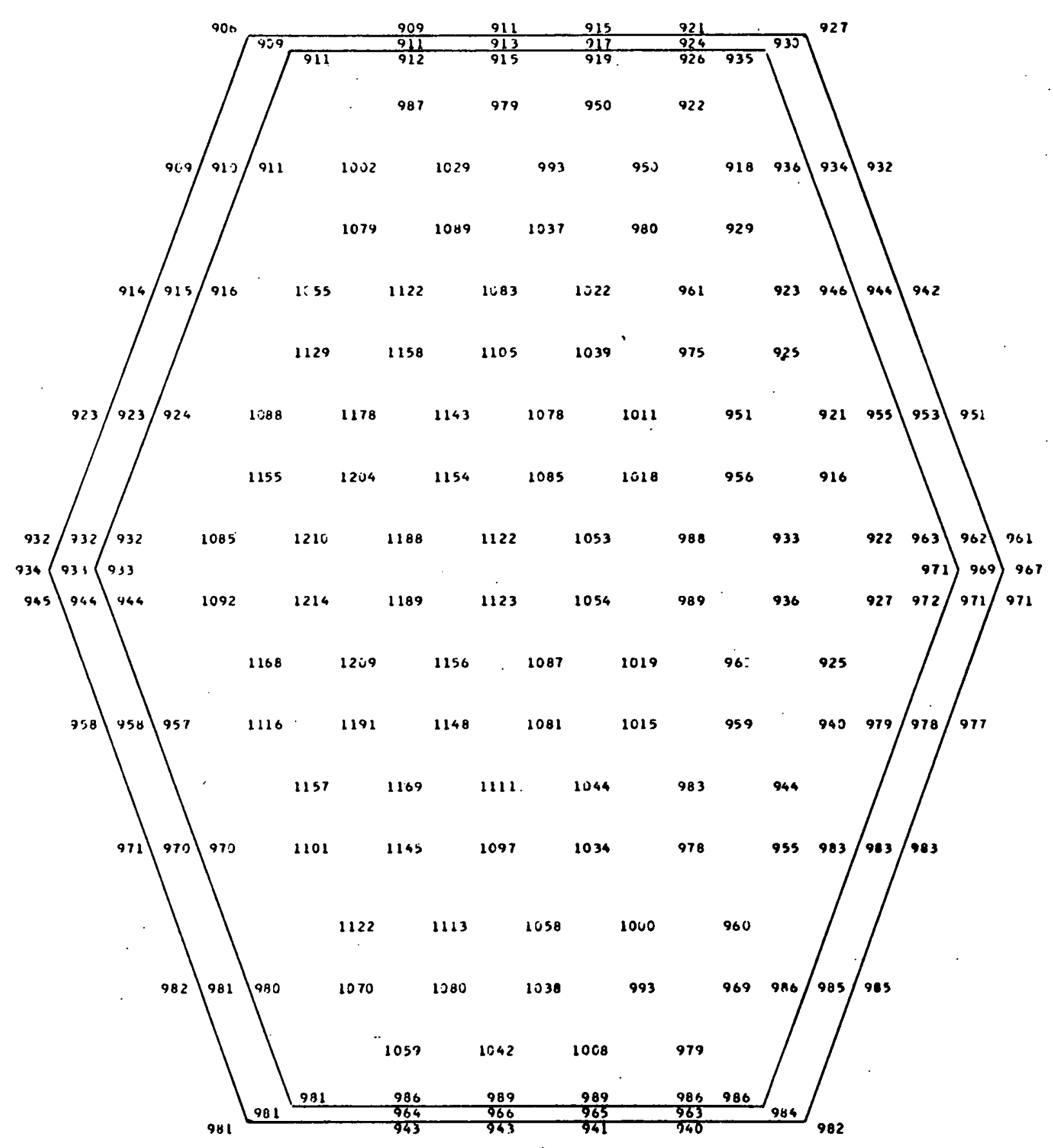

F1gure 26 
TEMPERATURE PREDICTION FOR ASSEMBLY $E_{1}$ COUPLED TO ASSEMBLY $\mathrm{A}_{2}$

Geometry: Blanket (Table 1)

Bundle flow rate $(\mathrm{Ib} / \mathrm{hr}) 28860$ Gap flow rate $(1 \mathrm{~b} / \mathrm{hr}) \cdots 600$ Bundle Reynolds No. $\quad 1.86 \times 10^{4}$ Gap Reynolds No. $2.94 \times 10^{3}$
Heat Generated: $\quad 554.1 \mathrm{Kw}$ Heat Entered: $\quad 14.1 \mathrm{Kw}$ Input Parameters (Ref.[5]):

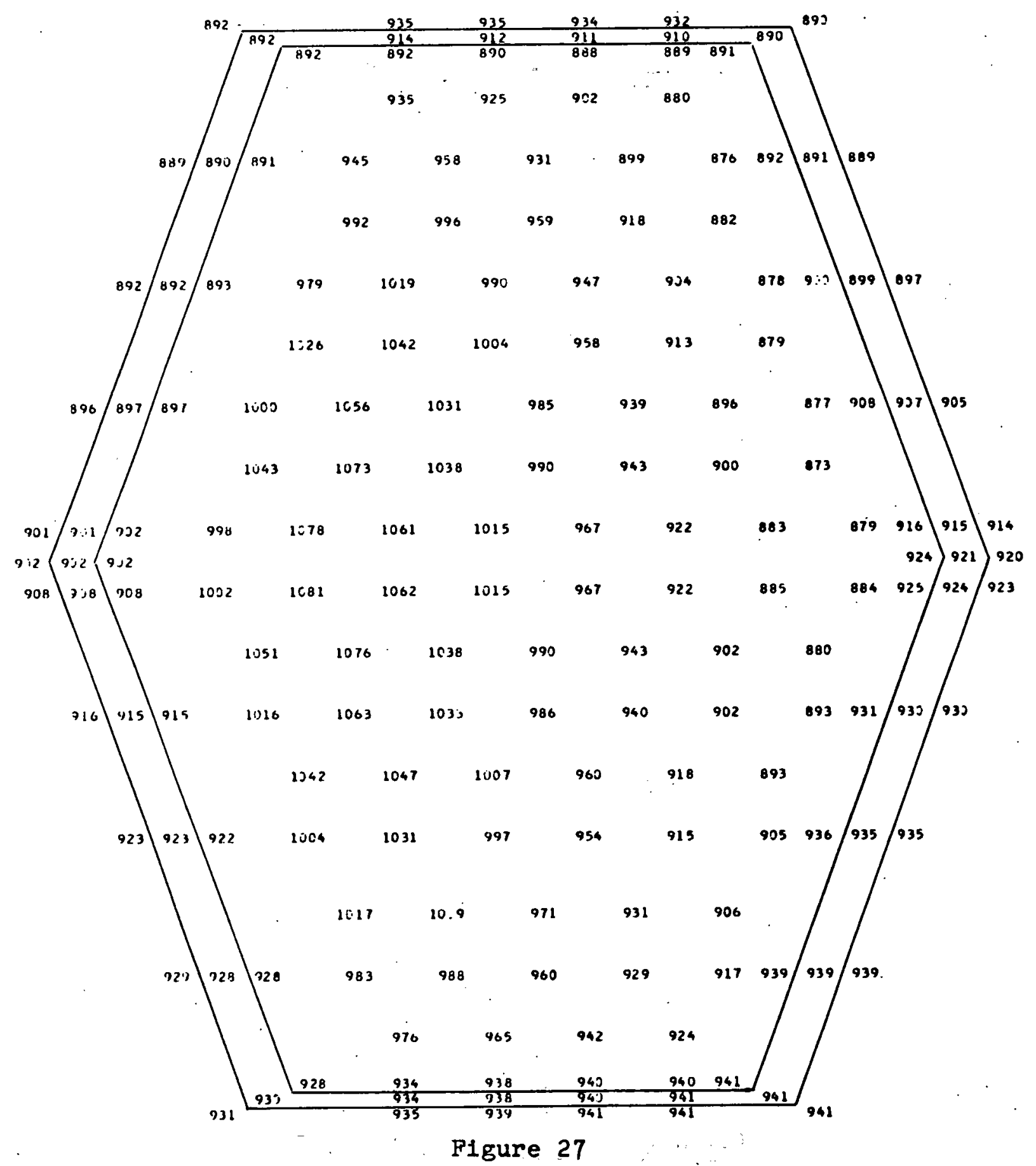




\section{TEMPERATURE PREDICTION FOR}

TWO COUPLED ZONE 8

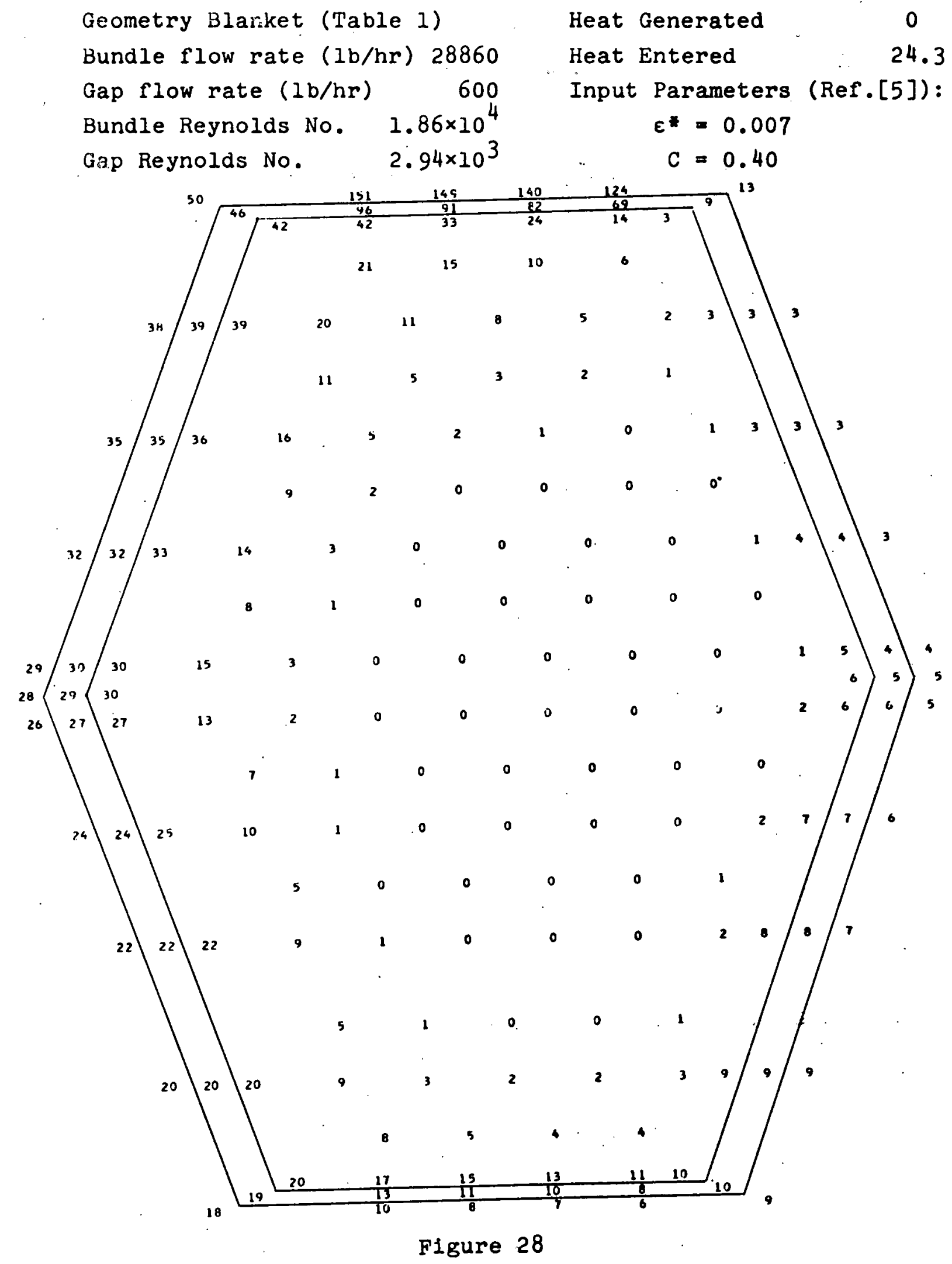


TEMPERATURE PREDICTION FOR

TWO COUPLED ZONE 8 ASSEMBLIES

Geometry: Blanket (Table 1)

Bundle flow rate $(\mathrm{lb} / \mathrm{hr}) 28860$

Gap flow rate $(\mathrm{lb} / \mathrm{hr})$

Bundle Rey nolds No. $1.86 \times 10^{4}$

Gap Reynolds No.
Heat Generated:

Heat Entered

Input Parameters (Ref.[5]):

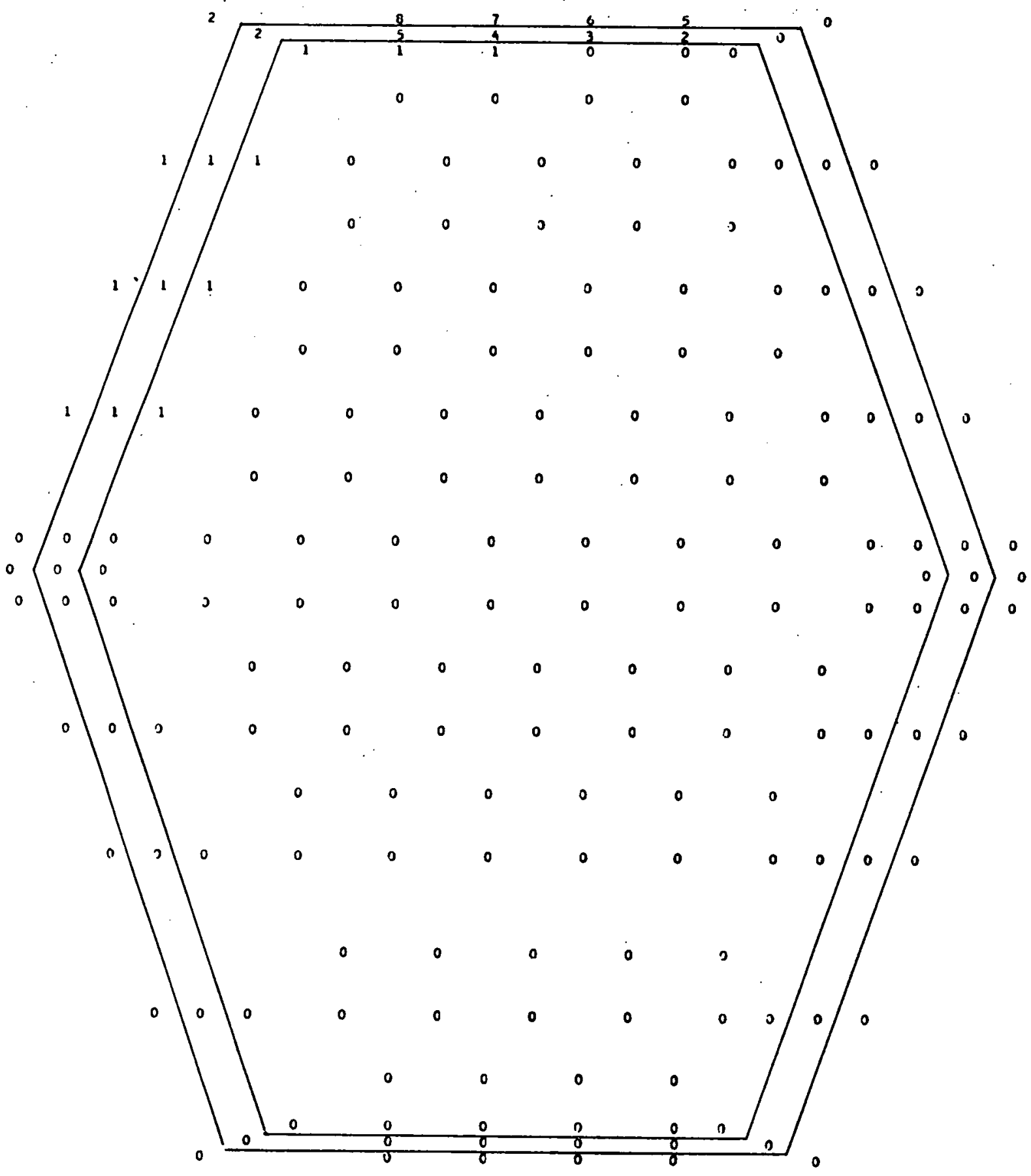

F1gure 29 
TEMPERATURE PREDICTION OF ASSEMBLY E $E_{1}$ BY USING NORMALIZED MAPS

Geometry: Blanket (Table 1 ) Bundle flow rate $(\mathrm{lb} / \mathrm{hr}) 28860$ Heat Entered: $0 \mathrm{Kw}$ Gap flow rate $(1 \mathrm{~b} / \mathrm{hr})$ Bundle Reynolds No. $1.86 \times 10^{4}$ Gap Reynolds No.

$$
2.94 \times 10^{3}
$$$$
\varepsilon=0.007
$$$$
c=0.40
$$

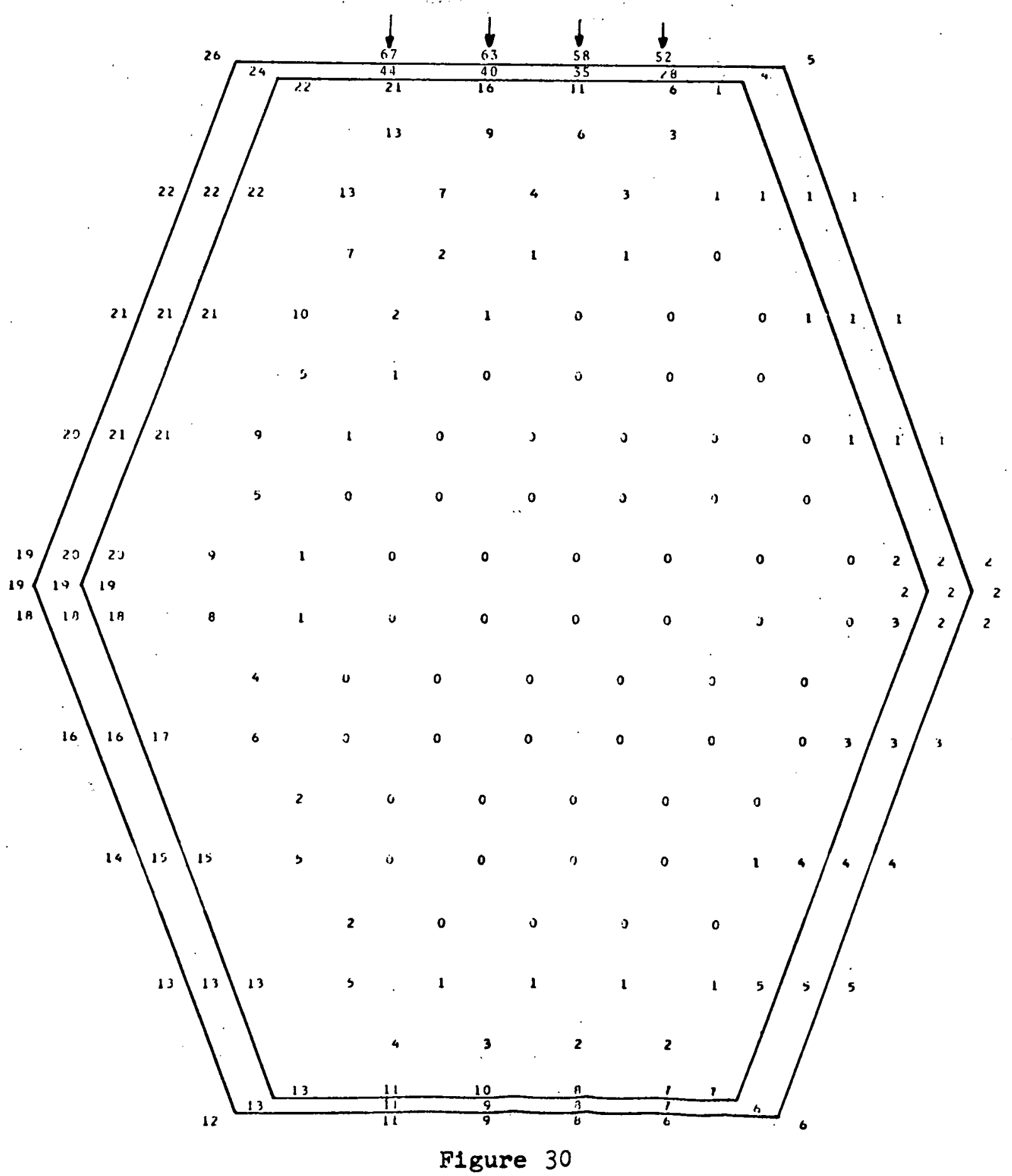


TEMPERATURE PREDICTION OF ASSEMBLY E FROM SUPERENERGY.

FOR THREE COUPLED ASSEMBLIES

Geometry: Blanket (Table 1)

Bundle flow rate $(\mathrm{lb} / \mathrm{hr}) 28860$

Gap flow rate (lb/hr)

Bundie Reynolds No.

Gap Reynolds No.
Heat Generated:

Heat Entered:

Input Parameters (Ref.[5]): $\varepsilon=0.007$

$c=0.40$

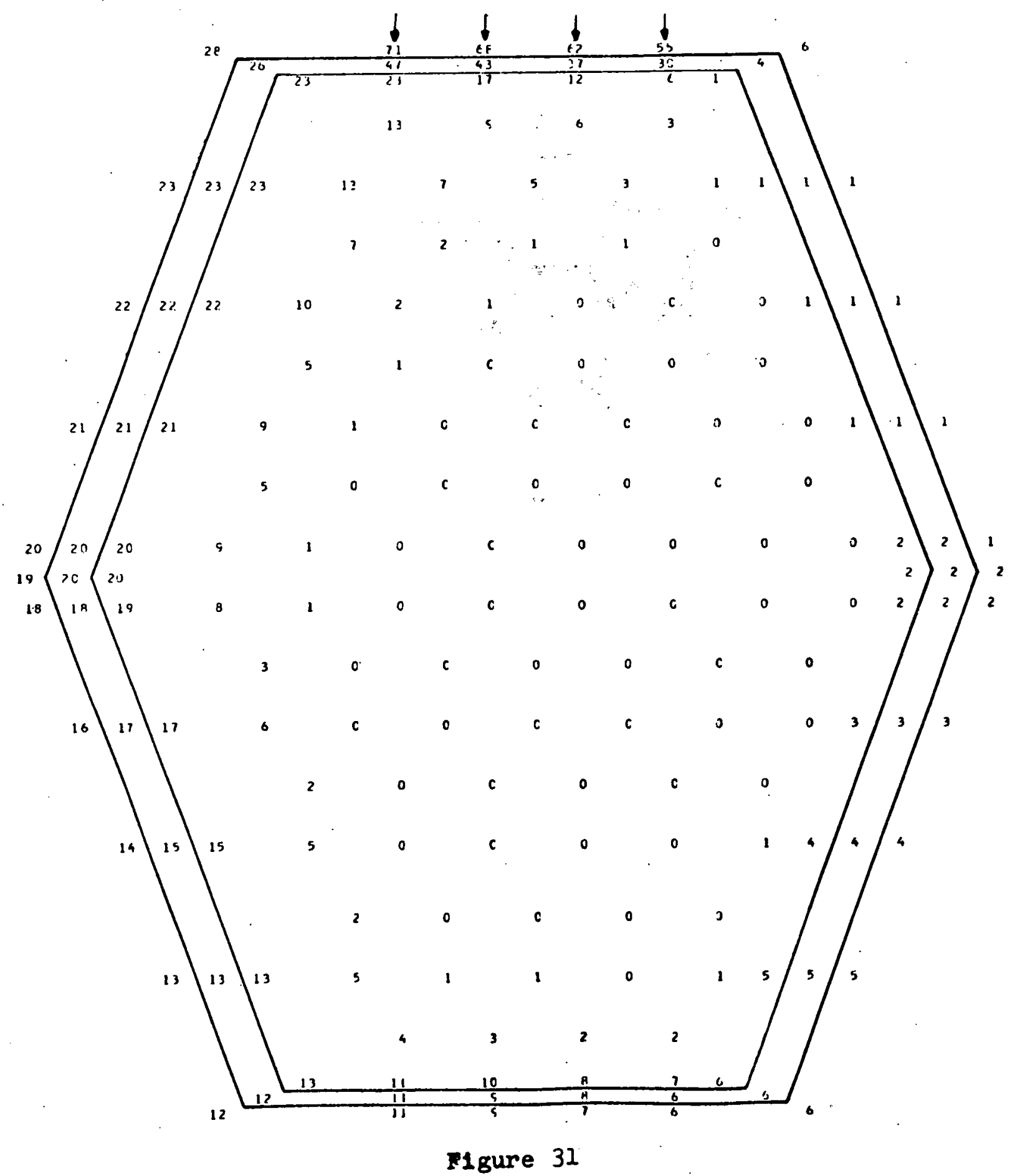




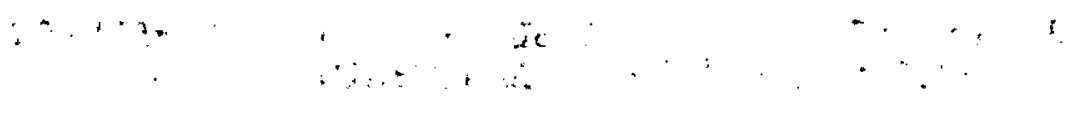

$$
\begin{aligned}
& \text { i. . : }
\end{aligned}
$$

\section{CLASSIFICATION OF HEAT PENETRATION PATHS}

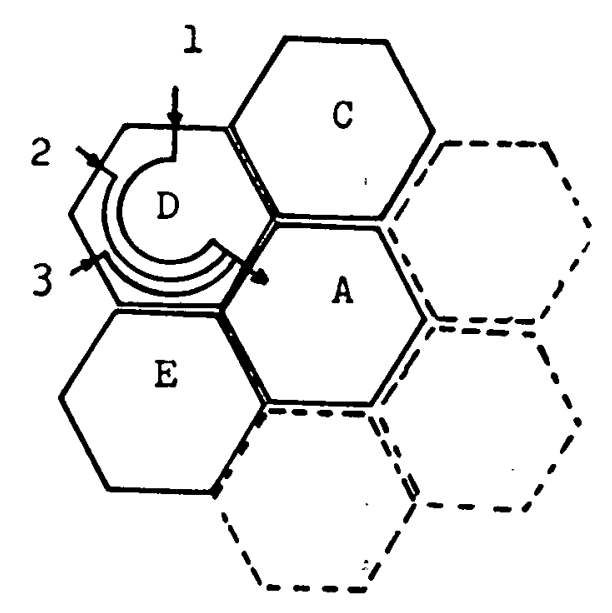

Figure 32 
TEMPERATURE PREDICTION FOR ASSEMBLY E BY USING

$$
\text { ISOLATED WALL BOUNDARY CONDITION }
$$

Geometry: Blanket (Table 1)

Bundle.flow rate $(\mathrm{lb} / \mathrm{hr}) 28860$

Gap flow rate ( $\mathrm{ib} / \mathrm{hr}$ ) 600

Bundle Reynotds No. $1.86 \times 10^{4}$

Gap Reynolds No. $\quad 2.94 \times 10^{3}$
Heat Generated $554.1 \mathrm{Kw}$

Heat Entered: $\quad 0 \mathrm{Kw}$

Input Parameters (Ref.[5]):

$$
\begin{aligned}
E & =0.007 \\
C & =0.40
\end{aligned}
$$

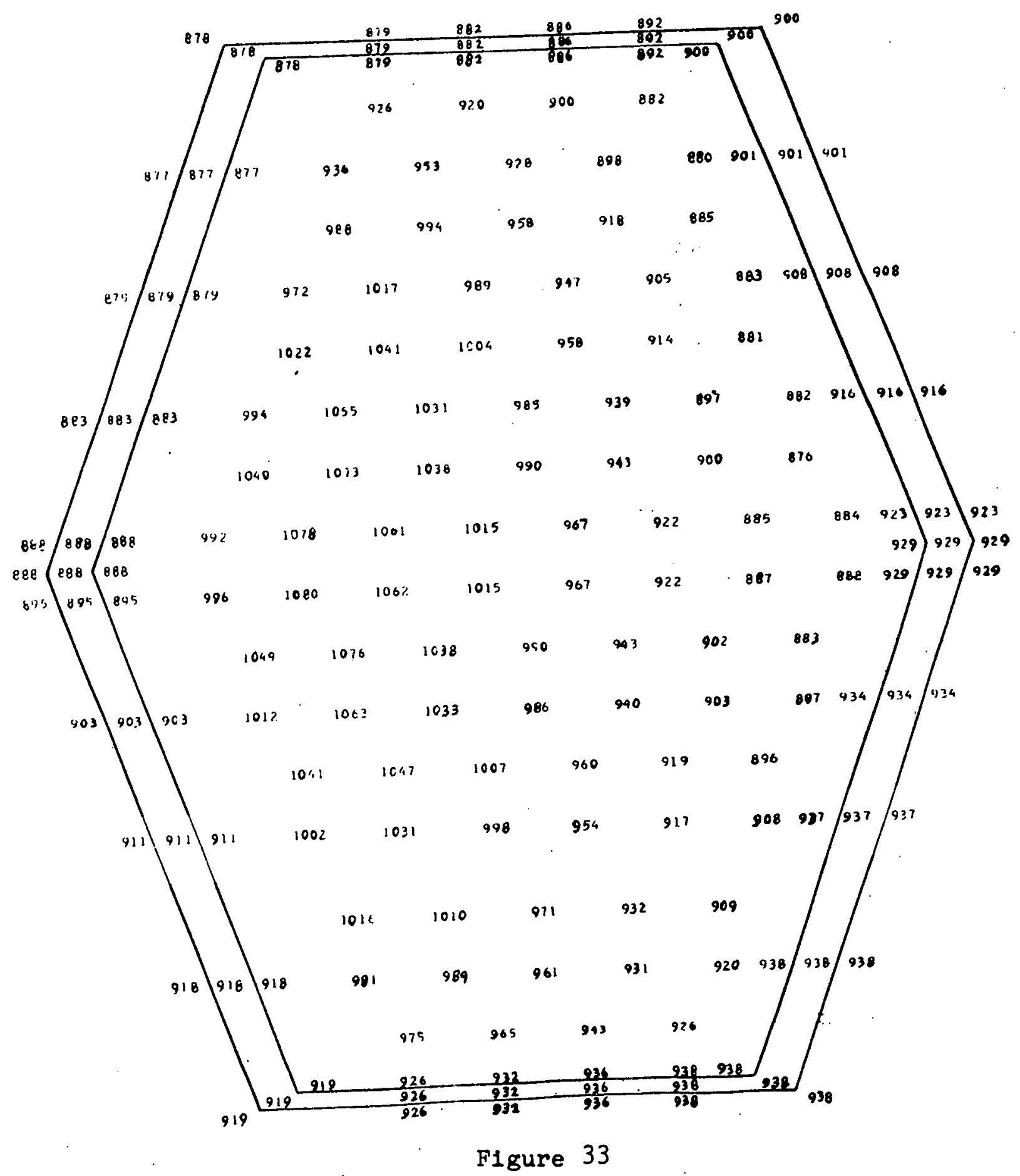


TEMPERATURE PREDICTION FOR ASSEMBLY E E BY . USING ISOLATED ASSEMBLY BOUNDARY CONDITION

Geometry: Blanket (Table 1)

Bundle flow rate $(\mathrm{lb} / \mathrm{hr}) 28860$ Gap flow rate (lb/hr)

Bundle Reynolds No. Gap Reynolds No.
Heat Generated:

Heat Entered:

Input Parameters (Ref.[5]):

$$
\begin{aligned}
\varepsilon * & =0.007 \\
c & =0.40
\end{aligned}
$$

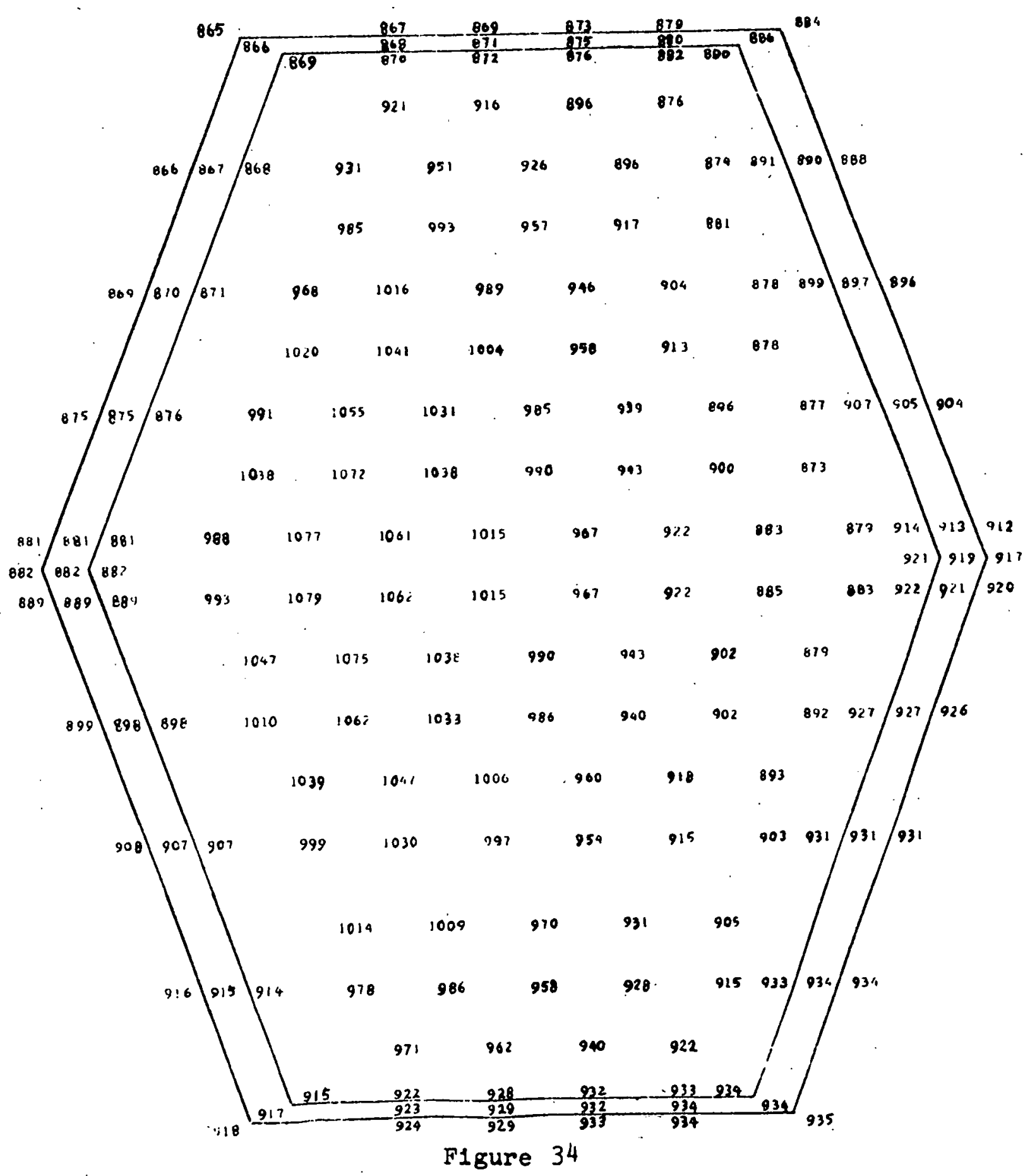


TEMPERATURE PREDICTION FOR ASSEMBLY E BY COUPLING SURROUNDING FIRST RING SIX ASSEABLIES

Geometry: Blanket (Table 1)

Bundle flow rate $(\mathrm{lb} / \mathrm{hr}) 28860$

Gap flow rate $(1 \mathrm{~b} / \mathrm{hr}) \quad 600$

Bundle Reynolds No. $1.86 \times 10^{4}$

Gap Reynolds No.

$2.94 \times 10^{3}$
Heat Generated:

Heat Entered:

Input Parameters (Ref.[5]):

$$
\begin{aligned}
\varepsilon^{*} & =0.007 \\
C & =0.40
\end{aligned}
$$

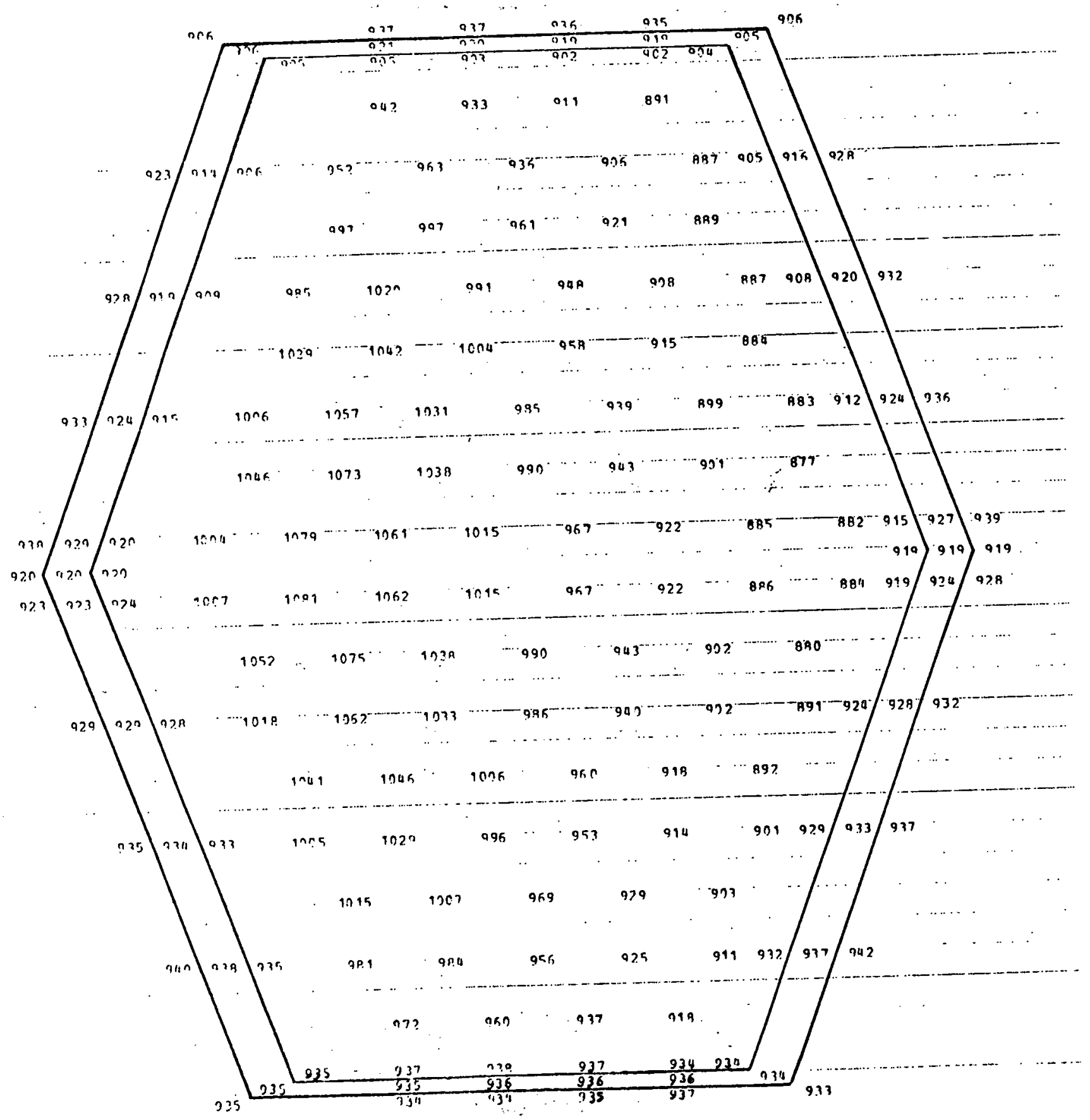

F1gure 35 

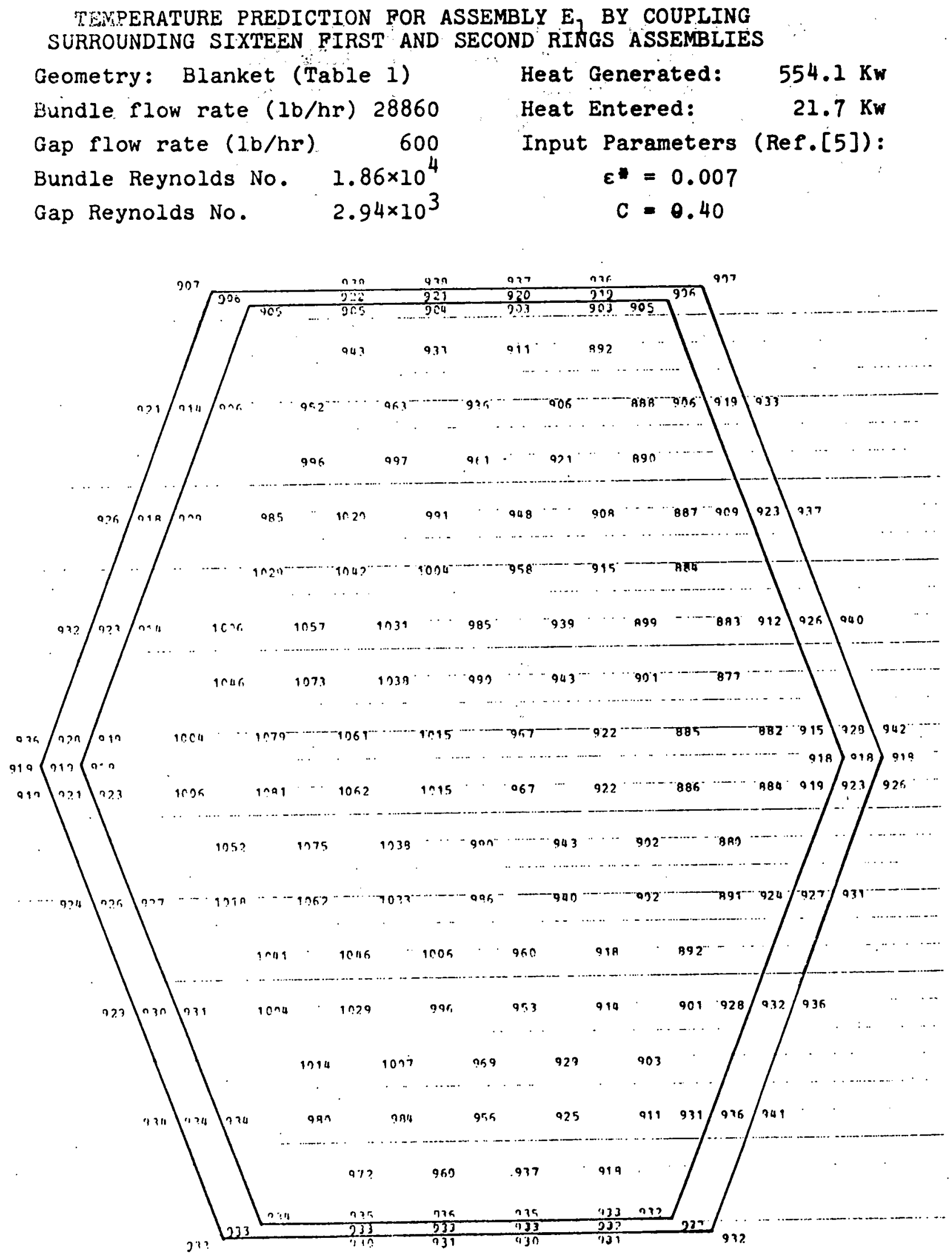

F1 gure 36 
FUEL RODS NUMBERING SCHEME

FOR 19 PIN ASSEMBLY

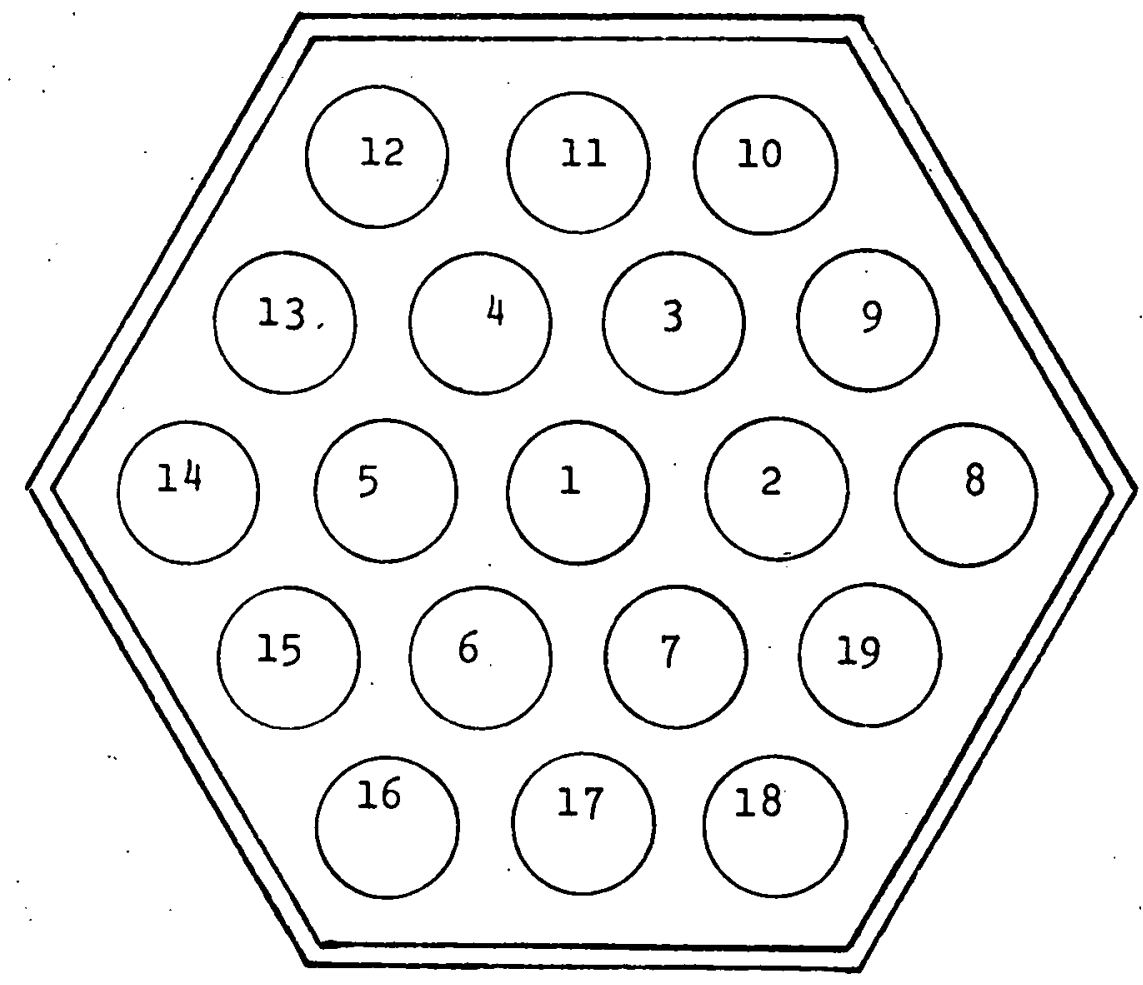

F1gure 37 
NUMBERING OF ASSEMBLIES WITH THEIR DATA PACKS

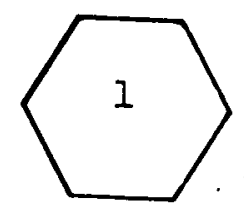

$\begin{array}{llllll}2 & 1 & 1 & 1 & 1 & 1\end{array}$

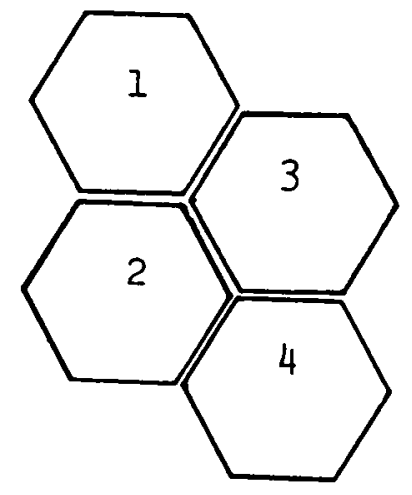

$\begin{array}{llllll}1 & 1 & 1 & 1 & 2 & 3\end{array}$

$\begin{array}{llllll}3 & 1 & 2 & 2 & 2 & 4\end{array}$

$\begin{array}{llllll}3 & 3 & 1 & 2 & 4 & 3\end{array}$

$\begin{array}{llllll}4 & 3 & 2 & 4 & 4 & 4\end{array}$

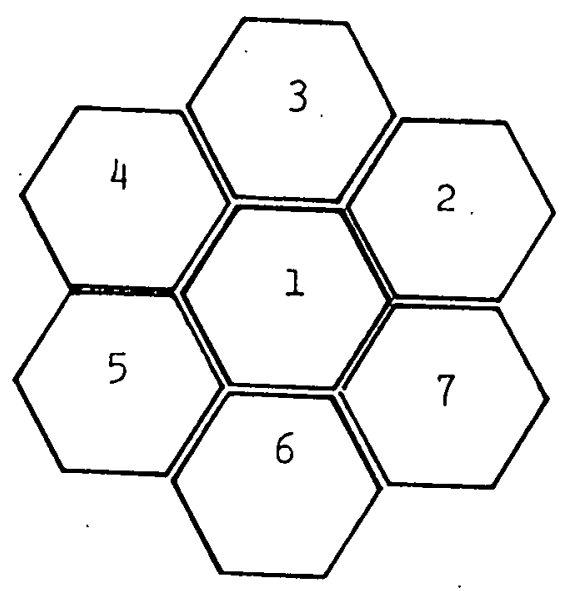

$\begin{array}{llllll}2 & 3 & 4 & 5 & 6 & 7\end{array}$

$\begin{array}{llllll}2 & 2 & 3 & 1 & 7 & 2\end{array}$

$\begin{array}{llllll}3 & 3 & 3 & 4 & 1 & 2\end{array}$

$\begin{array}{llllll}3 & 4 & 4 & 4 & 5 & 1\end{array}$

$14555 \quad 5 \quad 6$

$\begin{array}{llllll}7 & 1 & 5 & 6 & 6 & 6\end{array}$

$\begin{array}{llllll}7 & 2 & 1 & 6 & 7 & 7\end{array}$

Figure 38 
TABLE 1

Geometric Characteristics

of Demo Plant Assemblies

\begin{tabular}{lll} 
Parameter & Fuel & Radial Blanket \\
\hline Number of Rods & 217 & 61 \\
Cladding OD (Inches) & 0.230 & 0.520 \\
Cladding ID (Inches) & 0.200 & 0.490 \\
Pellet OD (inches) & 0.1935 & 0.4850 \\
Pellet Theoretical & 90.4 & $95.6 \%$ \\
Density (\%) & 0.056 & $0.037 *$ \\
Wire Wrap OD (inches) & 11.9 & 4.0 \\
Wire Wrap P1tch (1nches) & 0.5600 \\
Rod Pitch (inches) & .2879 & 4.450 \\
Across Hex Flats (inches) & 4.335 & .16 \\
Hex Corner Radius (inches) & .16 & .10 \\
Duct Thickness (inches) & .16 & .11 \\
Gap Thickness Between & .11 &
\end{tabular}


TABLE 2

Computer Space and TIme*

Required for SUPERENERGY

\begin{tabular}{|l|l|l|l|l|}
\hline INo. of Assemblies & 1 & 7 & 19 \\
\hline $\begin{array}{l}\text { Storage } \\
\text { Space }\end{array}$ & Blanket & $146 \mathrm{~K}$ & $198 \mathrm{~K}$ & $354 \mathrm{~K}$ \\
\cline { 2 - 5 } & Fuel & $146 \mathrm{~K}$ & $198 \mathrm{~K}$ & $354 \mathrm{~K}$ \\
\hline \multirow{2}{*}{$\begin{array}{l}\text { Running } \\
\text { Time }\end{array}$} & Blanket & $\sim .25 \mathrm{~min}$. & $\sim 0.9 \mathrm{~min}$. & $\sim 2.2 \mathrm{~min}$. \\
\cline { 2 - 5 } & Fuel & $\sim .4 \mathrm{~min}$. & $\sim 2 \mathrm{~min}$. & $\sim 5.0 \mathrm{~min}$ \\
\hline
\end{tabular}

* Data based on IBM $370 / 168$ 
Appendix i SUPERENTRGY Manual

1 Purpose and description of the code

The purpose of SUPERENERGY is to predict the imperature distributions in the hexagonal assemblies of vreeder reactor. These predictions include the emperature distribution in the coolant as well as in the ict. In this code, heat is allowed to leak out of the ict wall and to be carried away by the coolant in the เp. Heat is also allowed to be transferred between ighboring assemblies. These two features are the main fferences between SUPERENERGY and ENERGY I.

The code can be run for as many assemblies as the mputer storage allows. The code as listed in Appendix can be run for 19 fuel assemblies w1th 217 fuel pins in ch assembly. This is equivalent to running two full ags of fuel assemblies coupled to each other. For nputation of more than 19 assemblies, only the nensionality in the DIMENSION statements of the code has be altered. One doesn't have to change the COMMON ztements. Since the 19 assemblies do not have to be in lcentric rings, these dimensions are sufficlent for ;t of the practical calculations. For the clinch River seder Reactor, we can use the code for all the blanket iemulies in a sector of the core.since there are only blanket assemblies in the sector as shown in FIg. 4. 
The code can handle three types of assemblies, fuel assembly, blanket assembly, and any thirä type to be specified. It can be used for any geometrical combination of them nrovided a proper numbering scheme is utilized. For example, they can be combined in a straight line fashion or in a doughnut shape fashion. We shall discuss the numbering scheme in the input section. The code assumes liquid sodium as coolant and 304 stainless steel as the duct. If any other material is used, then the physical properties in the subroutine PROP should be changed. The code is written in Fortran IV. 'It requires $354 \mathrm{~K}$ bits of memory and $5^{\circ}$ minutes running time for a 19 fuel assembly calculation in a IBM $370 / 168$ computer. 1.2 Input Data

Section I. Multiassembly data pack

Card 1: Column 1-10 reads in the inlet temperature of the assemblies. Column $11-20$ reads in the average outlet temperature of the assemblies. The units are ${ }^{\circ} \mathrm{F}$ and the formats are Fio.l.

Card 2: Column $1-5$ reads in the number of assemblies to be computed. Column 6-10 reads in number of axial temperature distributions to be printed. Column 11-15 reads in the number of increments in axial steps between each axial temperature print outs. We recommend 
a total of 500 axial steps for the whole assembly length. column 16.20 reads in the boundary conditions to be used for the assemblies. Zero means all the assemblies are to be coupled. One means all the assemblies are to be computed by using isolated assembly boundary conditions. 'Two rneans all the assemblies are to computed by using isolated wall boundary conditions. The format to be used for this card is I5.

Section II. Assembly data pack

Card 1: Column $1-5$ reads in the type for the assembly. One stands for the fuel assembly. Two stands for the blanket assembly. Three stands for any other third type of assembly. The format for this card is I5.

Card 2: Column 1-10 reads in the diameter of the fuel rod. Column $11-20$ reads in the diameter of the wire wrap. Column 21-30 reads in the lead of the wire wrap. Column $31-40$ reads in the rod pitch. Column 41-50 reads in reads in the distance between the flats of the assembly. Column 51-60 reads in the length of the assembly. Column 61-70 reads in the thickness of the duct wall. Column $71-80$ reads in the thickness of the gap between the assemblies. The dimensions are all in inches. The format for this card is $8 I 10.5$.

Card 3: Column $1-10$ reads in the average heat flux of the assembly in the units of BTU/hr-ft ${ }^{2}$. Column 11-20 reads in the flow rate of the assembly in the units 
2billor. (joldmn $21-30$ reaäs in the flow rate in gap associated with tine assembly in the units of $1 \mathrm{bm} / \mathrm{hr}$. The format for this card is 8FI0.I.

Card 4: Column $1-40$ reads in four effective eddy diffusitivities for the assembly. We recommend using the same values for all four of them. Column 41-50 reads in the ratio of swirl flow velocity to the axial flow velocity. These values are to be taken from reference 5. The format for this card is $8 \mathrm{~F} 10.5$.

Card 5: Column $1-5$ reads in the number of points to specify the axial flux shape. Column 6-10 reads in the number of fuel rods in the assembly. The formats are I5.

Card 6 to $x$ : Column $1-10$ reads in the first axial distance to specify the flux shape. This axial distance is expressed in terms of the fraction of the total length of the assembly. This number is between 0 and 1. Column $1-20$ reads in the axlal flux mormalized to one over the whole length of the assembly. Column 21-30 reads in the second axial distance in terms of the fraction of the total length. Column $31-40$ reads in the normallzed flux. This input procedure repeats until the flux shape for the whole length of the core is specified. When the number of flux points equal to 32 , it takes 8 cards to specify the axial flux shape. The first axial point shall be 0.0 and the last axial point shall be 1.0 . The formats 
For these cards are 8 F 10.5 .

$\operatorname{cordi} x+I$ to $y:$ These cards read in radial power distributions for all the fuel rods. The numbering of rods starts at the center rod and then go counter-clockw1se along the ring. The beginning point of the ring is at 3 o'clock position. An example of the numbering scheme for 19 pins is given in Fig. 37. The formats for these cards are 8F10.5. For an assembly of 61 pins: It takes 8 cards to read in the radial power distributions. For multiassembly calculations, we shall repeat the input of Section II for all the assemblies.

Section III. AssembIy numbering data pack Assemblies can be numbered consecutively in any way which is convenient. But this ordering should be the same as the ordering of the data pack for the assemblies In Section II. After the numbering scheme is fixed, we shall define the upper right face (north east) of an assembly as the first face and the subsequent faces as the second face, the third face, and so on counter-clockwise. For each assembly, the code will read in the numbers of the neighboring assemblies starting from the first face of the assembly. Hence each assembly w1ll take one data card.

Card 1:. Column 1-5 reads in the number for the neighboring assembly to the first face of the first assembly. Column 6-10 reads in the number for the neighboring assembly to the second face of the first assembly. 
The same procedure holds for the reat of the faces of the f1rst assembly unt1l all s1x faces are exhausted. There are $30^{\circ}$ columns for six faces of the first assembly. When the assembly does not have a nelghbor next to its face, the number for the nelghboring assemblies of this face 18 the same as the number for the assembly 1tself. The format for this card is 6 I 5 .

Card 2 will be reading in the numbers for the nelghboring assemblies to the second assembly. The same procedure holds for the next card unt1l all the assemblies are exhausted. Examples of assembly numberings and their data pack for section III are given in FIg. 38 .

\subsection{Output}

The code prints out all the input data as soon as the data are read $1 \mathrm{n}$. Hence $1 \mathrm{t}$ w1ll print out the inlet temperature and the outlet temperature, number of assemblies to be computed, number of axial print outs, number of axial increments, and the boundary condition to be used for all the assemblies. It will then print out all the data pack for the assemblies. After the assembly data pack, the assembly numbering scheme will be printed. The above print outs are the input data. The following print outs are the computed quantities.

On the next page, it w1ll print out the average 
1...perature ins: de the duct, the total heat generation of the assembly, the enthalpy increase inside the duct, and the enthalpy increase in the gap of the assembly. It mints out the radial temperature distribution of the assembly. The information on this page is for the first assembly. On the next new page, it will print out the same information for the second assembly and so on for all the assemblies. If the above information is desired for more than one axial level, the above print outs will be repeated for different levels. In Appendix 3, we shall give a sample problem with its input and output. 


\section{APPENDIX 2}

\section{LISTING OF CODE SUPERENERGY}

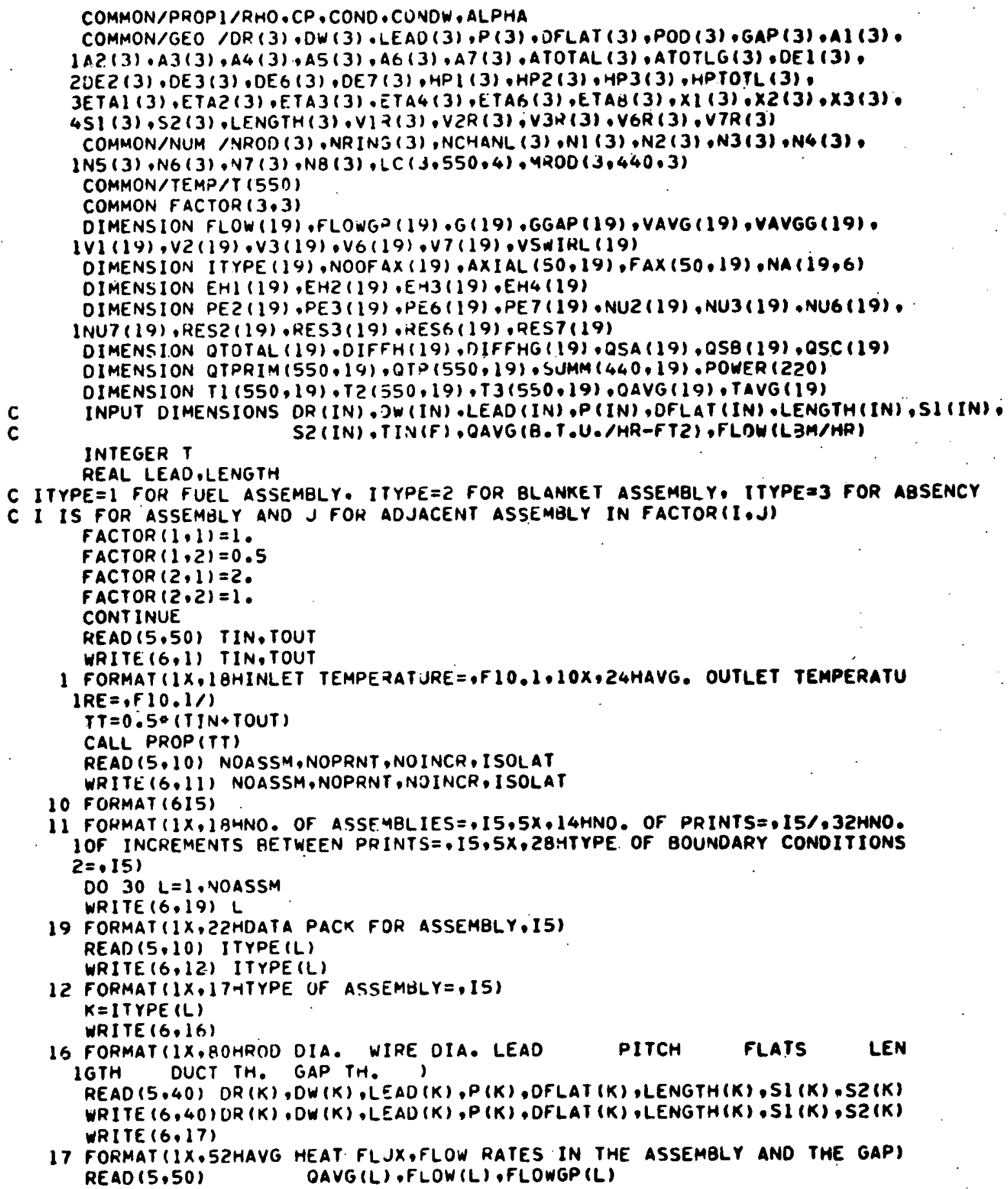

1 FORMAT $11 x_{0} 18 H I N L E T$ TEMPERATURE $=, F 10,1,10 x, 24 H A V G$. OUTLET TEMPERATU

16 FORMAT IIX,BOHROO DIA. WIRE DIA. LEAD PITCH FLATS LEN IGTH DUCT TH. GAP TH. I READ (5,40) DR (K), DW $(K)$, LEAD $(K)$, P $(K)$, OFLAT (K) ,LENGTH(K) , SI (K) , SZ (K) WRITE $(6,40)$ DR $(K)$, DW $(K)$, LEAD $(K), P(K)$, OFLAT $(K)$,LENGTH(K), SI (K), SZ (K) WRITE $(6,17)$

17 FORMAT $(1 X, 52 H A V G$ HEAT FLJX,FLOW RATES IN THE ASSEMBLY AND THE GAP) READ $(5,50) \quad$ OAVG $(L), F L O W(L), F L O W G P(L)$ 
WRITE 16.50 !

QAVG(L),FLOW(L),FLOWGP (L)

50 FONMAT (BF 10.1 )

WRITE $(6,18)$

18 FORMAT IX,6OHFOUR EFFECTIVE EOOY OIFFUSIIIVITIES ANO SWIRL VELOCIT

IY RATIO)

READ (5.40) EHSTAL,EHSTA2,EHSTA3,EHSTA $4, C 1$

WRITE $(0,40)$ EHSTAL, EHSTAZ, EHSTA3,EHSTA4, CI

REAO (5.10) NOOFAX (L), NKDO (K)

WRITE $(6,13)$ NOOFAX (L), NOON(K)

13 FOKMAT IIX,12HNO. OF FLUX $=.15,5 X, 12 H N O$. OF ROUS $=.15)$ NOUFA $=$ NOOF $A X(L)$

WRITE $(6,14)$

14 FORMAT (IX.35HAXIAL DISTANCE VS FLUX DISTHIBUTION)

READ $(5,40)$ (AXIAL $(I, L), F A X(I, L), I=1$, NOOFA)

WRITE $(5,40)$ (AXIAL $(I, L), F A X(I \cdot L), I=1$, NOUFA)

40 FORMAT ( $9 F 10.5)$

NRU $=N R O D(K)$

WRITE $(6.15)$

15 FORMAT(IX,38HRADIAL POWER DISTRIBUTION OF FUEL RODS) CONTINUE

READ (5,40) (POWER (I), I =1, NRO)

WRITE $(6,40)$ (POWER $(I), I=1$, NRO)

CALL NUMB (K)

CALL GEOM(K)

$M 2=N 2(K)$

$M 3=N 3(K)$

$M 4=N 4(K)$

$M 8=N B(K)$

$M K 2=M 2 \cdot 1$

$M K 3=M 3 \cdot 1$,

IOVER $=N R O D(K)+1$

POWER (IOVER) $=0$

DO $60 \quad I=1, M 4$

$P R O D=0$

$0070 \mathrm{~J}=1.3$

$M=M R O O(K, I, J)$

$P R O D=P R O D+P O W E R(M)$

70 CONTINUE

$\operatorname{SUMM}(I \cdot L)=P R O D$

60 CONT INUE

OTPAVG = (OAVG (L) HPTOTL $(K) / A T O T A L(K)): 12$

DO $80 \quad I=1, M 2$

OTPRIM II,L) =OTPAVG $(A T O T A L(K) / A I(K)) *(H P I(K) / H P T O T L(K)) \otimes S U M M(I, L)$

$1 / 3.0$

80 . CONT INUE

DO $90 \quad I=M K 2, M 3$

QTPRIM $(I, L)=$ OTPAVG $*(A T O T A L(K) / A Z(K)) *($ HPZ $(K) / H P T O T L(K)) * S U M H(I, L)$

$1 / 2.0$

90 CONTINUE

DO $100 \quad I=M K 3, M 4$

OTPRIM I I,L) = OTPAVG $*(A T O T A L(K) / A 3(K)) *(M P 3(K) / H P T O T L(K)) * S U M M(I, L)$

100 CONTINUE

$G(L)=(F L O W(L) / A T O T A L(K))=144.0$

GGAP $(L)=(F L O W G P(L) / A T O T L G(K)) \$ 144.0$

$\operatorname{VAVG}(L)=G(L) / R H O$

VAVGG $(L)=G G A P(L) / R H O$

$V I(L)=V A V G(L) \otimes V I R(K)$

$V Z(L)=V A V G(L) \otimes V Z R(K)$

$V 3(L)=V A V G(L) \circ V 3 R(K)$ 
VG $(L)=V A V G G(L) \otimes V G R(K)$

$V 7(L)=V A V G G(1.) \otimes V 7 R(K)$

CONVER =VAVG $(L) \triangle O R(K) / 12$.

EHI $(L)=E H S T A I * C O N V E R$

EHZ (L) =EHSTAZ CONVFR

EH $3(L)=E H S T A 3^{\circ}$ CONVER

EHA (L) =ENSTA ${ }^{\circ}$ CONVER

VSWIRL $(L)=C I * V A V G(L)$

PEZ $(L)=D E Z(K) * V Z(L) /(A L P+A * 12$.

PE $3(L)=0 E 3(K) * V 3(L) /(A L P+A \circ 12$ )

PE $6(L)=0 E G(K) * V 6(L) /(A L P H A D)$ ( )

PE $7(L)=0 E 7(K) \otimes V 7(L) /(A L P H A \oplus 12$.

NUZ $(L)=7.0+0.025 \circ P E Z(L) \otimes 0.3$

$N U 3(L)=7.0+0.025 * P E 3(L) * 0.8$

NU6 $(L)=7.0+0.025 * P E .6(L) * 0.8$

NUT $(L)=7.0 * 0.025 \otimes P E .7(L) * 0.8$

RES2 $(L)=11 / N U 2(L)+(S I(K) / O E 2(K)) *$ COND/CONUW/2)*0EZ $(K) / C O N D / 12$

RES $3(L)=(1 / N U 3(L)+(S)(K) / D E 3(K)) \cdot$ COND/CONOW/1.732) DE $3(K) / C O N D / 12$

RES6 $(L)=(1 / N U 6(L) \cdot(S 1(K) / D E 6(K)) * C O N O / C O N O W / 2) * 0 E 6(K) / C O N D / 12$

REST $(L)=(1 / N U 7(L) \cdot(S I(K) / D E 7(K)) \circ$ COND/CONUW/1.732) DOE $7(K) / C O N D / 12$

30 CONTINUE

WRITE $(6,31)$

31 FORMAT (IX, 24 HNE IGHBORS FOR ASSEMBLIES)

DO $32 L=1$, NOASSM

REAO $(5,10)$ (NA $(L, 1), I=1,6)$

WRITE $(6,10)$ (NA(L.I) I I $=1,6)$

32 CONT INUE

CONTINUE

$I I=I T Y P E(I)$

OPRINT =LENGTHIII) /NOPRNT

PRINT $=$ DPHINT

DZ = DPRINT / NOINCR

$Z=02 / 2$.

DO $1 ! 5 L=1$, NOASSM

OSA $(L)=0$

$\operatorname{OSB}(L)=0$

$\operatorname{OSC}(L)=0$

$K=$ I TYPE (L)

$M 8=N B(K)$

DO $110 \quad I=1, M 8$

$T 2(I, L)=T I N$

110 CONTINUE

115 CONTINUE

1000 CONTINUE

$2 O L=2 / L E N G T H(I I)$

DO $120 \mathrm{~L}=1$. NOASSM

CALL CURVE (FAXL, ZOL, FAX, AXIAL, NOOFAX, L.)

$K=I$ TYPE (L)

$M 4=N 4(K)$

DO $130 \quad I=1, M 4$

130 CONTINUE

OTP $I, L)=Q T P R I M(I, L) \otimes F A X L$

120 CONTINUE

DO $140 \quad L=1$, NOASSM

$K=I T Y P E(L)$

$M I=N I(K)$

$M 2=N 2(K)$

$M 3=N 3(K)$

$M 4=N 4(K)$

$M 5=N S(K)$ 
$M 6=N G(K)$

$M 7=N 7(K)$

$M B=N \&(K)$

$M K l=N](K) \cdot 1$

$M K Z=N 2(K)+1$

$M K 3=N 3(K)+1$

$M K 4=N 4(K)+1$

$M K S=N S(K)+1$

$M K G=N G(K)+1$

$M K 7=N 7(K)+1$

DO $150 \quad I=1 . M I$

$M M l=L C(K, I, l)$

$M M Z=L C(K, I, 2)$

$M M 3=L C(K, I, 3)$

$T 3(I, L)=T 2(I \cdot L)+O T P(I, L) * 0 Z / 12 /(V I(L) * R H U \cdot C P) \cdot((P(K)-O R(K)) * 0 Z /$

IAI $(K))((A L P H A+E H I(L)) / V I(L)) *(T 2(M M), L)+T 2(M M Z, L)+T 2(M M 3, L)-$

23*T2(I.L) IETAI K $: 12$

OSA $(L)=Q S A(L)+O T P(I, L)$

150 CONTINUE

DO $160 \quad I=M K 1, M 2$

$M M I=L C(K, I, 1)$

$M M 2=L C(K, I, 2)$

$M M 3=L C(K, 1,3)$

$R=(1-1) / 6$.

$N=S Q R T(R)+1.0001$

$10=(1-6 *(N-1) *(N-1)-1) /(2 * N-1)+0.0001$

IR=I-6*(N-1)*(N-1)-10*(2*N-1)・0.0001

$J=I R / 2$

IF (IR.EO.2*J) GOTO 1160

$E H A=E H I(L)$

$E H B=E H 2(L)$

ETAA $=E T A 1(K)$

ETAB $=E T A Z(K)$

GO TO 2160

1160 CONTINUE

$E H A=E H I(L)$

$E H B=E H I(L)$

ETAA $=E T A L(K)$

ETAB $=E T A 1(K)$

2160 CONT INUE

$T 3(I, L)=T 2(I, L)+O T P(I, L) \otimes O Z / 12 /(V I(L) * R H O \otimes C P)+((P(K)-O R(K)) * D Z) /$

$l(A l(K) * V l(L)) *((A L P H A+E H A) *(T 2(M M), L)+T 2(M M Z \bullet L)-2 * T 2(I \bullet L)) / E T A A *$

$2(A L P H A+E H B) *(T 2(M M 3, L)-T 2(I, L)) / E T A B) * 12$

QSA $(L)=O S A(L)+O T P(I, L)$

160 CONT INUE

DO $170 \quad I=M K 2, M 3$

$M M I=L C(K, I, 1)$

$M M 2=L C(K, I, 2)$

$M M 3=L C(K, I, 3)$

$M M 4=L C(K, I, 4)$

If (MMZ.GT.M3) GO 101170

ETAA $=E T A 3(K)$

$E H A=E H 3(L)$

GO TO 2170

1170 CONT INUE

ETAA $=E T A 4(K)$

$E H A=E H 4(L)$

2170 CONTINUE

IF (MM3.GT.M3) GO TO 3170

ETAB $=E T A 3(K)$ 
$E H B=E H 3(L)$

GO 104170

3170 CONTINUE

ETAB $=E T A 4(K)$

$E M E=E H 4(L)$

4:?0 COHTINAUE

$1: i I, L)=T Z(1, L) * O T P(I, L) * 0 Z / 12 /(V Z(L) * R H O * C P)+(G A P(K) * 0 Z / A Z(K)) *$

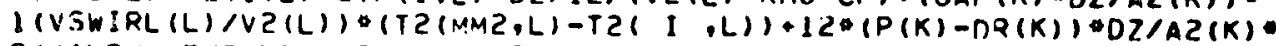

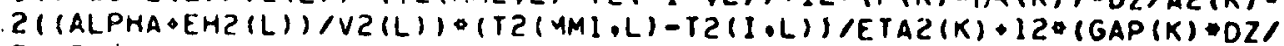

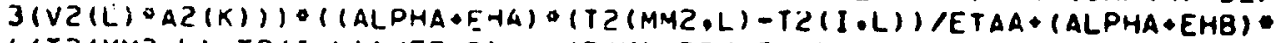
$4(T 2(M M 3 \cdot L)-T 2(I \cdot L)) / E T A P)+(P(K) \circ D Z / A Z(K)) \cdot(T 2(M M 4 \cdot L)-T Z(I \cdot L))$ $S\left(V Z(L) * R H O{ }^{\circ} C P * R E S Z(L)\right)$

$O S B(L)=O S B(L)+Q T P(I, L)$

170 CONTINUE

DO $180 \quad I=M K 3, M 4$

$M M I=L C(K, I, I)$

$M M Z=L C(K, I, Z)$

$M M 3=L C(K, 1,3)$

$T 3(I, L)=T 2(I, L)+O T P(I, L) \otimes D Z / 12 /(V 3(L) \otimes R H O * C P)+(G A P(K) * D Z / A 3(K)) *$

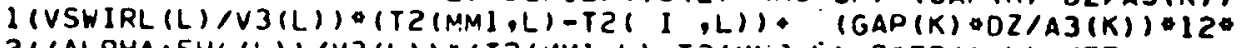
$2((A L P H A+E H 4(L)) / V 3(L)) \circ(T 2(Y M 1, L) \bullet T 2(M M Z, L)-2 \otimes T 2(T, L)) / E T A 4(K)$. $3(X)(K) \otimes D Z / A 3(K)) \otimes(T Z(M M 3 \cdot L)-T 2(I, L)) /(V 3(L) * R H O * C P \otimes R E S 3(L))$
OSC $(L)=O S C(L) * O T P(I, L)$

180 CONTINUE

DO $210 \quad I=M K 6, M 8$

$M M I=L C(K, I, I)$

$M M Z=L C(K, I, ?)$

$M M 3=L C(K, I \cdot 3)$

If (I.GT.MT) GO ro 7210

$A=A G(K)$

$V=V 6(L)$

RES $=$ RES6 (L)

$X=P(K)$

$T T T=T 2(I \cdot L)$

$I 0=(1-M G-1) / N R I N G(K)+1.0001$

$I R=1-M 6-(10-1) * N R I N G(K) \cdot 0.0001$

$J=I R / 2$

$J J=I R-5 * J$

LP=NA LL, IO:

I $1=1$ TYPE (L)

I $Z=I T Y P E$ (LP)

$F A C=F A C T O R(11,12)$

IF IISOLAT.EO.I) GO TO 2217

IF (LP.EO.L) GO TO 1215

IF (I0.GT.3) GO TO 1210

$M M 4=N 6(12)+(10 \cdot 2) * N R I N G(I 2) \bullet(N R I N G(K)-I R) \bullet F A C \cdot I$ GO TO 2210

1210 CONTINUE

$M M 4=N 6(I 2) \cdot(I 0-4) * N R I N G(I 2)+(N R I N G(K)-I R) * F A C$ I

GO TO 2210

1215 CONTINUE

TTT $=T 2(I \cdot L)$

GO TO 2217

2210 CONTINUE

IF (FAC.EO.1) GO TO 2215

IF (FAC.GT. I) GO TO 2213

IF (IR.GE. (NRING $(K)-1)$ GJ TO 2211

$T T T=T 2(M M 4 \circ L P)-\left(T 2\left(M M A_{0} L P\right)-T 2(M M 4-1, L P)\right) / 4_{0}+J J *(T 2(M M 4, L P)-$

l $2(M M 4-1 \cdot(P)) / 2.0$

GO TO 2217 


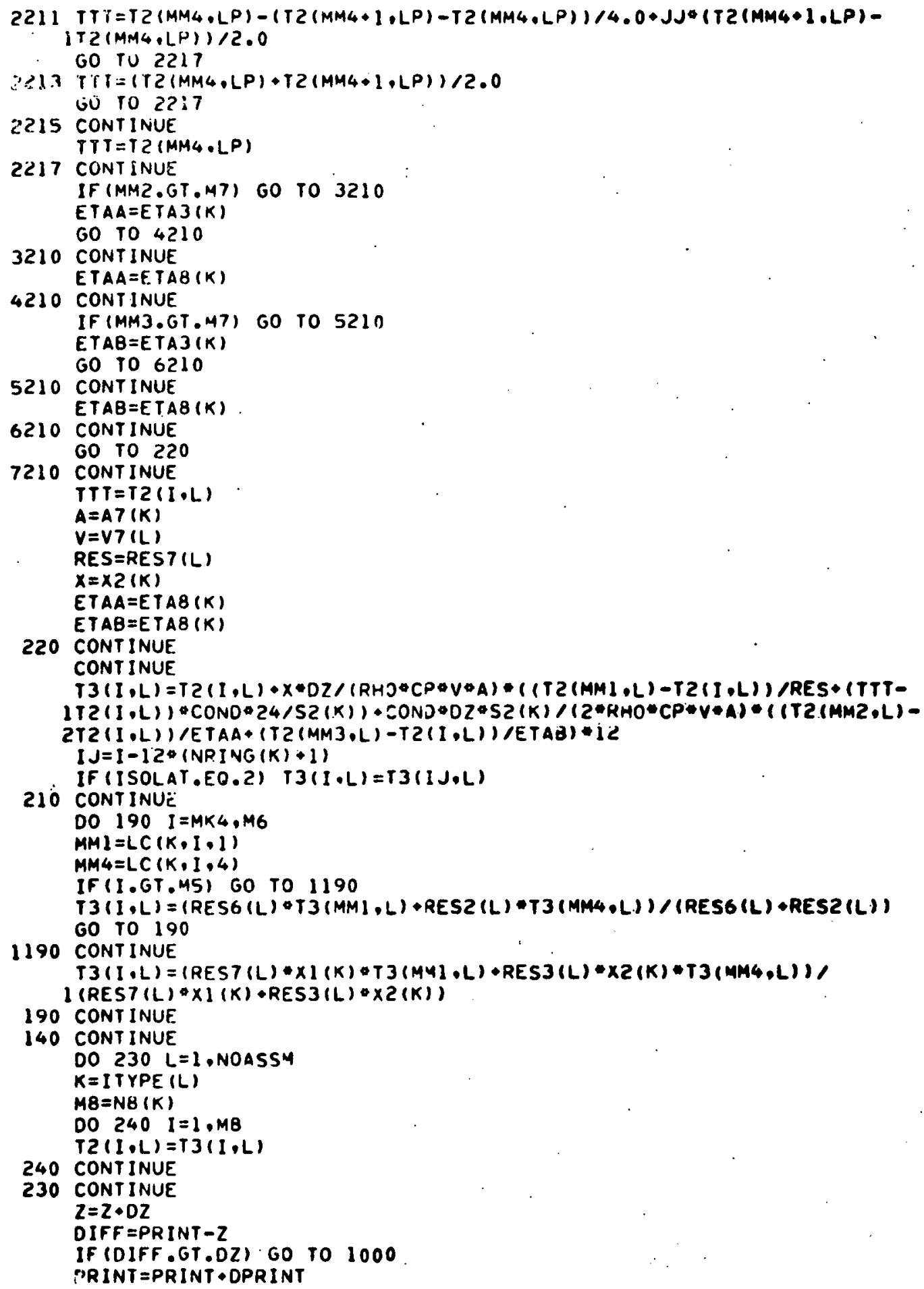


DO $250 \mathrm{~L}=1$, NOASSM

$K=I$ TYPE (L)

$M 2=N 2(K)$

$M 3=N 3(K)$

$M 4=N 4(K)$

$M S=N 5(K)$

$M A=A S(K)$

$M:=V 7(K)$

$M 8:=N E(K)$

$M K 2=M 2+1$

$M K 3=M 3+1$

$M K 6=M 6+1$

$M K 7=M 7+1$

DO $260 \quad I=1 . M 8$

$T(I)=T 2(I, L)$

CONTINUE

260 CONT INUE

$T 11=0$

$122=0$

$133=0$

$166=0$

$T 77=0$

DO $500 \mathrm{~J}=1, \mathrm{M2}$

$500 T 11=T 11 \cdot T 2(J, L)$

DO $501 \mathrm{~J}=M K 2, M 3$

$501 T 22=T 22+T 2(J, L)$

$00502 J=M K 3, M 4$

$502 T 33=133+T 2(\mathrm{~J} \cdot \mathrm{L})$

$00504 \mathrm{~J}=M K 6, M 7$

$504 T 66=T 66 \cdot T 2(J \cdot L)$

DO $505 \mathrm{~J}=M K 7 \cdot M 8$

$505 \quad T 77=T 77 \cdot T 2(\mathrm{~J}, \mathrm{~L})$

TAVG $(L)=(T 1) * V I(L) * A 1(K)+T 22 * V 2(L) * A 2(K)+T 33 * V 3(L) * A 3(K))$,

$I(M 2 * V I(L) * A l(K) *(M 3-M Z) * V 2(L) * A 2(K) *(M 4-M 3) * V 3(L) * A 3(K))$

QTOTAL $(L)=$ IOSA $(L) * A I(K)+2 S B(L) * A Z(K) * O S C(L) * A 3(K)) * D Z / 12 * 3 / 3412$ $H I N=R H O * C P * T I N *(M 2 * A I(K) * V I(L)+(M 3-M 2) * A 2(K) * V 2(L)+(M 4-M 3) * A 3(K) *$

IV3(L)) $/ 144 / 3412$

HING $=R H O * C P * T I N *(1 M 7-46) * A 6(K) * V 6(L)+(M 8-M 7) * A 7(K) * V 7(L)) / 144 / 3412$ HTOTAL $=R H O * C P *(T 1) * A I(K) * V I(L) * T 22 * A 2(K) * V 2(L) * T 33 * A 3(K) * V 3(L)) /$

$1144 / 3412$

HTOTLG $=R H O * C P *(T 66 * A 6(K) * V G(L)+T 77 * A 7(K) * V 7(L)) / 144 / 3412$

DIFFH(L) $=$ HTOTAL $-H I N$

DIFFHG $(L)=H T O T L G-H I N G$

WRITE $(6,503)$ TAVS (L),OTOTAL (L),OIFFH(L),OIFFHG(L)

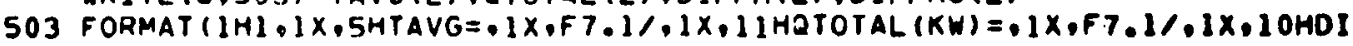

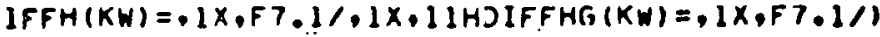

WRITE $(6,506) \mathrm{L}$

506 FORMAT (IX,37HTEMPERATURE DISTRIBUTION FOR ASSEMBLY,IS)

CALL PRIN(K)

250 CONTINUE

IF (PRINT.GT.LENGTH(II)) GO TO 2000

GO. TO 1000

2000 CONTINUE

3000 CONTINUE

STOP

END

SUBROUTINE PROP (TT)

COMMON/PROPI/RHO, CP, CONO, CONOW, ALPHA

$R H O=59.566-(7.9504 E-3) * T T-(0.2872 E-6) * T T * T T \cdot(0.06035 E-9) * T T * 3$ 
$C P=0.344021-(7.03539 E-5) * T T \cdot(2.68131 E-8) * 1 T * T T$

CONO $=54.305-(1.878 E-2) \cdot T T \cdot(2.0914 E-6) * T T \cdot T$

$A L P H A=C O N D /\left(R H O{ }^{\circ} C P\right)$

CONOW $=12.1$

RETUKN

END

SUUROUTINE CURVE $(F X, X, F, Y, N, J)$

DIMENSION $F(50,7), Y(50,7), N(7)$

$M=N(J)$

10 DO $20 \mathrm{KK}=1, \mathrm{M}$

If $(X-Y(K K, J)) 30.15,20$

15 IF (KK.EQ.M) GO TO 40

20 CONTINUE

GO TO 60

30 IF $(K K . E O .1)$ GO TO 60

$40 B=(X-Y(K K-1, J)) /(Y(K K \cdot J)-Y(K K-1 \cdot J))$

$50 F X=F(K K-1, J) \circ B \circ(F(K K, J)-F(K K-l, J))$

RETURN

60 PRINT OI

6) FORMAT (1X, PPROG.STOPPED.IN CLPVE')

RE TURN

END

SUBROUTINE PRIN(K) COMMON/TEMP/T (550)

COMMON/NUM /NROD (3) ,NRING (3),NCHANL (3),NI (3),NZ(3),N3(3),N4(3), IN5 (3),N6 (3),N7 (3),N8 (3) , LC (3,550,4), MROD (3,440,3)

IF INRING(K). F.0.4) GO TO 600

IF (NRING (K) .EQ.8) GO TO 700

GO 10800

600 CONTINUE

WRITE $(6,614) T(183), T(164): T(163), T(162) \cdot T(161), T(182)$

WRITE $(6,615) T(153), T(134), T(133), T(132), T(131), T(152)$

WRITE $(6.613) \mathrm{T}(123), T(104), T(103), T(102), T(10), T(122)$

WRITE $(6.602) T(68), T(65), T(64), T(62)$

WRITE (6.603) T(165),T(135),T(105),T(69),T(67),T(65),T(63),T(6),

$1 T(100), T(130), T(160)$

WRITE $(6,504) T(70), T(34), T(32), T(30), T(60)$

WRITE $(6,605) \mathrm{T}(166), T(136), T(106), T(7), T(35), T(33), T(3), T(29)$. IT (59), T $(99), T(129), T(150)$

WRITE $(6,606) T(72), T(36), T(12), T(10), T(28), T(58)$

WRITE (6.607) T(167).T (137), T (107),T (73),T(37),T(13),T (11),T(9).

IT $(27), T(57), T(98), T(128), T(158)$

WRITE (6,608) T(74),T (38),T (14),T(2),T (8),T (26),T(56)

WRITE (6.609) T(168),T (138),T(108),T(75),T (39),T (15),T(3),T(1).

IT (7), T (25),T(55), T (97) . T (127),T (157)

WRITE (6.610) T(184), T (154),T(124),T(121),T(151),T(181)

WRITE (6.611) T(169), T(139), T (109), T (76), T (40),T (16),T $(4), T(6)$,

IT (24),T (54),T (96),T $(120), T(150) \cdot T(180)$

WRITE (6,608) T(77), T(4), T (17),T (5),T (23), T (53),T.(95)

WRITE $(6,507) T(1 / 0), T(140), T(110), T(78), T(42), T(18), T(20), T(22)$,

$1 T(52), T(94), T(119), T(149), T(179)$

WRITE $(6,606) T(79), T(43), T(19), T(2)), T(51), T(93)$

WRITE $(6.605) T(171), T(141), T(111), T(80), T(44), T(46), T(48), T(50)$. $1 T(92) \cdot T(118), T(14 B), T(17 B)$

WRITE (6,604) T(8)),T(45),T(47),T(49),T(91)

WRITE (6.603) T(172),T (142),T (112),T (82), T $(84), T(86), T(88), T(90)$, $1 T(117), T(147), T(177)$

WRITE $(6,612) T(8.3), T(85), T(87), T(89)$

WRITE $(6,601) T(125), T(113), T(114), T(115), T(116), T(126)$

WRITE $(6,615) T(155), T(143), T(144), T(145), T(146), T(156)$ 
WRITE (6.614) T(185),T(173) .T(174) T T(175) .T (176).T(186)

001 FORMAT $(27 \times .5110 .15)$

602 FORMAT $(37 \times, 4110 / 1 / 1$

DO3 FOKMAT $(17 x, 315,5110,315 / 1 /)$

GO 4 FORMAT $(32 \times .5110 / 1 /)$

6OS FORMAT $(12 x, 315.6110 .315 / 1 / 1)$

606 FORMAT $(27 \times .6110 / 1 /)$

607 FORMAT $(7 X .315 .7110 .315 / 11)$

OO8 FORMAT $(22 x, 7110 / 1 /)$

609 FOKMAT $(2 x, 315.8110 .315 / 1)$

610 FORMAT $(1 x, 315,82 x \cdot 315 /)$

611 FORMAT $(2 X, 315,8110.315 / 11)$

612 FORMAT $137 x, 4110 / 1)$

613 FORMAT $(27 \times, 5110,15 / 1)$

614 FORMAT $(17 x, 110,10 x, 4110,5 x, 110)$

615 FORMAT $(22 x, 110,5 x, 4110,110)$ GO TO 249

700 CONTINUE

WRITE $(6,721) T(543), T(508), T(9-07), T(506), T(505), T(504), T(503)$,

$1 T(502), T(501) \cdot T(542)$

WRITE (6,722) T(489), T(454), T(453), T (452), T (451), T (450), T (449),

IT (448), T $(447), T(488)$

WRI TE $(6,719) T(435), T(400), T(399), T(398), T(397), T(396), T(395)$,

IT (394), T (393), T (434)

WRITE $(6,702) T(324), T(322), T(320), T(318), T(316), T(314), T(312)$,

$1 T(310)$

WRITE $(6,703) T(509), T(455), T(401), T(325), T(323), T(321), T(319)$,

$1 T(317), T(315), T(313), T(3) 1), T(309), T(392), T(446), T(500)$

WRITE $(6,704) T(326), T(242), T(240), T(238), T(236), T(234), T(232)$,

$1 T(230) \cdot T(308)$

WRITE $(6,705) T(510), T(456), T(402), T(327), T(243), T(241), T(239)$,

$1 T(237), T(235), T(233), T(231), T(229), T(307), T(391), T(445), T(499)$ WRITE $(6,706) T(328), T(244), T(172), T(170), T(168), T(166), T(164)$,

$1 T(162), T(228), T(306)$

WRITE $(6,707) T(511), T(457), T(403), T(329), T(245), T(173), T(171)$, lT $(169), T(167), T(165), T(163), T(161), T(227), T(305), T(390), T(444)$, $1 T(498)$

WRITE $(6,708) T(330), T(246), T(174), T(114), T(112), T(110), T(108)$,

IT (106), T $(160), T(22.6), T(304)$

WRITE $(6,709) T(512), T(453), T(404), T(331), T(247), T(175), T(115)$,

$1 T(113), T(111), T(109), T(107), T(105), T(159), T(225), T(303), T(389)$,

$2 T(443) \cdot T(497)$

WRITE $(6,710) T(332), T(248), T(176), T(116), T(68), T(66), T(64), T(62)$.

IT (104), T (15B), T (224), T (302)

WRITE $(6,711) T(513), T(459), T(405), T(333), T(249), T(177), T(117)$, IT $(69), T(67), T(65), T(63), T(6)), T(103), T(157), T(223), T(30), T(388)$, 2T $(442), T(496)$

WRITE $(6,712) T(334), T(250), T(178), T(118), T(70), T(34), T(32), T(30)$,

$1 T(60), T(102), T(156), T(222), T(300)$

WRITE $(6,713) T(514), T(450), T(406), T(335), T(251), T(179), T(119)$,

$1 T(71), T(35), T(33), T(31), T(29), T(59), T(101), T(155), T(22)$, T (299). 2T (387), T (44), T (495)

WRITE $(6,714) T(336), T(252), T(180), T(120), T(72), T(36), T(12), T(10)$, $1 T(28), T(58), T(100), T(154), T(220), T(298)$

WRITE $(6,715) T(515), T(461), T(407), T(337), T(253), T(181), T(121)$, IT (73),T(37), T (13),T (11),T $(9), T(27), T(57), T(99), T(153), T(219)$, $28(297), T(386), T(440), T(494)$

WRITE $(6,716) \mathrm{T}(338), T(254), T(182), T(122), T(74), T(38), T(14), T(2)$,

$1 T(8), T(26), T(56), T(98), T(152), T(2), T), T(246)$

WRITE $(6,720) T(516), T(462), T(408), T(339), T(255), T(183), T(123)$. 
IT (75),T(39!,T(15),T(3),T(1),T(7),T(25),T(S5),T(97),T(151),T(217), 2T (295), T (385), T (439), T(493)

WRITE $(6,7$ P.) T (544),T(490),T(436), T(433),T(487),T(54)

WRITE $(6.717) T(517), T(463), T(409), T(340), T(256), T(184), T(124)$. $1 T(76), T(40), T(16), T(4), T(6), T(24), T(54), T(96), T(150), T(2)$, cेT $(294), T(384), T(432), T(496), T(540)$

WRITE $(6,716) T(34)), T(257), T(185), T(125), T(77), T(4), T(17), T(5)$. IT (23),T(53),T(95),T(149),T(215),T(293),T(383)

WRITE $(6.715) T(5)(8), T(464), T(410), T(342), T(258), T(186), T(126)$, $1 T(78), T(42), T(18), T(20), T(22) \cdot T(52), T(94), T(148), T(214), T(292)$. $2 T(382) \cdot T(43)) \cdot T(485) \cdot T(539)$

WRITE $(6,714)$ T (343), T (259), T (187), T (127), T (79), T (43), T (19), T (21), IT $(51), T(93), T(147), T(213), T(291), T(381)$

WRITE $(6,713) T(519), T(465), T(411), T(344), T(260), T(188), T(128)$, IT $(80), T(44), T(46), T(48), T(50), T(92), T(146), T(2) 2), T(290), T(380)$, $2 T(430) \cdot T(4 B 4) \cdot T(538)$

WRITE $(6,712) T(345), T(261), T(189), T(129), T(8)), T(45), T(47), T(49)$, IT $(91), T(145), T(211), T(289), T(379)$

WRITE $(6,711) T(520), T(466), T(412), T(346), T(262), T(190), T(130)$, $1 T(82), T(84), T(86), T(88), T(90), T(144), T(210), T(288), T(378), T(429)$, $2 T(483) \cdot T(537)$

WRITE $(6,710) T(347), T(263), T(191), T(131), T(83), T(85), T(87), T(89)$. IT $(143) \cdot T(209), T(287), T(377)$

WRITE $(6,709) T(521), T(467), T(413), T(348), T(264), T(192), T(132)$, $1 T(134), T(136), T(138), T(140), T(142), T(208), T(286), T(376), T(428)$, 2T $(482), T(536)$

WRITE (6,708) T(349), T (265), T (193), T (133), T (135), T (137), T (139), IT $(141) \cdot T(207) \cdot T(285) \cdot T(375)$

WRITE $(6,707) T(522), T(459), T(414), T(350), T(266), T(194), T(196)$, $1 T(198) \cdot T(200) \cdot T(202), T(204), T(206), T(284), T(374), T(427), T(48)$.
$2 T(535)$

WRITE $(6,706) T(35), T(2.67), T(195), T(197), T(199), T(201), T(203)$, IT (205) $\cdot T(283) \cdot T(373)$

WRITE $(6,705) T(523), T(469), T(415), T(352), T(268), T(270), T(272)$, IT $(274), T(276), T(278), T(280), T(282), T(372), T(426), T(480), T(534)$ WRITE (6,704) T(353),T(269),T(271),T(273),T(275),T(277), T(279). IT (2B1), T (37)

WRITE (6,703) T(524), T (470), T (416),T (354),T (356), T (358), T (360), IT $(362), T(364), T(366), T(368), T(370), T(425), T(479), T(533)$ WRITE $(6,702) T(355), T(357), T(359), T(361), T(363), T(365), T(367)$, $1 T(369)$

WRITE $(6,701) T(437), T(4) 7), T(418), T(419), T(420), T(421), T(422)$, IT (423), T (424), T (438)

WRITE $(6,722) T(491), T(471), T(472), T(473), T(474), T(475), T(476)$, IT (477), T (478), T (492)

WRITE $(6,721) T(545), T(525), T(526), T(527), T(528), T(529), T(530)$, IT (531), T (532) , T (546)

70) FORMAT (32X, 10I5)

702 FORMAT $(37 \times .815 /)$

703 FORMAT $(19 X, 1515 /)$

704 FORMAT $(34 x .915 /)$

705 FORMAT $(17 \times \cdot 1615 /)$

706 FORMAT $(32 \times .1015 /)$

707 FORMAT $124 \times .1715 / 1$.

708 FORMAT $(29 \times, 1) 15 /)$

709 FOHMAT $(12 x, 1815 /)$

710 FORMAT $(27 x, 1215 /)$

711 FORMAT $\left(9 x_{0} 1915 /\right)$

712 FORMAT $(24 x+13$ I5/) 


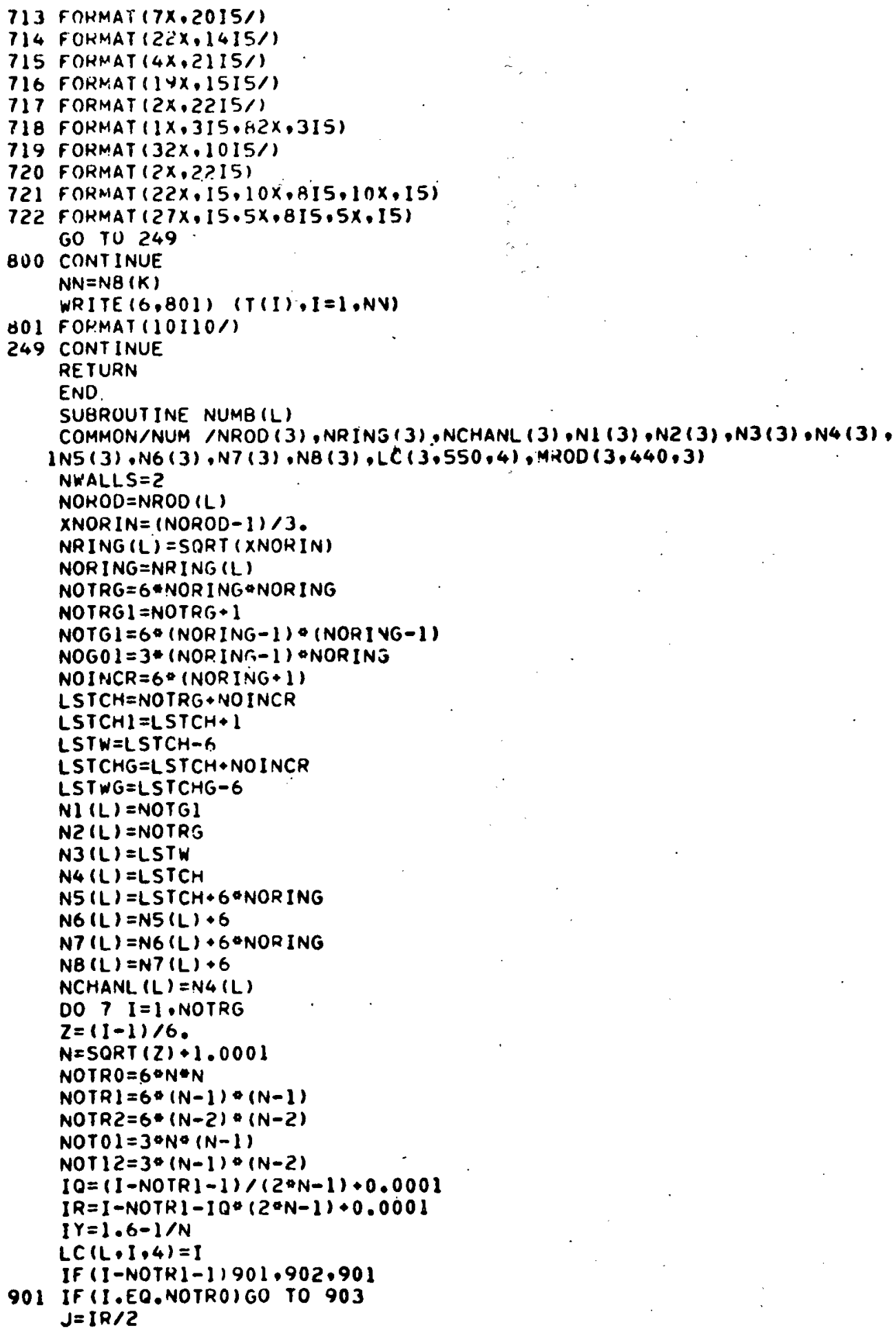


If $(I R-J * 2) 905,905,904$

$90512: i .0001 /($ NOTRO-I)

$L C(L, I, I)=N O T R 2+10 *(2 * N-3) \cdot I R-1$

$L C(L, I, 2)=I-1$

$L C(L, I, 3)=I+1$

MROD $(L, 1 \cdot 1)=1+N O 112+10 *(V-1)+1 R / 2$

MROD $(L, I, 2)=M R O D(L, 1,1)+1-6 * I Z *(N-1)$

$M R O D(L, I, 3)=N O T O I+I 0 * N+12 / 2+2$

GO TO 6

$904 L C(L, I, 1)=1-1$

$L C(L, I, 2)=1+1$

MROD $(L, I, 1)=N O T 12+10 \cdot(V-1)+(1 R+1) / 2+1 Y$

$M R O D(L, I, 2)=1+N O T O 1+10 * N \cdot(I R+1) / 2$

MROD $(L, I, 3)=M R O O(L, 1,2)+1$

908 IF (N.EO.NORING) GO TO. $90 \mathrm{~B}$

$L C(L, I \cdot 3)=N O T R O \cdot I 0 *(2 * N+1)+I R+1$ GO TO 6

$906 L C(L, I, 3)=N O T R O \cdot I Q * N+(I R \cdot 1) / 2$ GO TO 6

$903 L C(L \cdot I, 1)=$ NOTRI +1

$L C(L, I, 2)=$ NOTRO - I

MROD $(L, I, I)=I+I Y+N O T 12$

$M R O D(L, 1,2)=2+N O T O 1$

$M R O D(L, I, 3)=1+3 \otimes N \otimes(N+1)$

GO TO 908

$902 L C(L, I, 1)=$ NOTRI +2

$L C(L, I, 2)=$ NOTRO

$M R O D(L, I, I)=I+I Y+N O T 12$

$\operatorname{MROD}(L, 1,2)=2+N O T O 1$

$M R O D(L, I, 3)=\operatorname{MROD}(L, I, 2)+1$

GO TO 908

6 CONTINUE

7 CONTINUE

DO 9 I =NOTRGI,LSTCH

$M R O D(L, I, 3)=V O R O D+1$

IF (I.LE.LSTW) GO TO 801

$I 0=I-L S T C H+5$

$L C(L, I, 2)=N O T R G+I Q \otimes N O P I N G \cdot I$

$L C(L, I, 3)=L S T C H G-5 \cdot 10$

$L C(L, I, 4)=1$

MROD $(L, I \cdot 1)=2+N O G O 1+10+N O R I N G$

$M R O D(L, I, 2)=N O R O O+1$

IF (IQ.EO.O) GO TO 802

$L C(L, I, I)=N O T R G+I Q \otimes N O R I N G$

GO TO 8

$802 L C(L, I, I)=I-1$

GO TO 8

$80112=1.0001 /(L 5 T C H-5-1)$

$I Q=(I-N O T R G-1) / N O R I N G+0.000 I$

$I R=I-N O T R G-I 0 * N D R I N G+0.0001$

$L C(L, I \cdot 1)=N O T G I+I Q *(2 * N O R I N G-1)+2 * I R-1$

$L C(L, I, 4)=L S T C H+I Q * N O R I N G+I R$

$M R O D(L, I, I)=I+N O G O I+I 0 * N O R I V G+I R$

MROD $(L \cdot I \cdot 2)=M R O D(L \cdot I, 1)+1-6 * 12$ *NORING

IF (IR.EO.1) GO TO 803

IF (IR.EQ.NORING) GO TO $\$ 04$

$L C(L \cdot I \cdot 2)=I-1$

$L C(L, I, 3)=1+1$

GO 108

$803 L C(L, I, 2)=L S T w \cdot I 0+1$ 
$L C(L, I \cdot 3)=1+1$

GO TO 8

$804 L C(L, I, 2)=I-1$

$L C(L, 1,3)=(1-I Z) *(L S T W+I 2+2)+1 Z *(I+1)$

GO TO 8

8 CONTINUE

9 CONTINUE

DO $13 \mathrm{~J}=1$, NWALLS

DO $11 I=L S T C H I, L S T C H G$

IF (I.LE.LSTWG) GO TO 701

$I A=I-L S T W G-1$

$L C(L, I \cdot I)=L S T W+1+10$

$L C(L, I, 3)=L S T C H+10 * N O R I N G+1$

IF (J.EQ.NWALLS) GO TO 12

$L C(L \cdot I, 4)=L S T W G+N O I N C R+I 0+]$

60 TO 14

12 CONTINUE

LC $(L, 1,4)=1$

14 CONTINUE

IF $(I Q . E O .0)$ GO TO 702

LC $(L, 1,2)=L S T C H+I O * N O R I N G$

GO TO 10

$702 L C(L, I, 2)=I-1$

GO TO 10

$701\{X=1.0001 /(L S T W G+1-1)$

$I Q=(I-L S T C H-1) / N O R I N G+0.0001$

$I R=I-L S T C H-I O * N O R I N G+0.0001$

$L C(L, I, I)=N O T R G+I 0 * N O R I N G+I R$

IF (J.EQ.NWALLS) GO TO 16

$L C(L, I, 4)=L S T C H G+10 * N O R I V G+I R$

GO TO 18

16 CONTINUE

LC $(L, I, 4)=1$

18 CONTINUE

IF (IR.EO.L) GO TO 703

IF (IR.EQ.NORING) GO TO 704

LC $(L, 1,2)=1-1$

$L C(L, 1,3)=1+1$

GO TO 10

704. $L C(L, I, 2)=1-1$

$L C(L, I, 3)=(1-I X) *(L S T W G+10+2)+1 X *(I+1)$

GO TO 10

$703 L C(L, I, 2)=L S T W G \cdot 10+1$

$L C(L, I, 3)=I+1$

GO TO 10

10 CONTINUE

II CONTINUE

NOTRG $=$ NOTRG + NOINCR

LSTCH $=$ LSTCH +NOINCR

LSTCHI $=$ LSTCHI +NOINCR

LSTW=LSTW +NOINCR

LSTWG =LSTWG + NOINCR

LSTCHG $L$ LSTCHG + NOINCR

13 CONTINUE

RETURN

END

SURROUTINE GEOM(L)

COMMON/GEO /OR (3), DW (3) , LEAD (3) ,P (3) , DFLAT (3) ,POD (3) , GAP (3) , AI (3),

$1 A 2(3), A 3(3), A 4(3), A 5(3), A 6(3), A 7(3)$,ATOTAL (3) •ATOTLG (3),DE 13$)$.

$20 E 2(3), D E 3(3), D E 6(3), D E 7(3), H P 1(3), H P 2(3), H P 3(3), H P T O T L(3)$, 
3ETAI (3), ETA2 (3), ETA3 (3), ETA $(3)$, ETA $6(3), E T A B(3), X 1(3), \times 2(3), \times 3(3)$, $451(3), 52(3), L . E N G T H(3), V I 2(3), V 2 R(3), V 3 R(3), V 6 R(3), V 7 R(3)$ COMMON/NUM /NROO (3), NRING (3),NCHANL (3),NI (3),N2 (3),N3 (3) คN4 (3), IN5 (3),N6 (3),N7 (3),NB(3),LC $(3,550,4), M R O D(3,440,3)$

NI $1=N 2(L)$

$N 22=N 3(L)-N 2(L)$

$N 33=N 4(L)-N 3(L)$

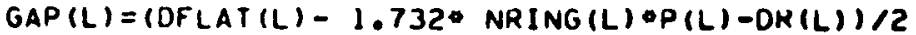

OFACE $=D F L A T(L) / 1.732$

$P I=3.141592$

$X I(L)=1 O R(L)+2 \cdot G A P(L)) / 1.732$

$\times 2(L)=x 1(L)+2 * S 1(L) / 1.732$

$\times 3(L)=\times 2(L) \cdot 52(L) / 1.732$

$\operatorname{ETAL}(L) \cong P(L) / 1.732$

$E T A Z(L)=(E T A)(L)+G A P(L)+D R(L) / 2) / 2$.

ETAJ $(L)=P(L)$

ETAL $(L)=E T A 3(L) / 2 \cdot+\times 1(L) / 4$.

$\operatorname{ETAB}(L)=E T A 3(L) / 2+(X)(L)+\times 2(L)) / 4$.

$\operatorname{ETAB}(L)=E T A 3(L) / 2+(\times 2(L)+\times 3(L)) / 4$.

Al $(L)=1.732 * P(L) * 2 / 4 .-10 R(L) * 2 * D W(L) * 22) * P I / 8$.

$A Z(L)=P(L) \otimes(D R(L) / 2+G A P(L))-(D R(L) * \otimes 2+D W(L) * 2) * P I / 8$.

$A 3(L)=(D R(L) / 4+G A P(L) / 2) *(D F A C E-P(L) * N R I N G(L))-(D R(L) * 2 * D W(L) * 2$

$11 \triangle P I / 24$.

$A 4(L)=E T A 3(L) * S 1(L)$

$A 5(L)=(X)(L)+\times 2(L)) \circ S 1(L) / 2$.

$A 6(L)=E T A 3(L) * S 2(L) / 2$

$A 7(L)=(\times 2(L)+\times 3(L)) \otimes 52(L) / 4$

ATOTAL $(L)=N 11 * A 1(L)+N 22 \cdot A 2(L)+N 33 * A 3(L)$

ATOTLG $(L)=\{N R I N G(L) * A 6(L) * A T(L)) * 6$

$W P I=(D R(L)+D W(L)) \otimes P I / 2$.

$W P Z=P(L)+W P I$

$W P 3=(D R(L)+D W(L)) \neq P I / 6+D F A C E-P(L) \bullet N R I N G(L)$

WPG $=E T A 3(L)$

WPT $=\times 2(L)$

DE $I(L)=4.0 * A 1(L) / W P 1$

$D E 2(L)=4.0 \% A 2(L) / W P 2$

DE $3(L)=4.00 \Delta 3(L) / W P 3$

DEG (L) $=4.0 * A 6(L) / W P 6$

$D E 7(L)=4.0 \times A 7(L) / W P 7$

$H P I(L)=D R(L) \otimes P I / 2$

$H P Z(L)=O H(L) \triangle P I / 2$

$H P 3(L)=O R(L) \otimes P I / 6$

HPTOTL $(L)=N 11 \%$ HPI (L) +N22०HPZ (L) +N33*HP3(L)

$V I R(L)=A T O T A L(L) /(N)) * A I(L) * N 22 * A 2(L) *($ (DE2 $(L) / D E I(L)) * 0.714) *$ IN33*A3 (L) * ( (DE3 $(L) / D E I(L)) * 0.714))$.

VZR $(L)=A T O T A L(L) /(N I I * A I(L) *($ COEI $(L) / O E 2(L)) * 0.714) * N 22 * A 2(L)$ * IN33०A3(LI०(IDE3(L)/DE2 (L)):0.714))

$V 3 R(L)=A T O T A L(L) /(N I) * A I(L) *($ (DE I (L)/OE3 $(L)) * 0.714)+N 22 * A 2(L) *$ 1 (IDE $2(L) / D E 3(L)) \circ 0.714)+N 33 * A 3(L))$

VGR $(L)=A T O T L G(L) /(N R I N G(L) \$ A 6(L)+A 7(L) *(10 E 7(L) / 0 E 6(L)) * 2) / 6$ $V 7 R(L)=A T O T L G(L) /(N R I N G(L) * A G(L) *(10 E 6(L) / 0 E 7(L)) * 2) * A 7(L)) / 6$ RE TURN

END 


\section{APPENDIX 3}

\section{A SAMPLE PROBLEM}

The sample problem predicts the temperature distribution for the 16 coupled assemblies surrounding the assembly $E_{1}$ in Figure (4). All the data are taken from the clinch RIver Breeder Reactor. The first 8 pages are the print outs of the input data. The next 16 pages are the temperature distributions for assemblies $E_{1}, C_{3}, A_{2}, A_{1}$, $A_{1}, A_{2}, C_{3}, B_{3}, B_{2}, B_{1}, 32,25,32, B_{1}, B_{2}$, and $A_{3}$ respectively. Because of the core symmetry, there are two sets of print outs for assemblies $C_{3}, A_{2}, A_{1}, B_{3}$, $B_{2}, B_{1}$, and 32. Although their heat generation is symmetric with respect to the line jolning the core central assembly and assembly $E_{1}$, the temperature distributions are not symmetrical due to the swirl flow inside the assemblies. 


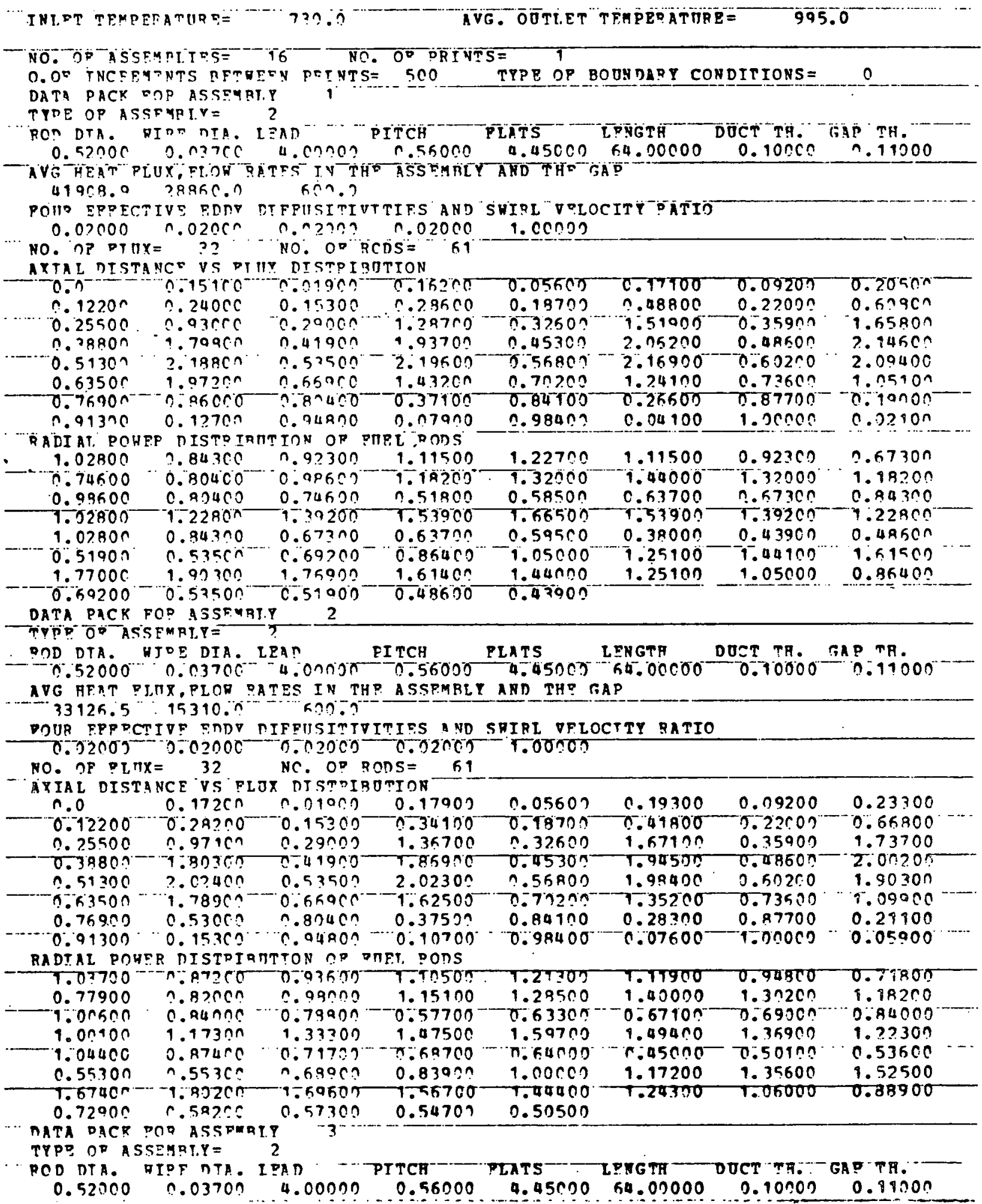


AVG HEAT PIIIX, FI.ON PATRS IN THE ASSEMPI,Y AND THE GAP 57547.7 ?aяkก.0 60r.

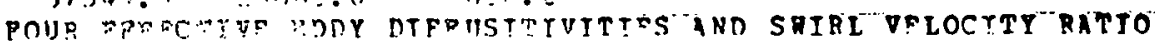
0.02002
$0 . \operatorname{coch}$ ?
0.0050 0. 0.0000
$1.0000 ?$

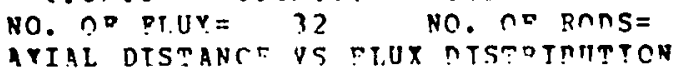

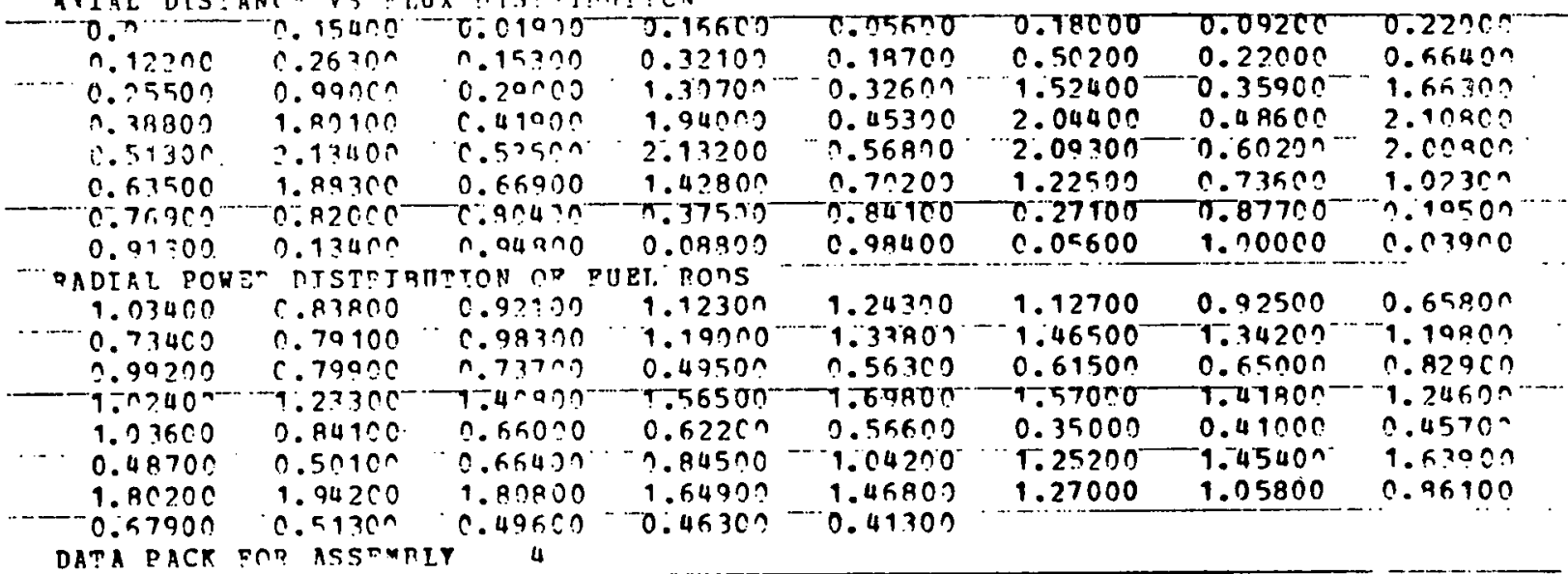

DATA PACR SOR ASSTRIIY 4

TYPP OP ASSFMPI,Y $=--2$

RCD RIA. BIR? NTA. LFÁ PITCH

$0.52000^{\circ}$. .03700 . 4.00000

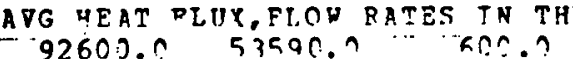

POHR FFFECTTVE FOTY DIPDTSTTIVTTTES AND SUIRL VETOCTTY RATTO

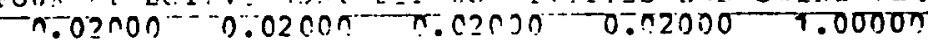

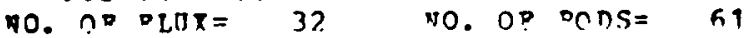

AYIAL DTSTANCE VS RLUX DISTRIALTTON

0.0 C. 12 å०

$0.12209 \cdots 0.30300$

$0.25500 \quad 1.10200$

ก. 01930

$-0.15390$

0.14500

0.29000

0.38800

$0.5130 n$

$1.897 \mathrm{C}$ :

1.06100

0.53500

0.63500

$1.610 \mathrm{Cr}$

$0.7 n 3 n 0$

$\because 65000$

0.76900

$0.125 n 0$

Q. 80400

0.94900

RADTAL PORPE NISTIIBUTTON CO PUFL PODS

$1.040700 .838 n n-0.92409-1.134 n]$

$0.73100 \quad 0.78900$ C.9890n 1.2020 .

0.99700

$0.7900 n$

1. $227 \mathrm{Cm}$

$1.2440 n$

0.7310 ?

$9.4300 ?$

0.64130

1.20209
0.43300

9.5940 ?

$1.32500^{-2} \quad 3.82 .5 C^{\circ}$

0.47200

$0.48 ? 00$

n. 5510 ?

0.62900 0.8380 .3

7.83000

T.665J7

C. 4740 ?

n.65100 n.494no

DATA PACK PRP ASSFMPLT

TYPE OD ASSEMGTYY =

PCD DTA. DIOF NIA: LPAT

0.52000 0.n37C 4.0 .3000 0.44500

\subsection{0}

0.1870 ก

0.3260 ?

0.45390

C. 5KBCD

0.72200

$0.941 \mathrm{cn}$

0.984 .0
1. PNG TR DOCT TH. GMP TH. THion -.......... $1.9502 n$ .02602 Т: 25700
0.17600

0.53800 1.63500 1.98600 1.84800 0.2660 n 0.06800

1.13300 1. 49800 0.50700 1.59100 0.55430 4.73900 0.55500 $1.040 n 3$ 1. $4580 n$ 0.3970 .
$0.3330 \%$

1. 25900 1.25900 1.26300
0.0920 ?

$0.2300 n$

0.35000

ก. 50200

0.73500

$0.8770 n$

1.00000
0.496 on
0.23302

$0.8370 n$

1.76500

1.98500

$1.7430 n$

0.97900

0.18000

0.0580 ?
$92600.053590 . ?$

POIS? FRDOCTIVF FDDY DTPOISTTIVTTIFS AND SUIPL VELOCTTY BATIO
C. 02000
C. 22500
$0 . r 20 n ?$
1. 00000

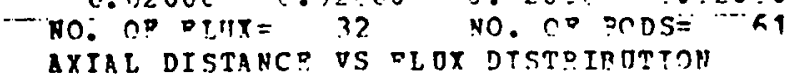

\begin{tabular}{|c|c|c|c|c|}
\hline $\begin{array}{l}0.0 \\
0.12250 \\
0.25500 \\
0.39800 \\
0.51300 \\
0.67500\end{array}$ & 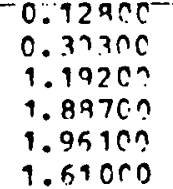 & $\begin{array}{l}C .04007 \\
0.15200 \\
0.29090 \\
0.41000 \\
0.53500 \\
0.56000\end{array}$ & $\begin{array}{l}0.14507 \\
0.39700 \\
1.41300 \\
1.95 \cap 00 \\
1.92602 \\
1.44900\end{array}$ & $\begin{array}{l}00 \\
01 \\
0 ? \\
0 ? \\
00 \\
00\end{array}$ \\
\hline
\end{tabular}

$\begin{array}{rr}0.17500 & 0.09200 \\ 0.53800 & 0.22000 \\ 1.53500 & 0.35900 \\ 1.98600 & 0.98600 \\ 1.84800 & 0.60200 \\ 1.26300 & 0.73600\end{array}$

0.23 .300 C. $8370 n$ 9:9650n 1.98500 $1.7470 n$ 0.97900 


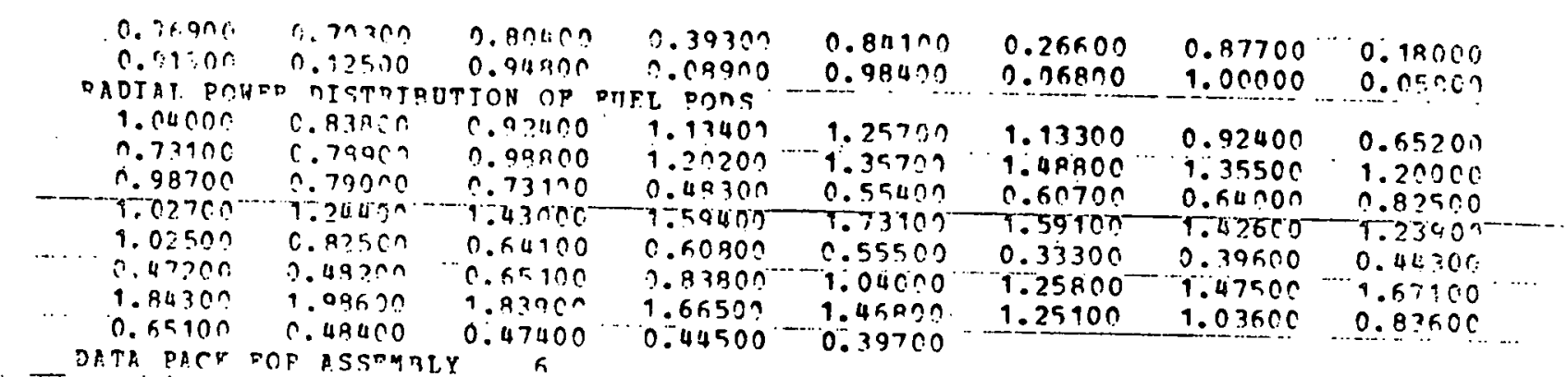

TYPF: CD ASSTMTYY

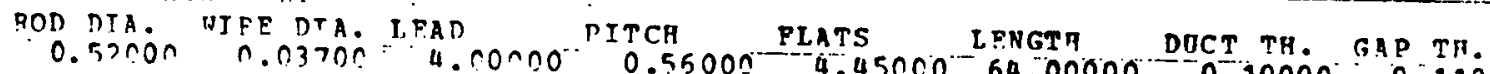

AVG HFAT FLUX, FLOR PATES IN THE ASSPYBL

57547.728850 .

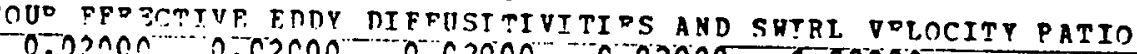

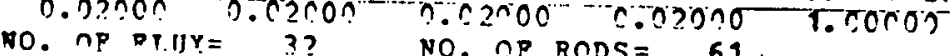

3? NO, OP RONS= 61

CF VS PLITX nTSTPIDUTION

- .. 0.0

$0.0 \quad 0.15400 \quad 0.01000$

0.16602

ก.12200

$0.26303-0.15300$

$0.2560 n$ c. $990 \mathrm{cn}$ c.

$0.79800^{-}-9.9310 \pi-0.499 \pi 0$

0.51 .30 ?

$? .87101$

0.53500

$0.5350 n$

?. $134 n \mathrm{C}$

$0.6590 n$

C. 76900

$1.8930 r$

$3.8 \cap 40$ ?

$0.9130 ?$

$0.8 ? C \mathrm{CO}$

0.94900

QADTAI, PAYSP NISTP

$0.1660 ?$
$0.3 ? 1 \mathrm{CO}$

1.3070?

$1.9490 \%$

2. 1320 ?

1.42800

$0.2750 n$

0.08830

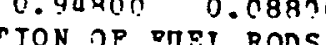

1. $03400^{0.8380 n-0.93100-1.12355}$

ก. $734 n 0$

0.98301

0790

$1.2330 \%$

1.0240?

0.77700

1.47900

1. 190000

0.49500

$1.5650 \mathrm{C}$

c. 66900

$0.4970 n$

$0.5 n 100$

0.66400

$0.522 \mathrm{CN}$

0.84500

0.6790 ?

$1.942 \pi$ ?

$0.513 \times 0$

DTA PAC R POD ASSEMRI.

TYPE OD ASSTMRLY

DOD "NIA." hIOF DIA." IFAD

C.52COC PITCH

TrG 0.03700 4.0n000 0.56000

33126.5 15310.0 G.0 R.S 0

- POUR DRP FCTIVF PDNY DIFPIISIT

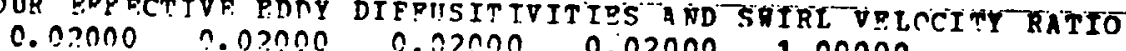

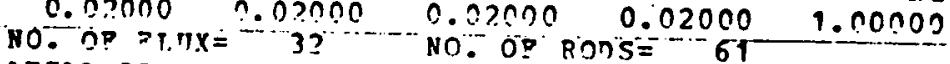

ATIAL DISTANCE VS PLIT nISTDIBUTION

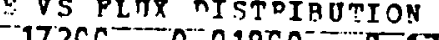

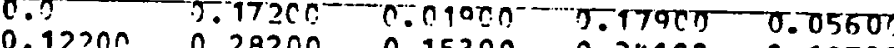

$0.12300 \quad 0.28200$

0.15 .300

$0.9710 n$

.. 29 con

0.34100

0.38900

$1.803 \cap \mathrm{C}$

0.49000

$0.5130 \mathrm{C}$

2. 07400

0.63509 $1.789 C \mathrm{C}$

.769 .90

$0.5300 \mathrm{cr}$

0.53500

C. 6.5900

$0.9130 n$

n. $1536 r$

C.P. 40 ?

ก. OUROก

1.03700

0.03700

DISTPT

$0.87 ? C \mathrm{C}$

9.82200

1. 0563 ? 3.84000

T.0n 10n

1. nu4no

0.55300

1.6740?

0.72900

7. $777 n c$

$0.87 a n$ ?

$0.5530 n$

1. 80200

0.59200

DATA PACR POT ASSPMBLY
C. . . $\div 0$

C. 980^0 C.7982C

?.33390

0.717100

C.58900

1.59600

0.57320

8 c. 187no

ก. $326 \mathrm{CO}$

$0.45 ? 63$

$0.56 R C O$

C. 72200

0.84100

0.99400

1.24305

1. 37800

".. $5670 n$

1.69800

n.5650

1. 04200

\section{$0.0560 n$}

0.18 . 00

0.50200

$1.5240 \mathrm{C}$

2.04400

2.09300

1.22500

C. 27100

c. $05600^{-}-8780$ non

$1.1270 n$

$1.465 n n$

$0.6150 n$

1.57000

0.35100

1.25200

T.27ñon
0.92500

1.34200

0.65000

1. $418 \mathrm{CC}$

0.41000

1.45400

1.058:0

\begin{tabular}{rr}
0.19300 & 0.0920 \\
0.41800 & 0.22000 \\
1.67100 & 0.3590 \\
1.94500 & 0.4860 \\
1.98400 & 0.5020 \\
1.35200 & 0.73500 \\
1.28300 & 0.87700 \\
0.07600 & 1.00000 \\
1.11900 & 0.94900 \\
1.40000 & 1.3920 \\
0.67100 & 0.69900 \\
1.49800 & 1.35900 \\
0.45000 & 0.50100 \\
-1.17200 & 1.35600 \\
1.24300 & 1.06000 \\
\hline
\end{tabular}

0.23300

0.6550 r

1.73700

2. . 2ก? 20

1.90300 1.00900

7.29900 0.05900

0.71800

1. 19200 ก. 84000

T. 22300

0.53600

1. $52500^{-}$

0.88900

$0.2200 n$

$.6630 n$

ac?

. n23on

.10500

0.03900

.65800

19900

.? 450 :

1. 6.3900

86100 
TYEP, NE ASSEMBT.Y $=2$

RID OTI. ATPE DIA. LFAD PITCH PIATS LENGTH DNCT TH. GAP TH. n.52000 0.93700 4.03030. 0.56000 4.45000 64.00000 0.13000 0.11001\%

AVG HOAT PLITP FLON RATES TN THE ASSPMPLT AND THP GAP

31739.9 1531n.n 50n.?

PONR FPPFCTTVE EDTY DTESTSITIVITIES AND SRTRL VPLOCITY RATIO

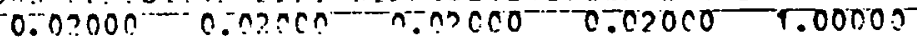

NO. OF PT,"IY $=32$ NO. กP RONS= 61

ATIT DISTAMCF, VS ELUX NISTRIRUTION

$0.174 n 0$ 0.0100? 0.19300

$0.12200 \quad 0.29500 \quad-0.15350$

0.35902

$0.0560 n$

1.3520 ?

0.32600

c. 29 ron

1.9 9 10ก0

TRZC?

1. $0 ? 900$

$0.4 \operatorname{TanO}$

$0.5130 n$

2. 02501 ก. 0.5350 ?

0.6250 ?

$1.7500 n$

0.55900

2.01203

0.45300

$1.54900-0.70290$

0.36100

$\hat{0} .84100$

0.152 ก

ก.8. 040 ?

$0.112 n$

$\because .94900$

PADTA?. POKED DISTPIBUTTIN OD FUPL RONS

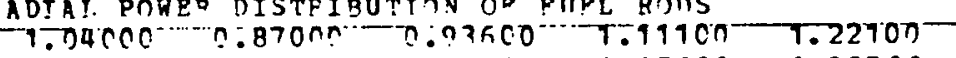

0.7730 ?

0.81600

ก. 8 38กी

0.99200

$1.1590 ?$

1.29500

$0.5640 n$

1.09500

1. 19200

ก.78.3.0

$0.8720 n$ …

1.4990 ?

0.62200

0.69000

1.61100

1.04500

?. 530 ano

ก. 59270

0.8380 ?

$0.63 \operatorname{con}$

0.530 n?

1 - $840 \mathrm{ch}$

1.7110 !

0.72300

0.57300

0.56300

0.53500

1. 0 5 500

$0.4430 n^{-2}-0.22000$

0.24200

DATA PACK PCR ASSOMBT

TYDP OP ASSEMBLY =

ROD OP ASSMEY

0.52000 O.037חC 4.CON

A VG HFAT ?LIX,FLOD 49304.8 29850.1

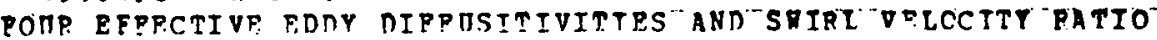
ก. 02 con 0.02 COn

0.02000

0.02000

1.0000 ?

NTIAT. DISTANCF VS FLUX DISTRIBTTION

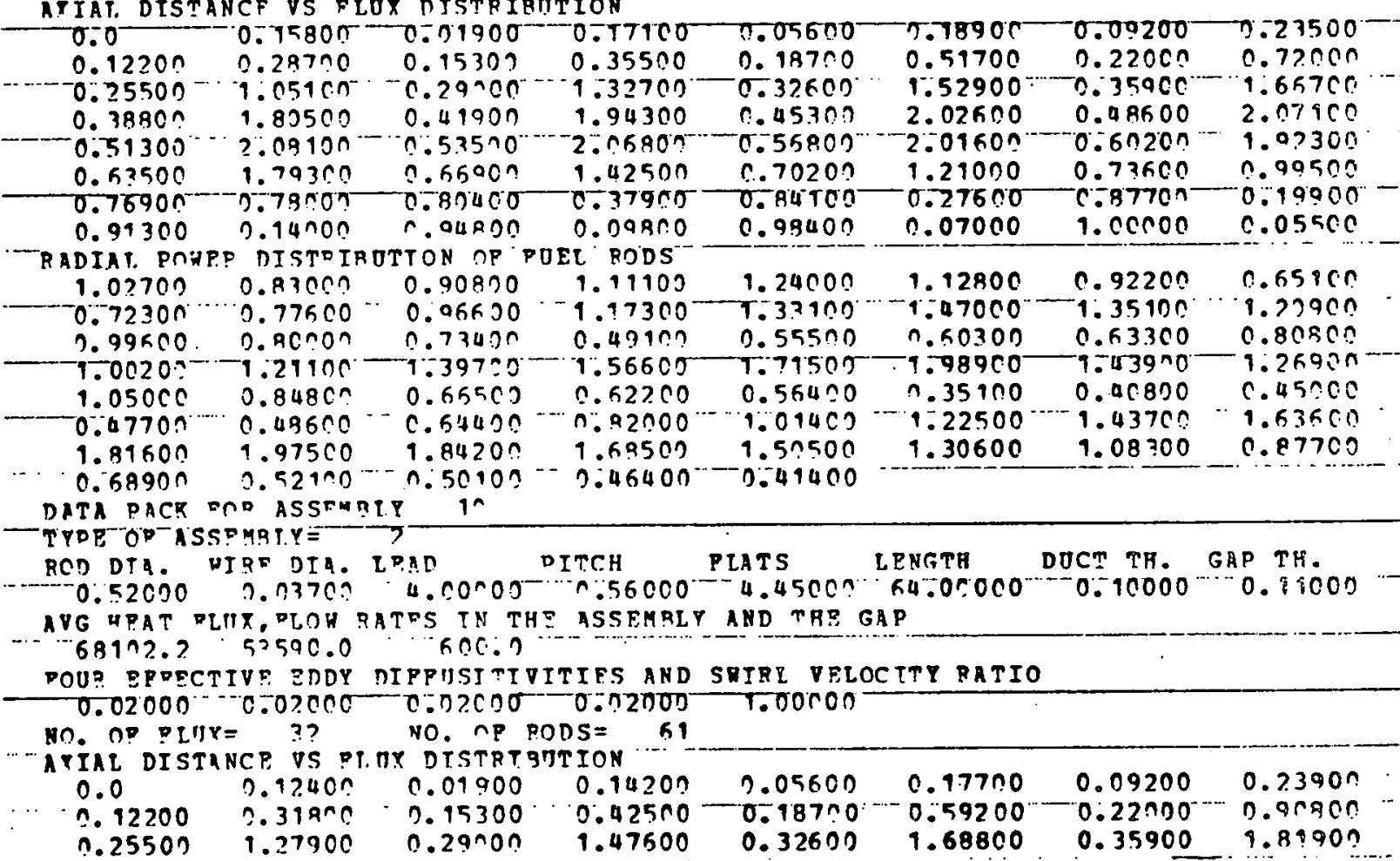




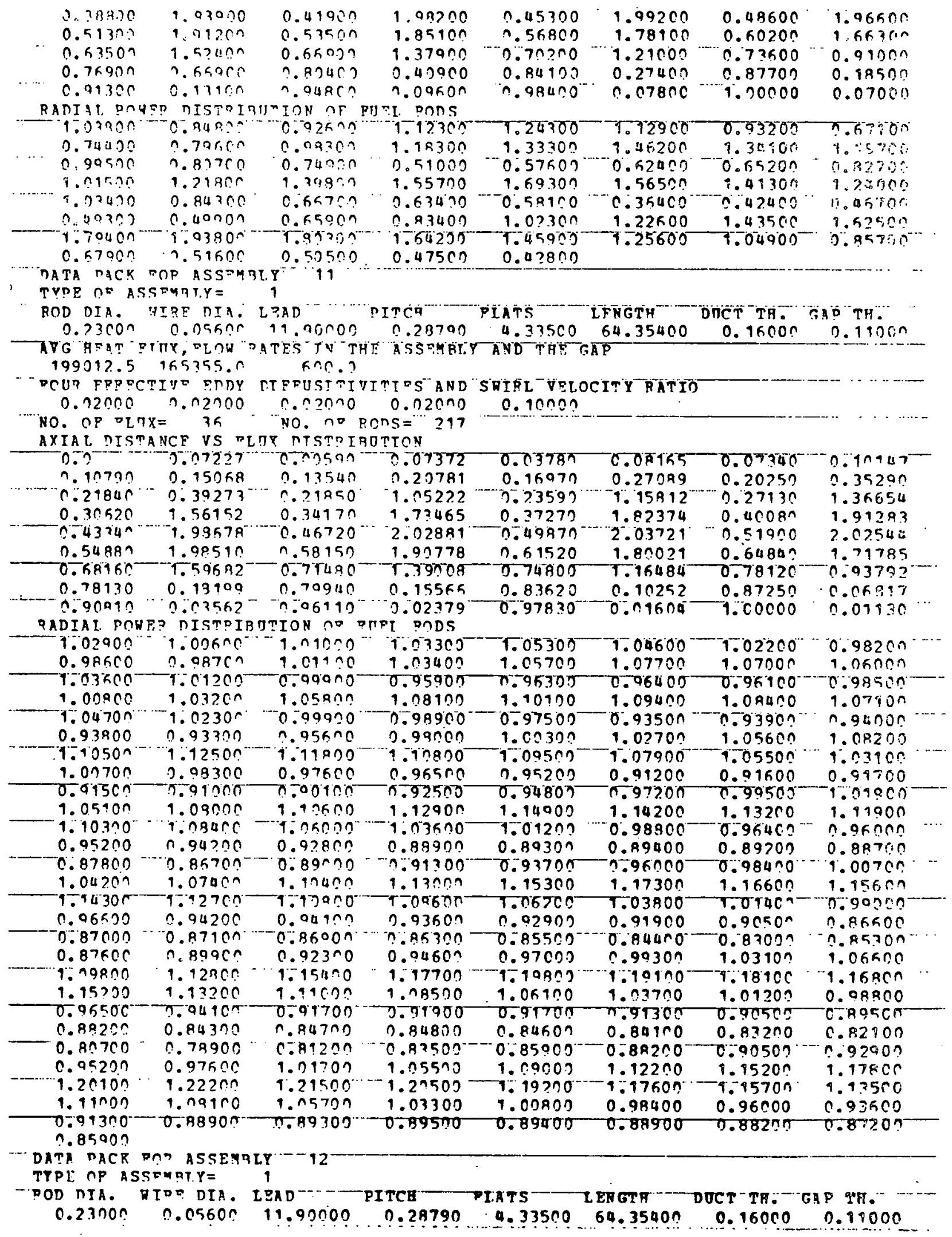


QVG IT\&T FIUX, FLOH FATES IN TA? ASSEMBLT AND THE GAP

$222733.4953=5.0$ for 3

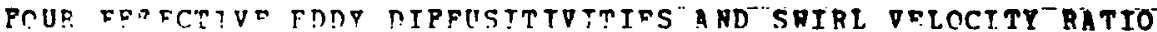

n.nzocr n.nzono n.n2000 n.020no 0.10000

No. $\cap P P L Y Y=$ BS NO. OP PODS=-217

AYIAT DISTANCE VS FIUT NISTRTBUTION

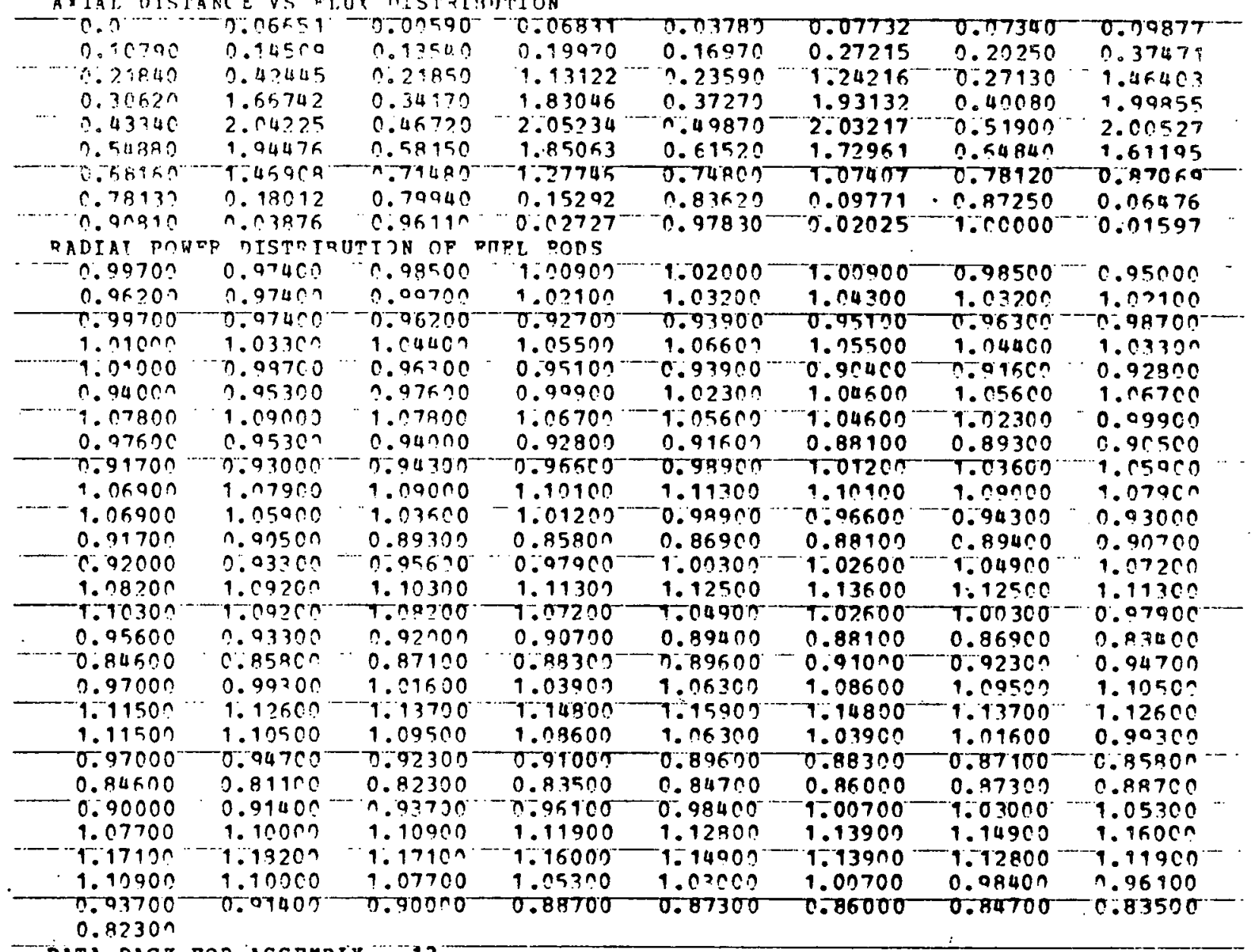

DATA PACR POP ASSDMELY

TYPS CD ASSTMBLY=

"PCDODIA. HIDD DIA. IRAT

0.05600 11.90000

0.28791

LATS

4. 33500 TERTR 64.35400

TIET TH. GAP'TH.

AVG HAT PTIX, PLOH RATESIN THE ASSEMLP AND THF GAP 190ก12.5 165355. ก 60?.0

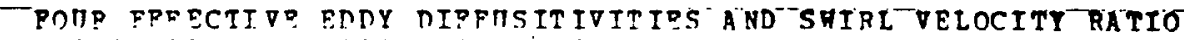
0.03000
$0.020 \mathrm{C} ?$
0.02000
0.02000
0.10003

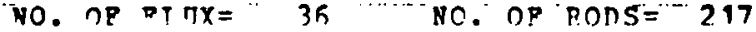

AXIAL DISTANC? VS FLIX NISTOIRITION

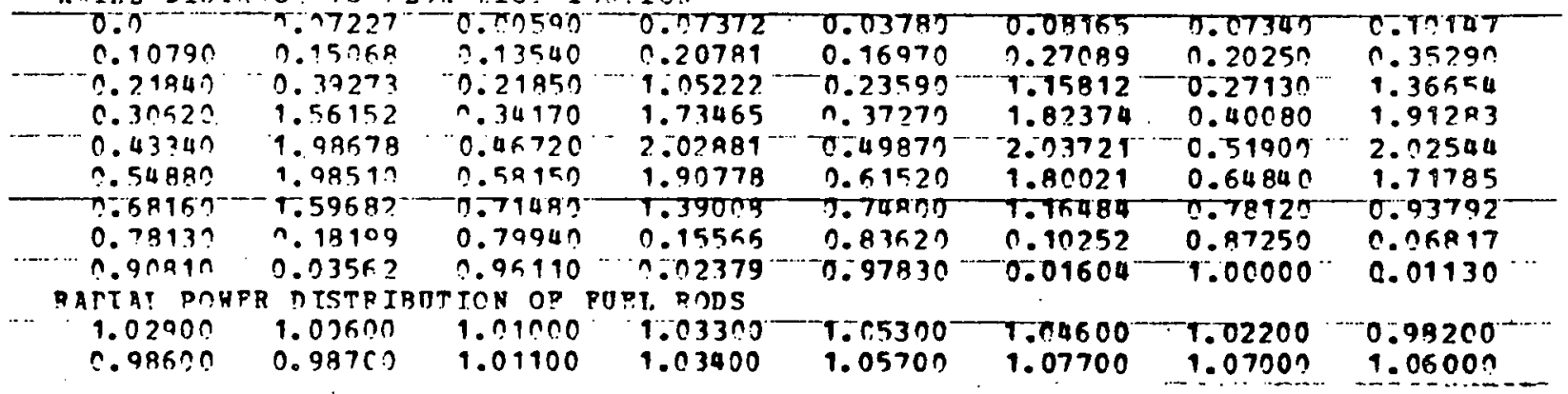




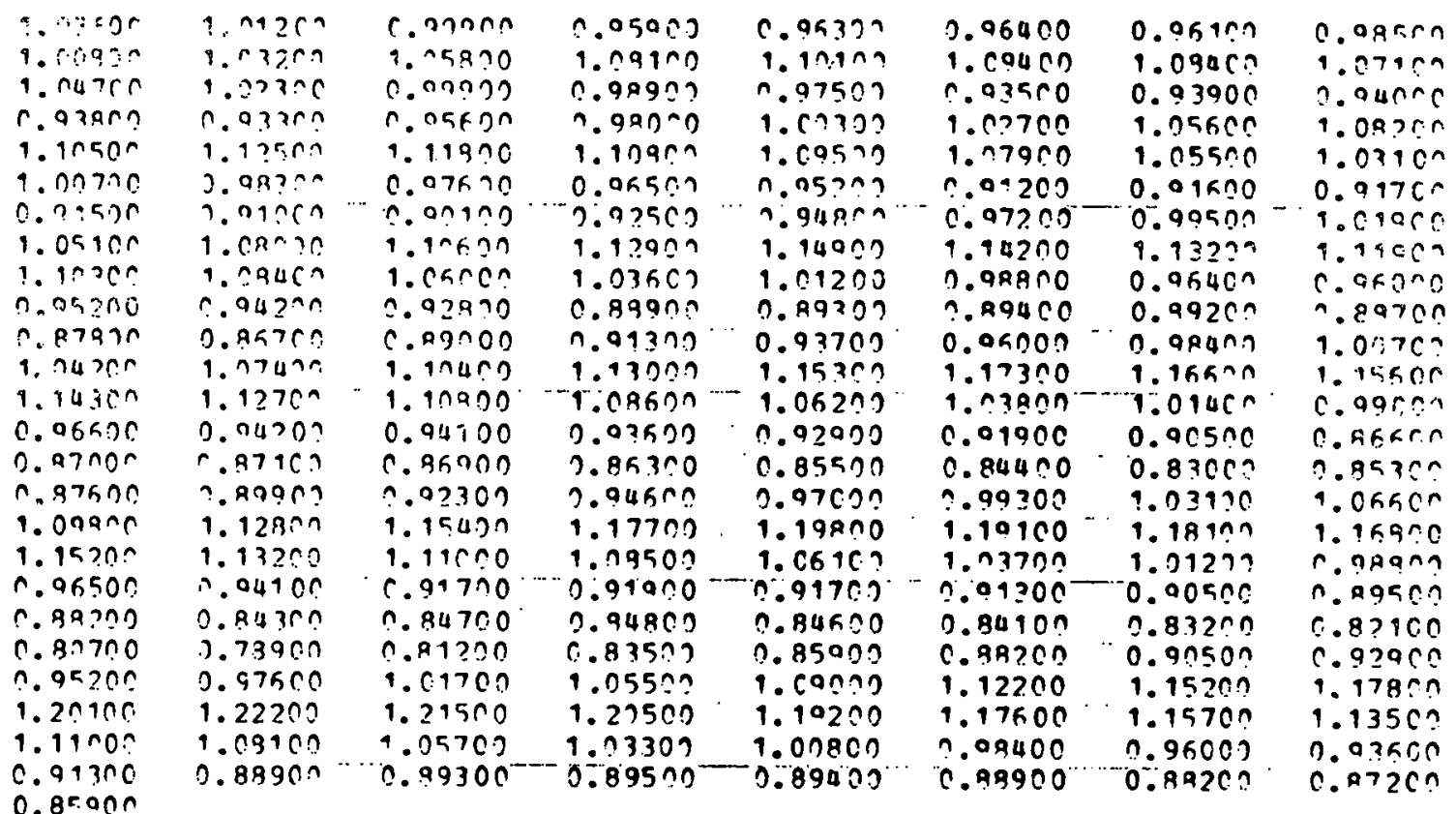

DATA PACK ECQ ASSEMRLT

TYDP, CD ASSTMBTY = ?

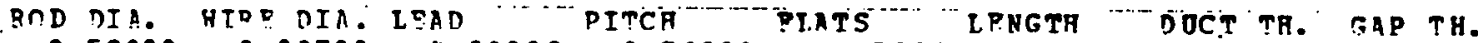

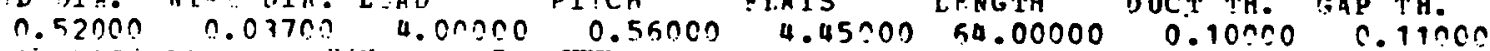

AVG YPAT FLUY, FLOW "QATES TN THEXSSTMRTY AND TRP GAD"

GA10. 53592.0 fon.n

FOUR FPPECTTY EDTP DTPEISTTIUITTES AND SHIRL VFLOCITT RATIÓ

$0.02000 \quad 0.020 r 0 \quad 0.02000 \quad 0.02000 \quad 1.00000$

No. OP PIIIX 32 NO. OF PODS= 6

AXIAL DTSTANCF VS PI.TY DTSTRTATTTON

$0.10 .12400^{-0.01900^{-1} 0.14200-0.05600}$

$0.1220 n \quad 0.31800 \quad 0.1530 n \quad 0.42500 \quad 0.1870 n$

$0.25500 \quad 1.27900 \quad 0.20000 \cdots 1.47600 \cdots 0.32600^{\circ}$

$0.38900 \quad 1.93900 \quad 0.41000 \quad 1.99209 \quad 0.45303$

$0.51700 \quad 1.01200$

0.53500

$1.85100^{\cdots-0.56800}$

0.63500

$1.524 r 3$

C. $6 \circ 90 \mathrm{0n}$

1.37900

$0.7 n ? 00$

0.76904

$0.669 c ?$

C. $8 \cap 400$

$0.0 \times 90 \%$

0.84400

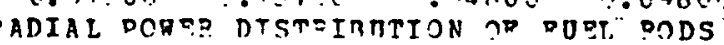

1.n.360? $0.84303 \quad 0.026 \cap 0 \quad 1.12300$

ก. 74400

- $706 c^{\circ}$

ก.98400

0.97700

0.59200

0.09200

0.3500 ?

$1.992 \mathrm{CO}$

0.48600

$1.78100^{-0.6020 ?}$

1.21000

0.7350 .2

$0.27400-0.8770$ ?

$0.07800 \quad 1.00000$

c.

0.99509

$0.093 \cap 0$

1.24300

0.07800

$0.932 n 0$

1.12900

$1.3410 ?$

1.32300

1.46200

$0.652 \cap 0$

$1.0150 \mathrm{C}$

1. $218 \mathrm{C}^{-}$

1. 3กดว

0.51003

ก. 57600

0.62400

1. 91300

$0.5570 \%$
$n .63400$

?.56500

0.42403

$0.403 n c$

n. 8430 ?

$0.834 \cap 0$

1. 02300

0.36400

$1.435 n$

$1.64 ? 70$

1.45900

1.22600

1.04909

$0.57900 \quad 0.51500 \quad 0.57500$

$0.4750 .0 \cdots .429 n 9$

1.25600 15

DATA PACK FCD ASSTMRTY

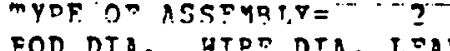

FOD DTA. WTPE DTA. T. DA PTTCH

- tats

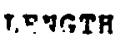

DIIC? TH. GAP TF.

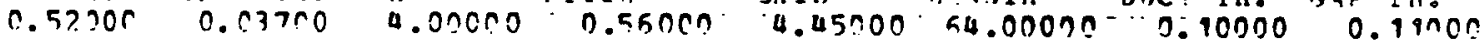

AVG HEAT PLIIY, FLרN PATES IN TIF ASSPEBLY AND THP GAD

4930.4 .8 28959.0 6?n.

POTO PPOPCTTVE EDNY DIPFISTTTVITIPS AND SRIPI VPLCCITY OATTO

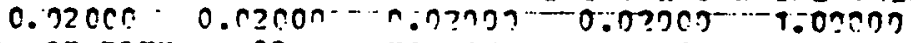

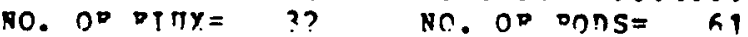

AYTAL DTSTANCE VS PLDX DTSTPISTTTON
$\because 0$
0.15900
$0.9190 n$
0.17100
$n .1530 n$
$n .29 n 00$
$0.3550 n$
$0.0550 . ?$

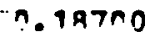
?.2550?
1.0510n

$0.3260 n$

$\begin{array}{ll}0.19900 & 0.09200 \\ 0.517 n 0 & 0.22000 \\ 1.52900 & 0.35900\end{array}$

$0.2350 n$

0.72 non

1.3270 月

1.6670n

?. $2300 \mathrm{con}$ . 9nвor

1.06500

1.66200

$0.9900 n$

c. 19500

0.67100

1. 19700

.8270 ?

ค. 46700

$1.525 \mathrm{nr}$

0.9570 ? 


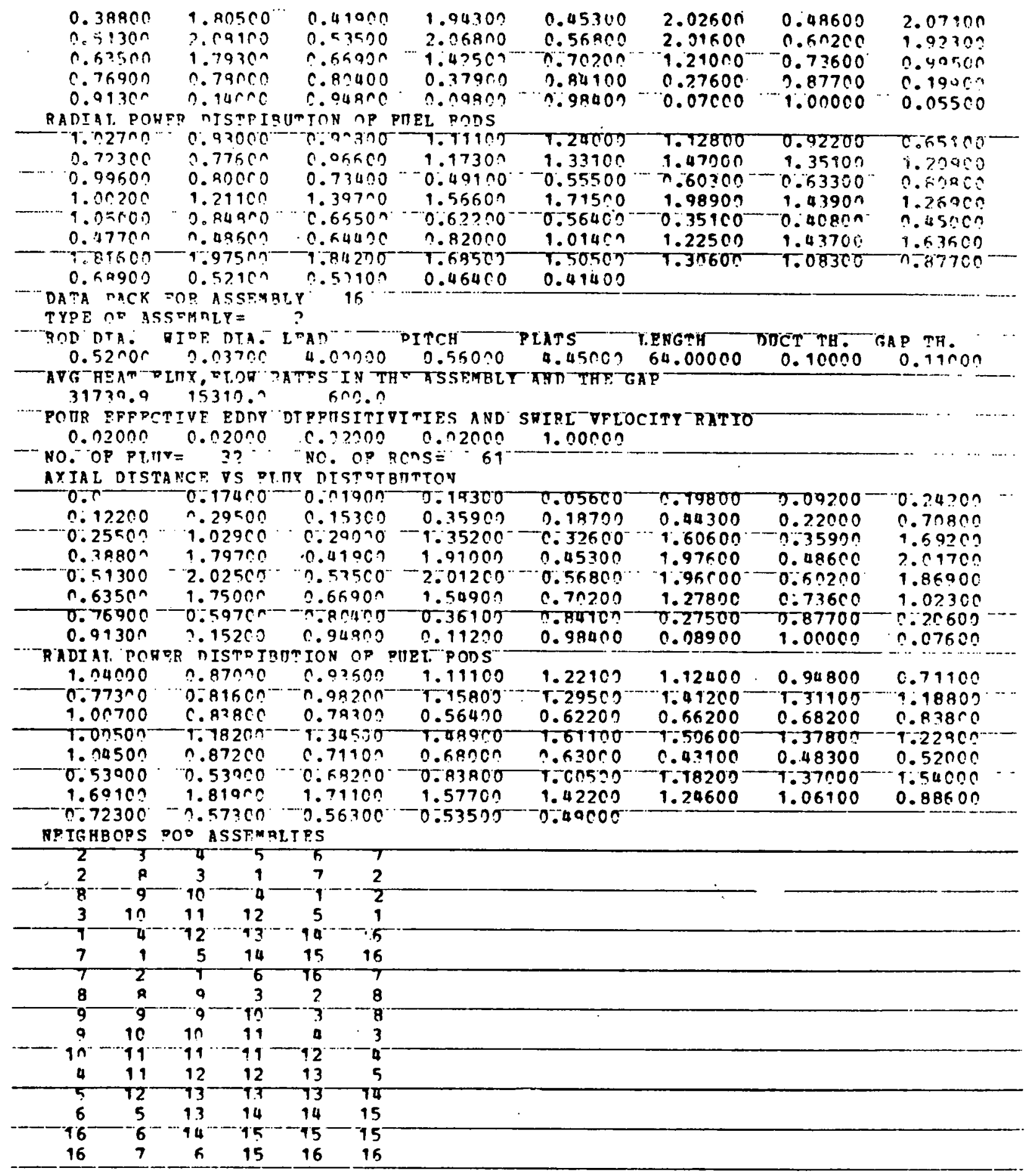




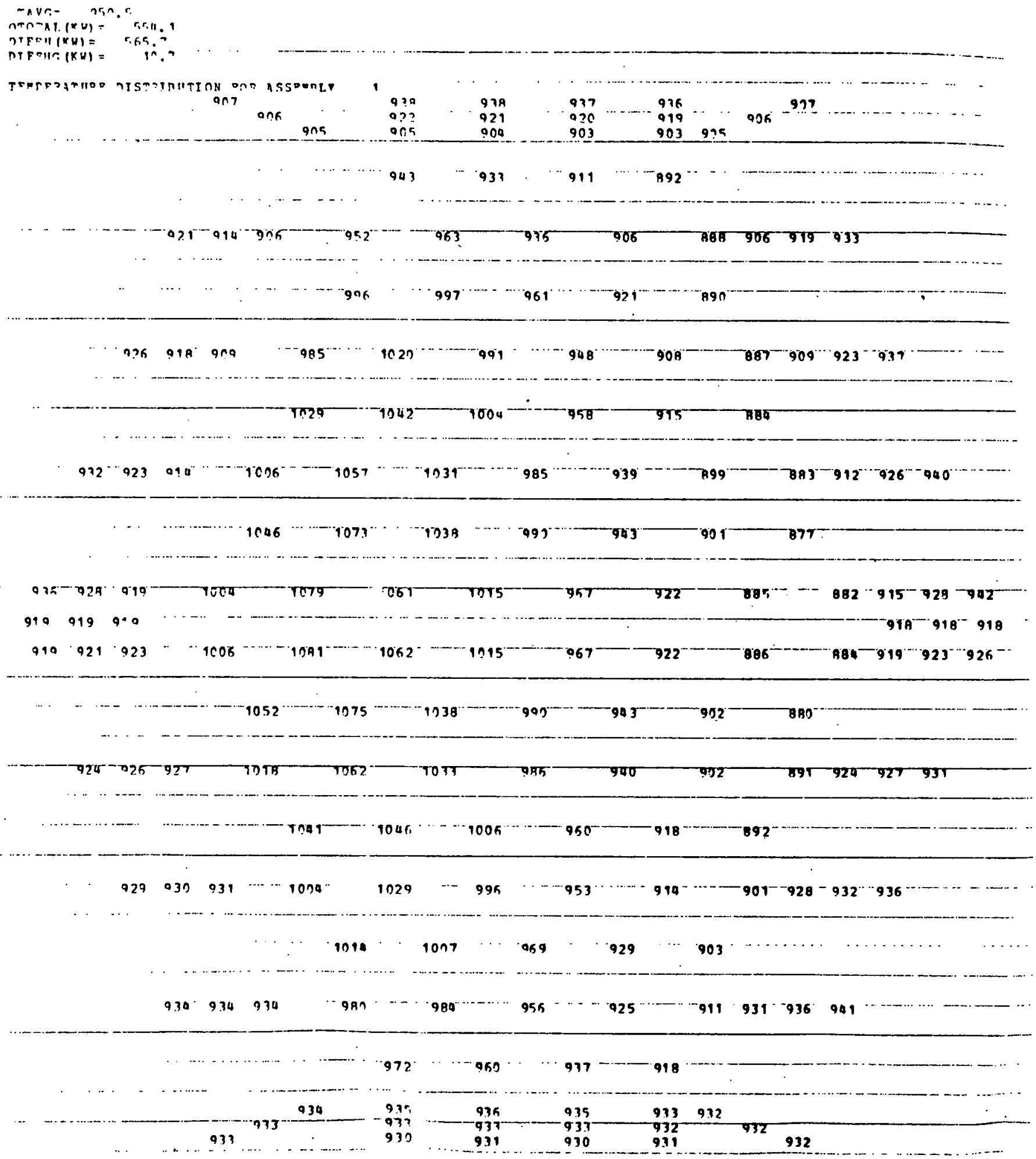

$\cdot$


THUS: $=1027.7$

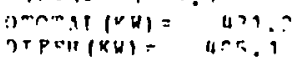

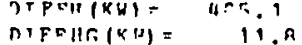

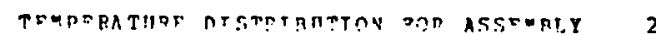

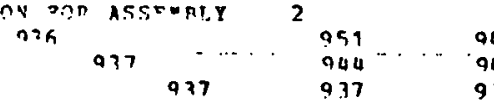

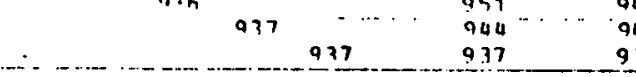

1006

999

$\begin{array}{r}946 \\ 1\end{array}-938-945$

945

970

928

940

$964-945-94 r^{-} \longrightarrow 190-1 n 24$

T5T

972

व36 व3्य 932035

$:-1087$

$9101 \cdots \cdots+1058$

$1005^{-\cdots-1 . \cdots 95}$

$95595 ? \quad 049$

$\ln 67^{-}$

$-1179$

$-\cdot 1100^{\circ}$

$\cdots \operatorname{lnak}$

$-990^{-}$

$942939^{-938^{-\cdots} 936}$

133

7167

1224

1265

T0ர5

952

$063^{\cdots} 060^{\circ} 957^{\cdots \cdots} .9095^{\cdots}$

1 ค2

$1759-1162$

$1942-$

$-983^{--1}$

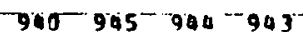

$1153^{--1209^{--}}$

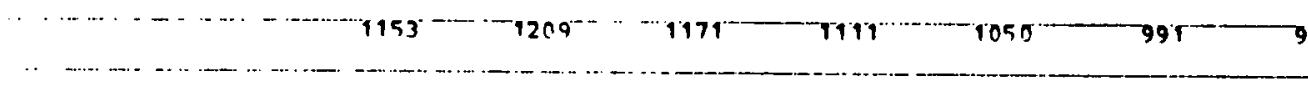

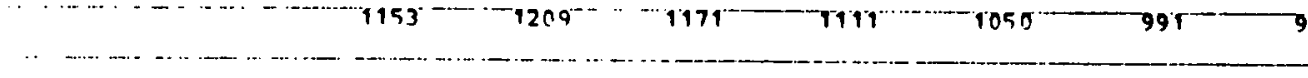

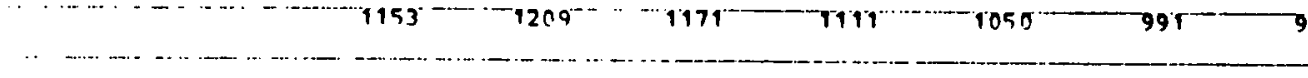

963

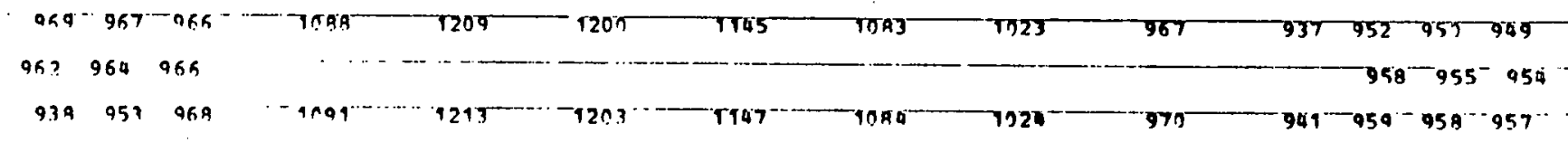

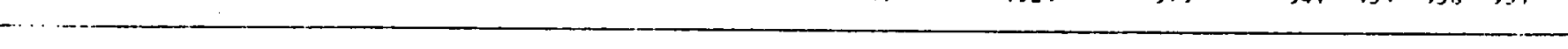

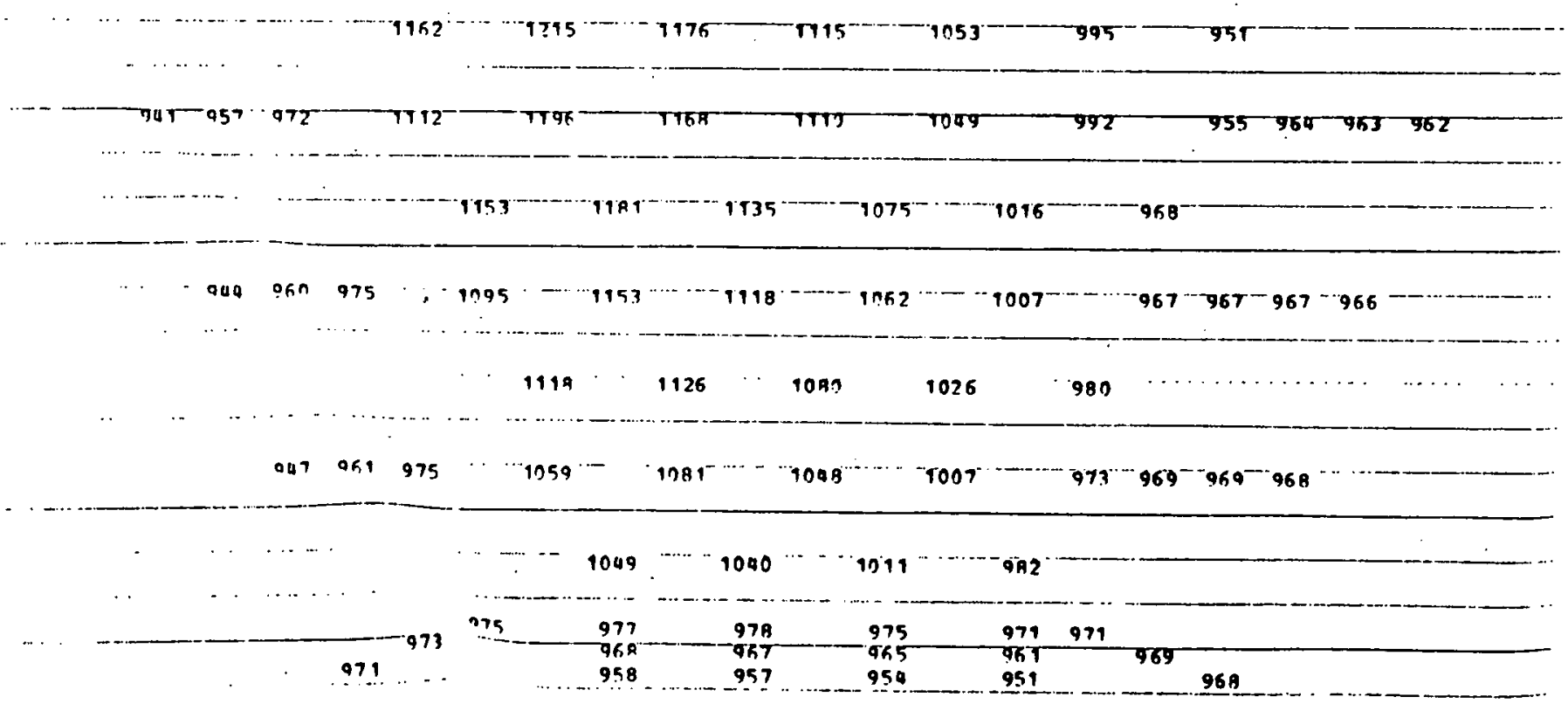

$971 \ldots$.

957

950

951

96 月 


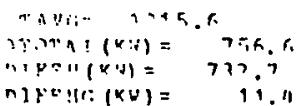

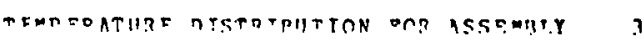

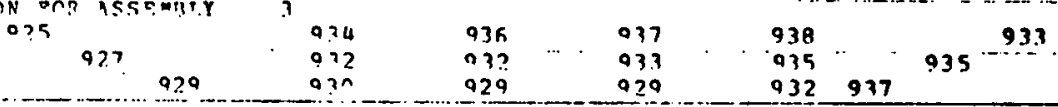

$1000^{\cdots} \cdot 990^{\cdots \cdots} \quad 950^{\circ} \cdots \cdots 39$

$913 \cdots 9.91-92 n \cdots-\cdots 1946-\cdots-1937$

$1009-956$

ब26-938 $939-940$

$1085^{\cdots} \cdots 1.92$

1009

983

934

$\ldots \ldots$

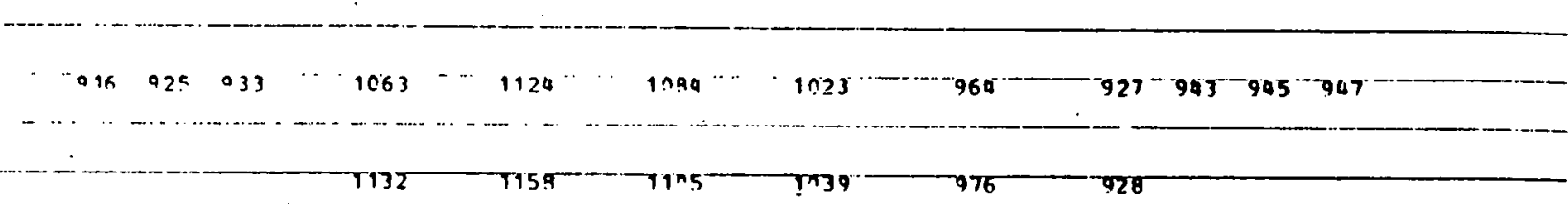

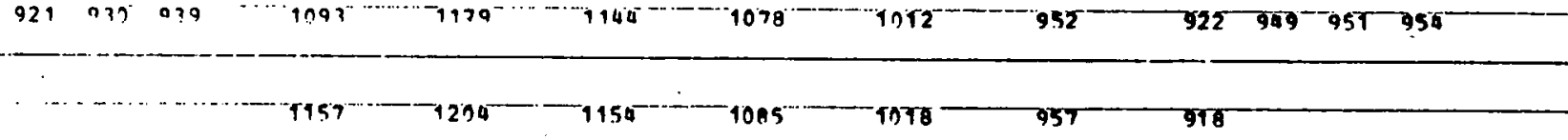

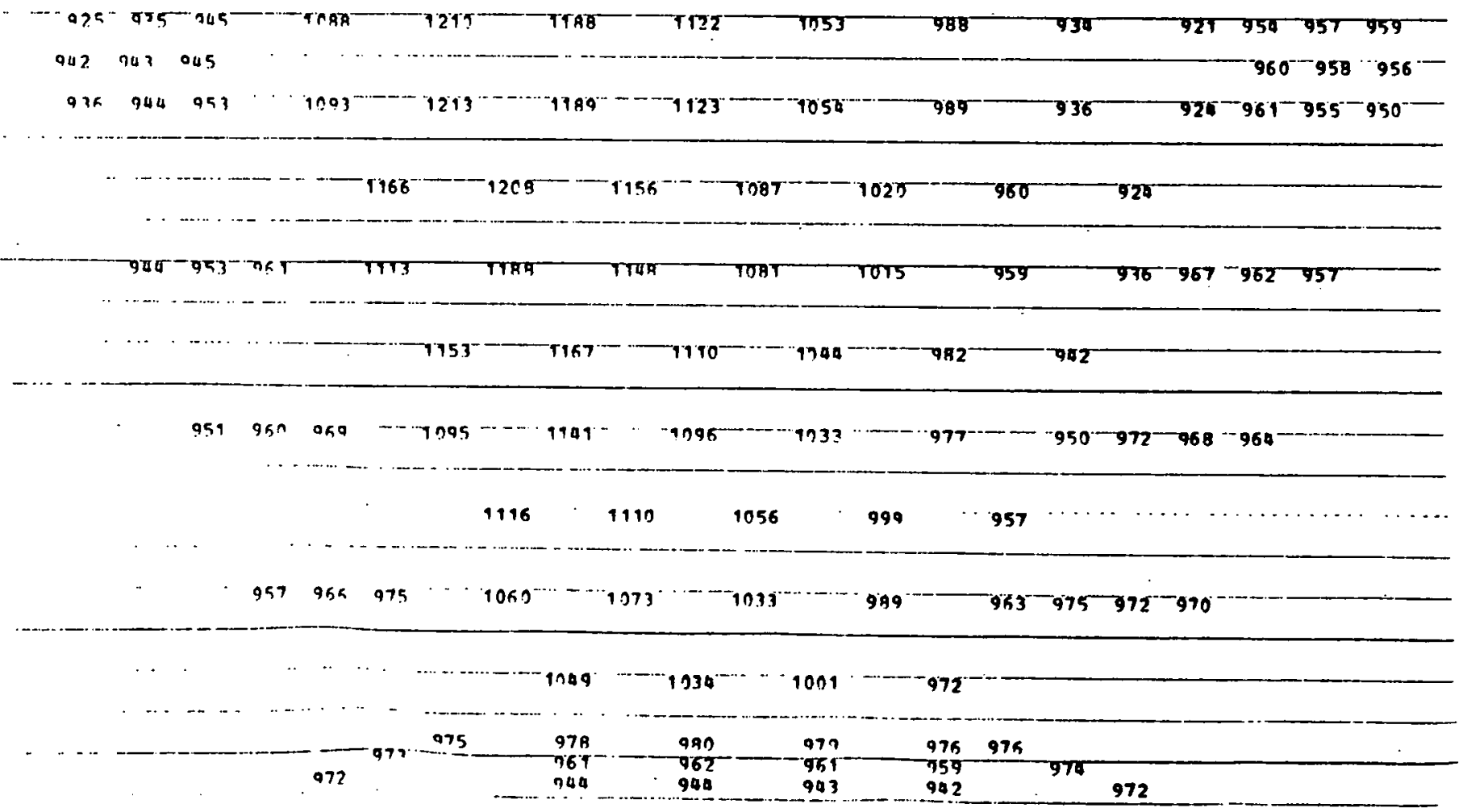




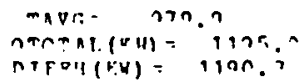

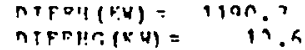

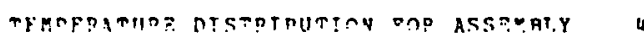

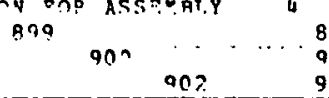

$8 n 9$
$\operatorname{ang}$
$9 n 2$

$9 \times 2$

$952 \ldots . \cdots 92$

926

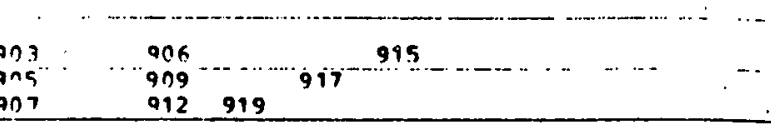

... ... . . . .......

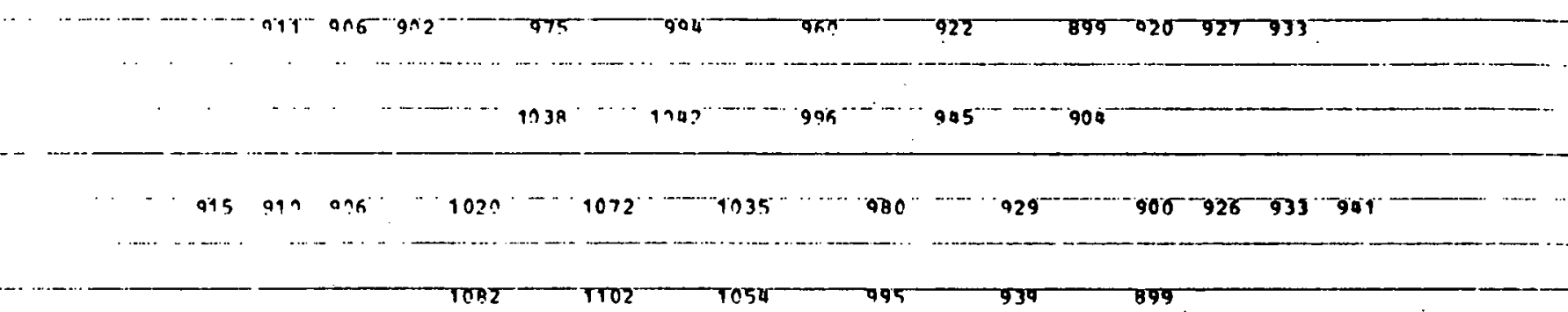

98

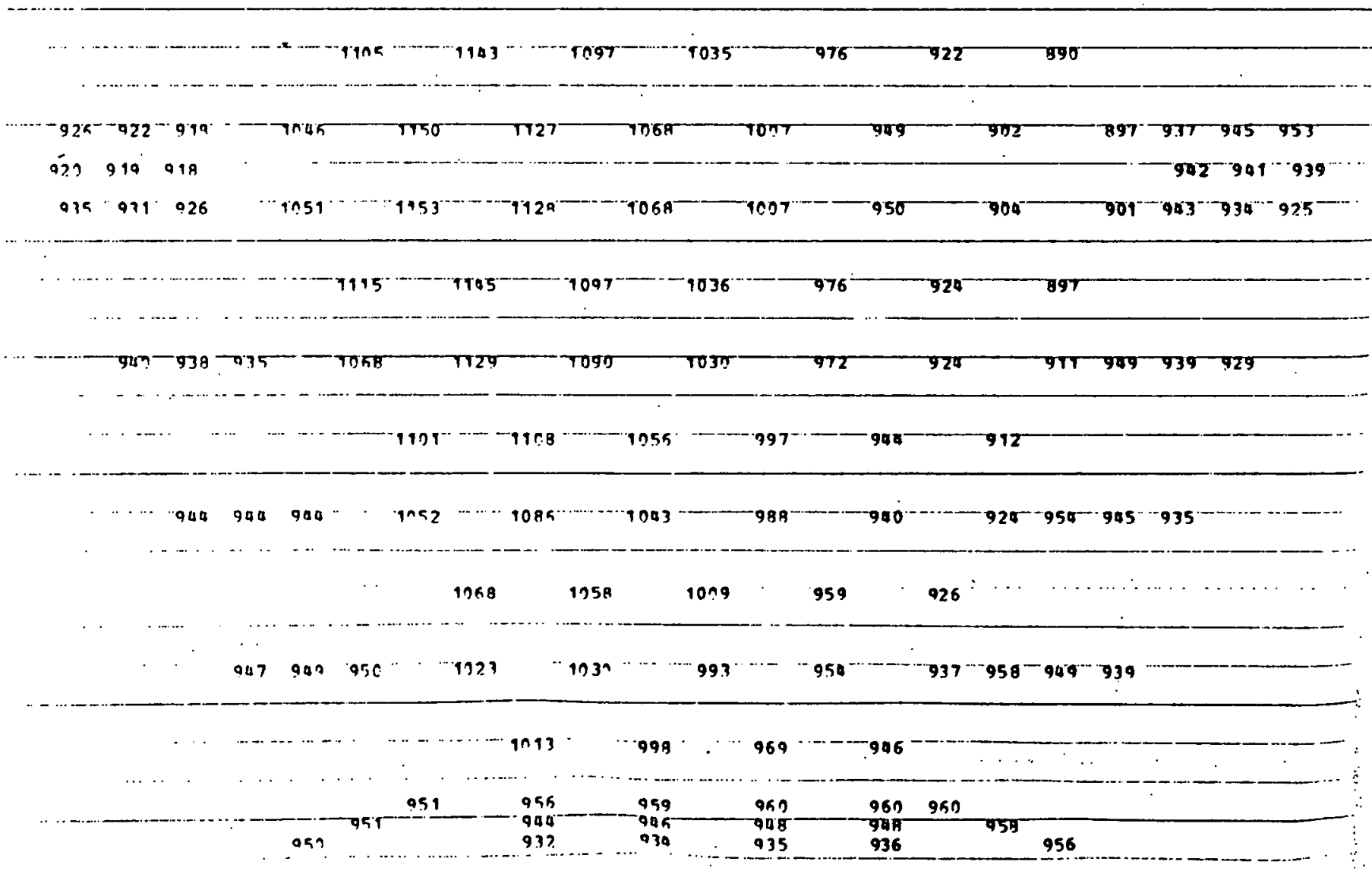


mat- nan.

nThili $(x)=$ ins

$n+F) \|(k)=1101.6$

nTPPHr: $(K H)=$ in.

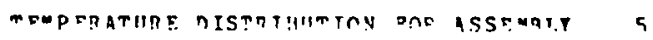

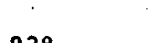

905

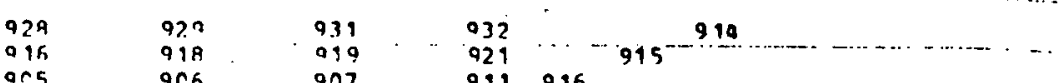

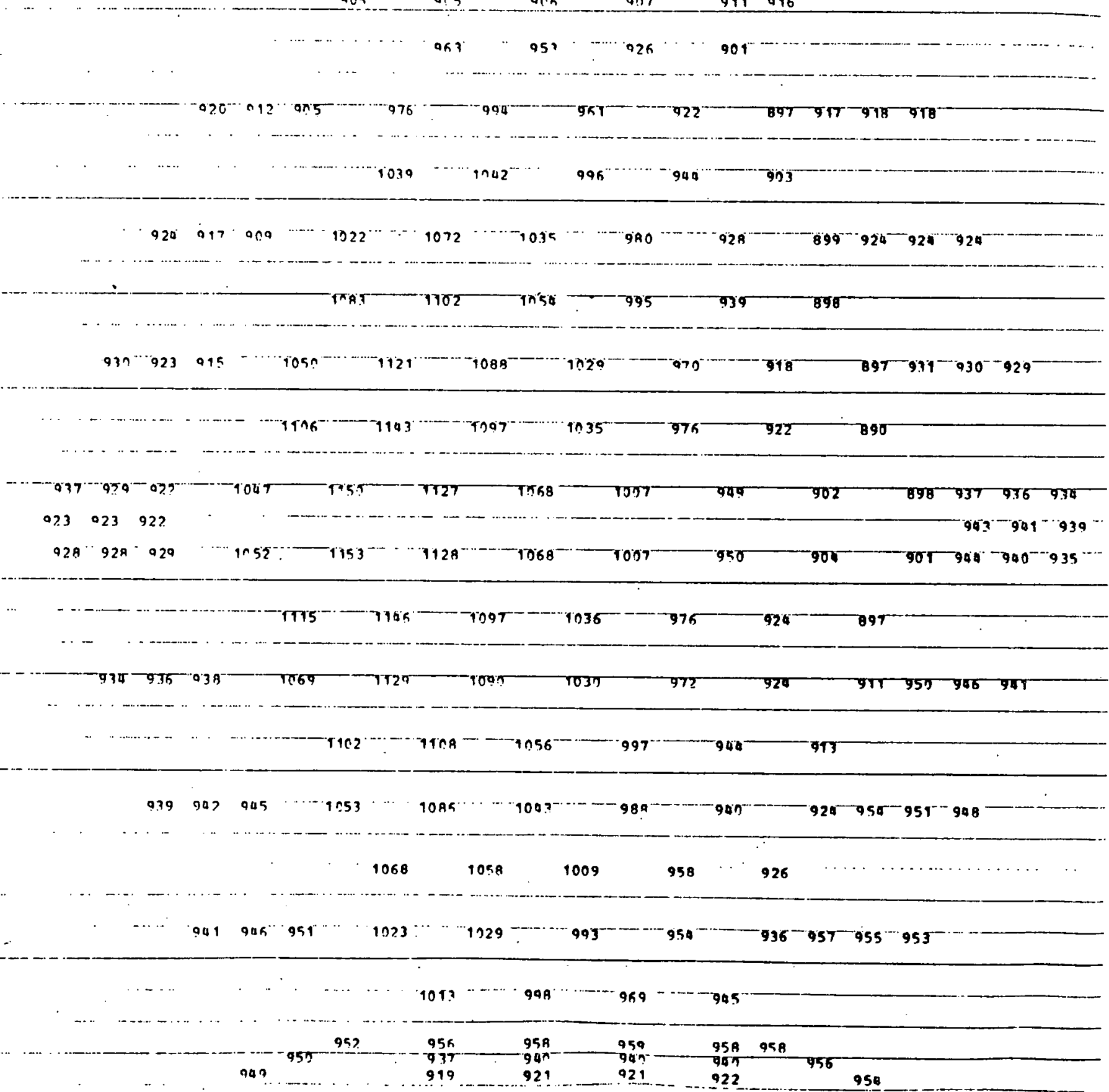

919

$921 \quad 921-922$ 
Thuti

JTrTAT (KN) = Tr,i.h

nifDil(kस)

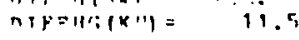

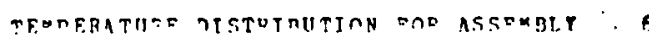

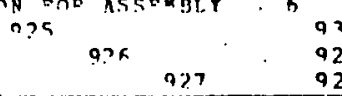

920

92

928

988

\begin{tabular}{rrrr}
030 & 929 & & 934 \\
929 & 939 & 9 & 935 \\
929 & 932 & 939 \\
\hline
\end{tabular}

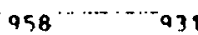

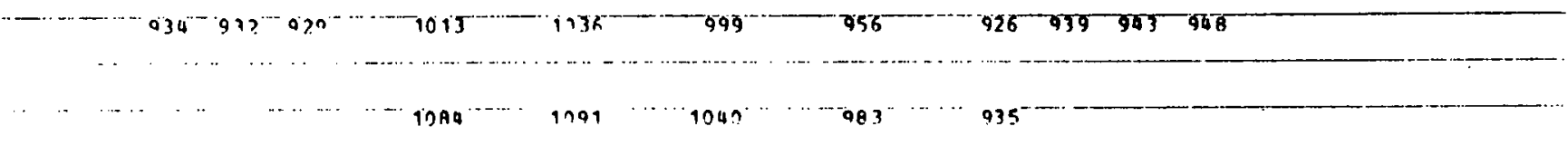

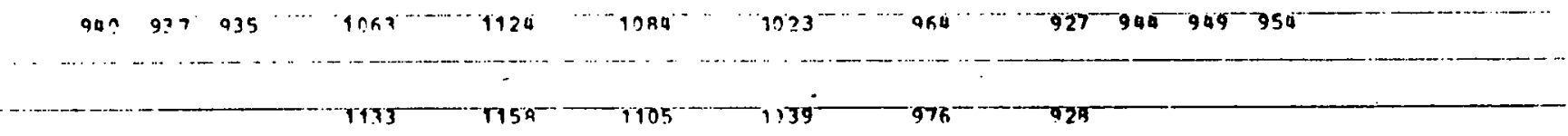

$-1-1-1-1$.

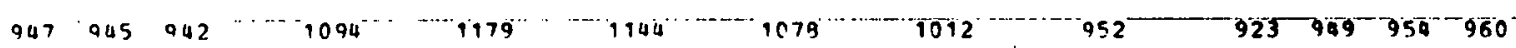

..

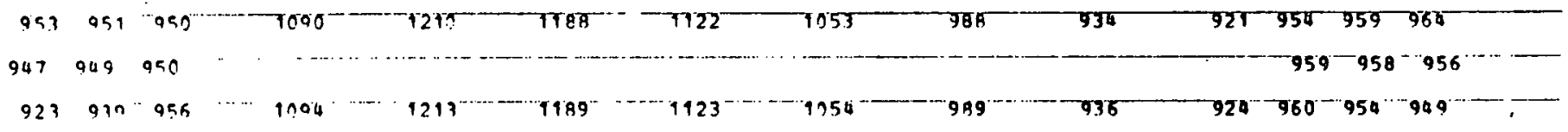

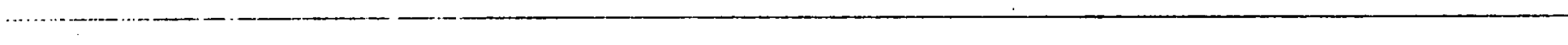

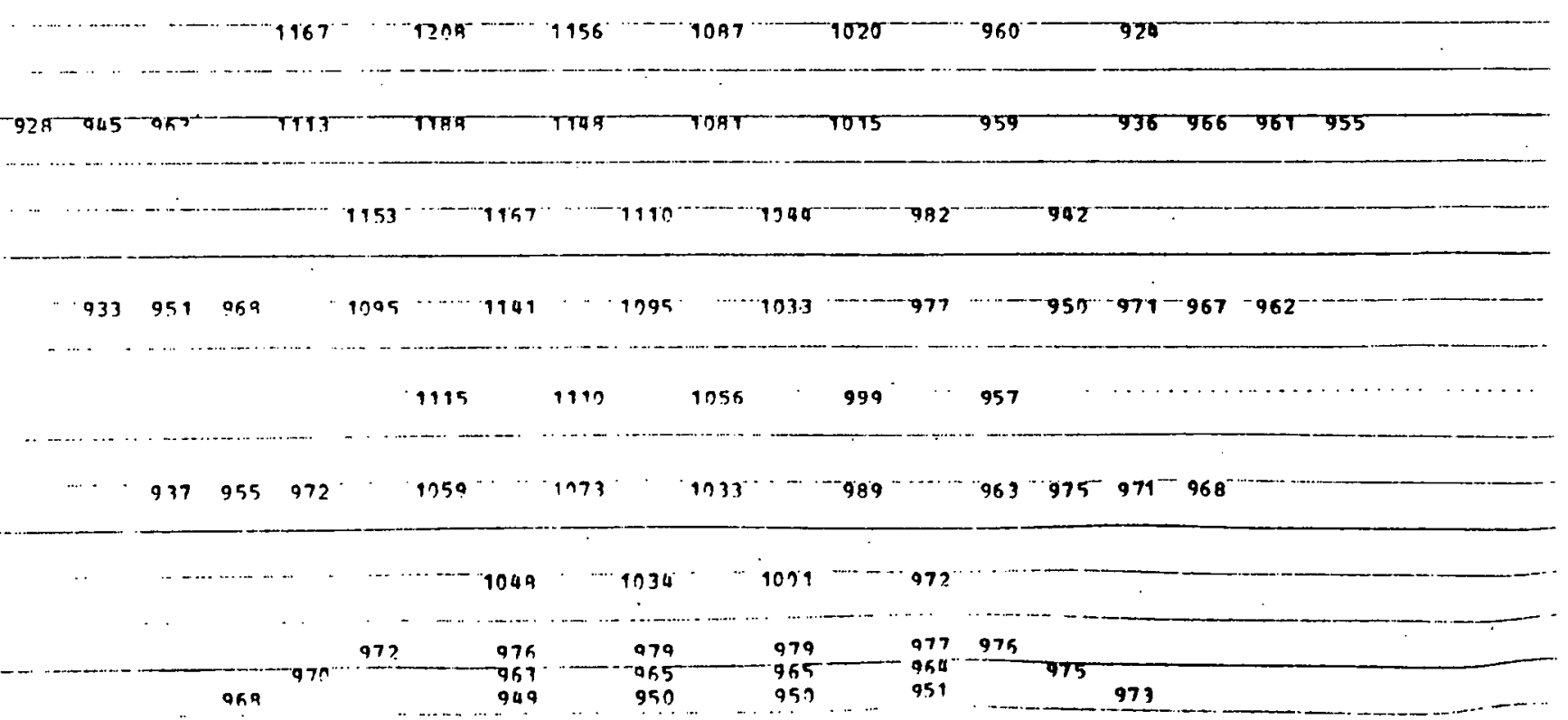




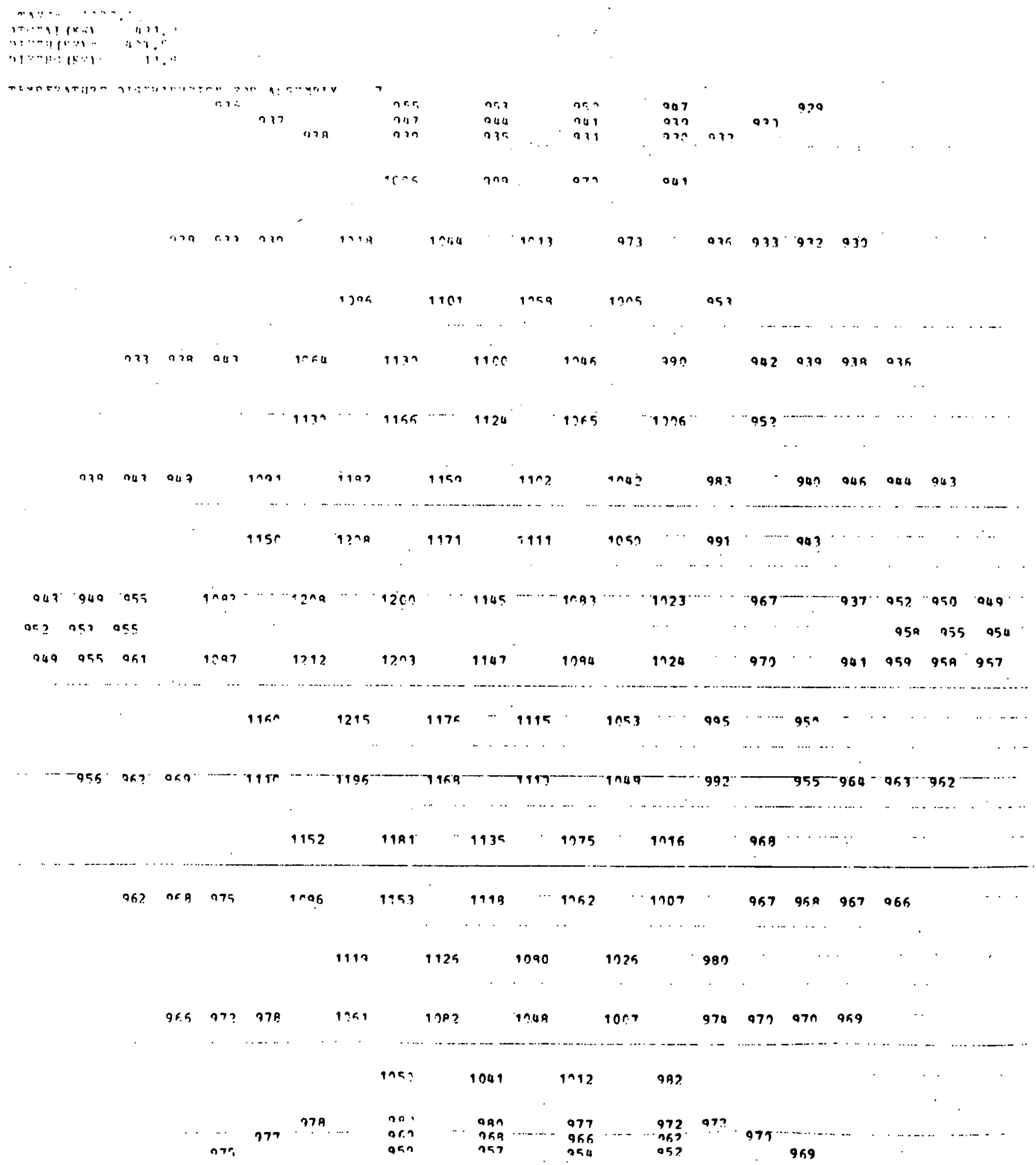


and 12.1

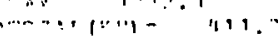

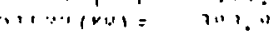

$-1:-11:\left(F^{(1)}\right)=11.1$

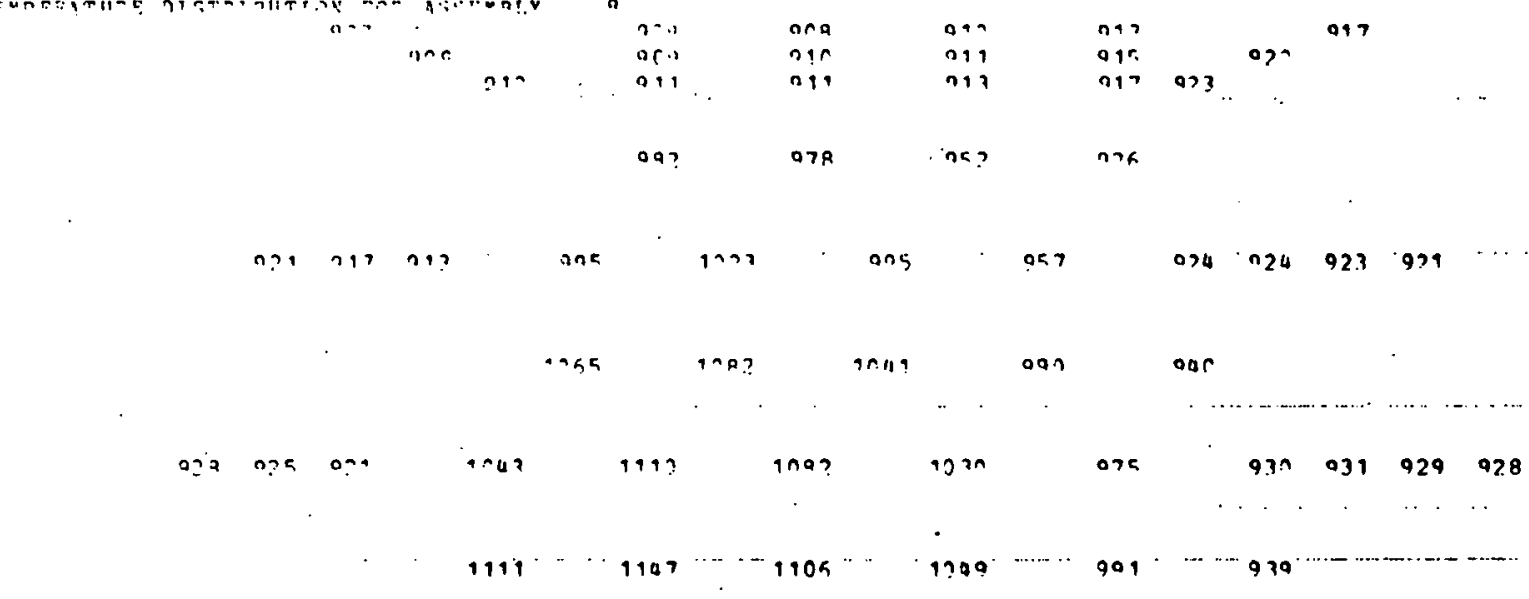

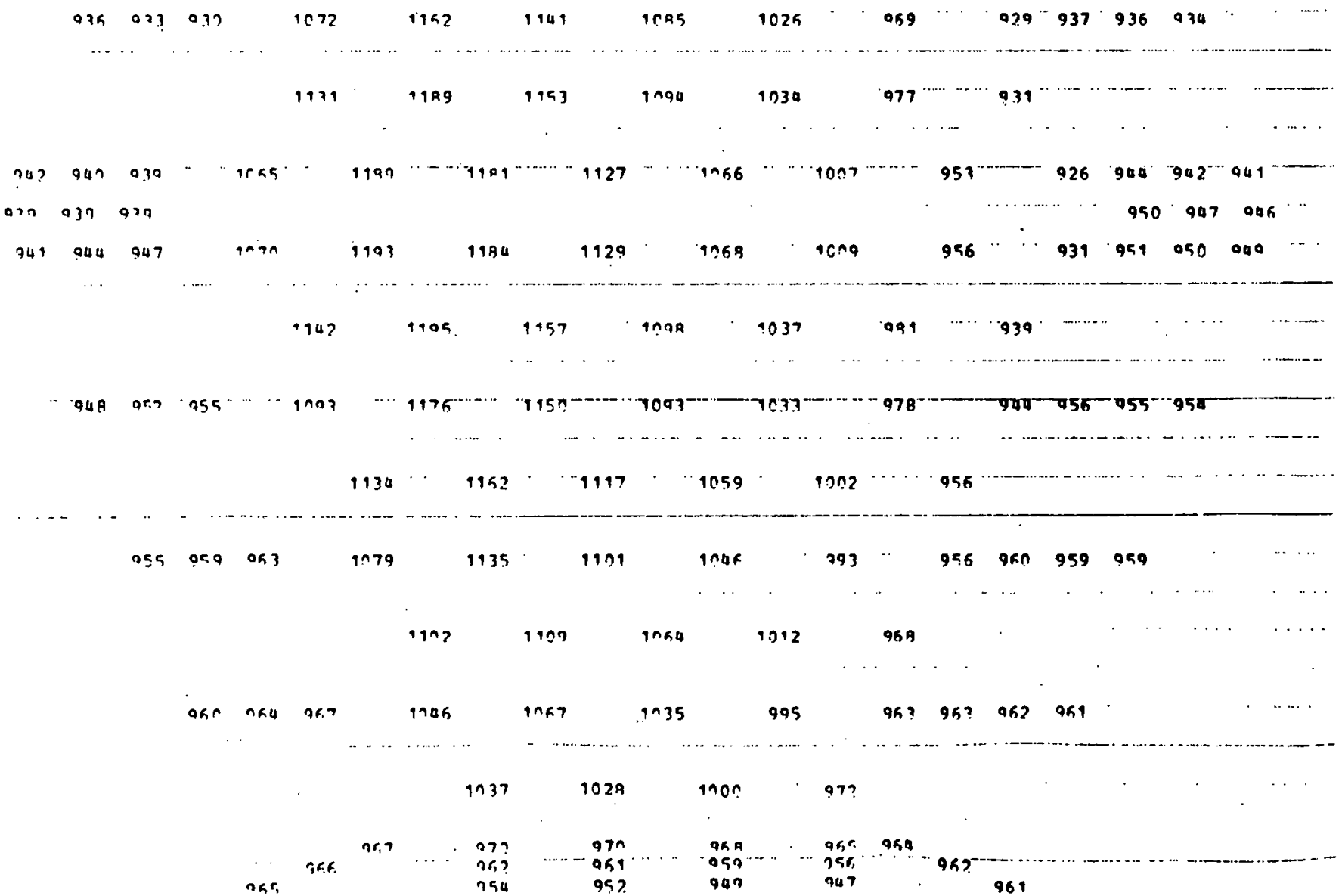




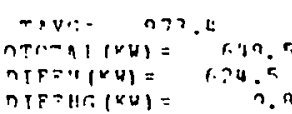

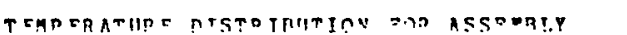

Q94 RAF
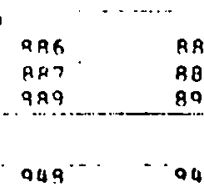

ค89

809

896

$941^{\circ} \because 946^{\cdots \cdots} \quad 994^{-}$

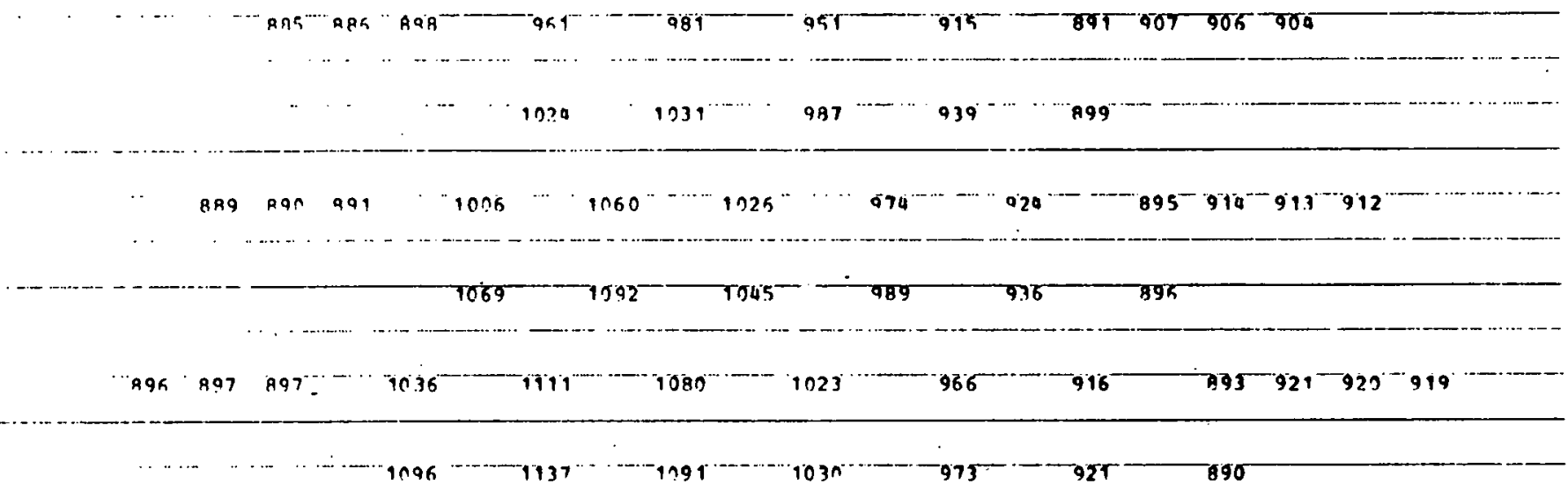

........

-.... .

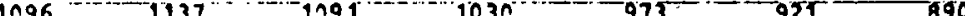

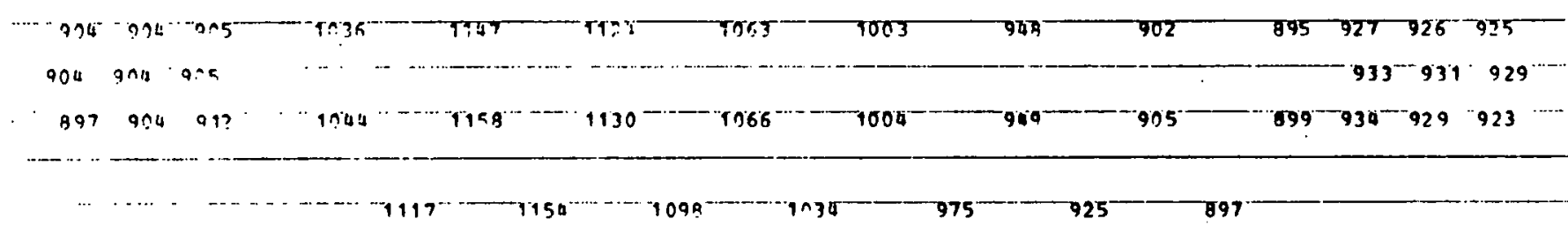

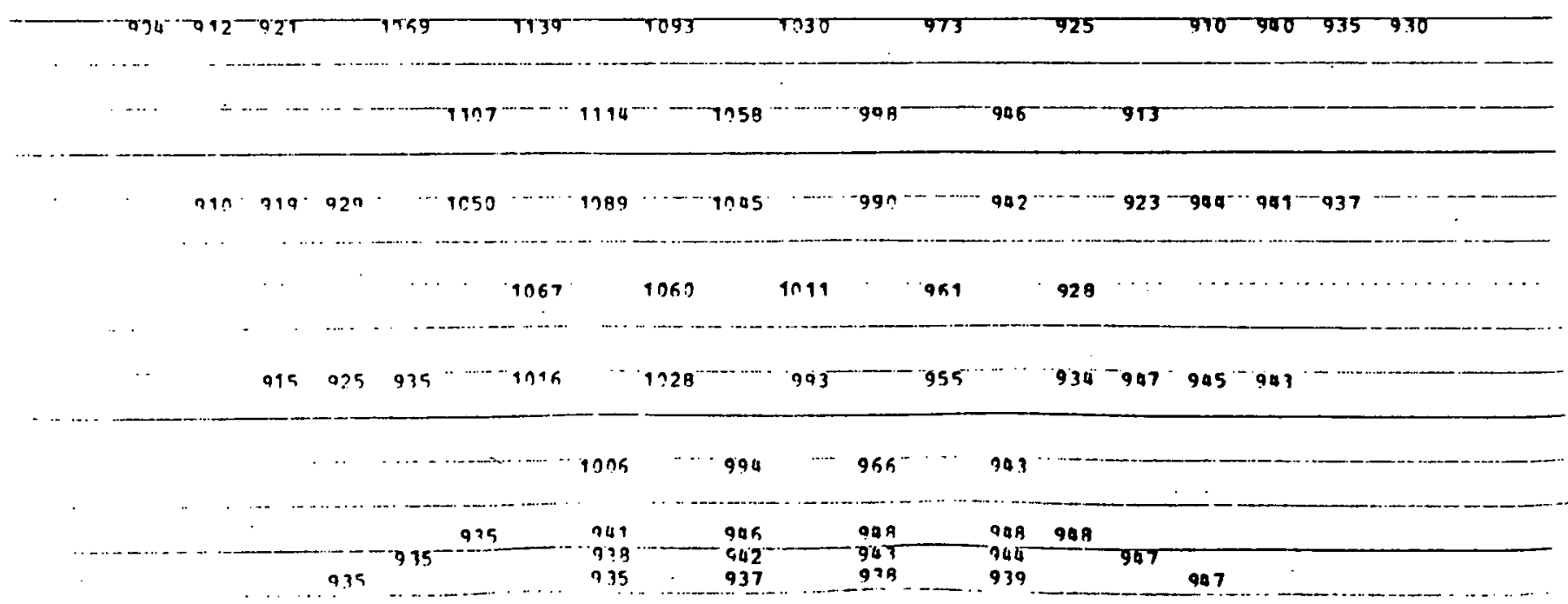


TAQR:= $n$ in.

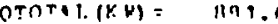

nIFण I $(K H)=$ Ba?.:

nTFOll, (ru) = a.a

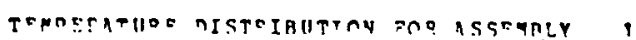

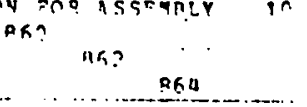

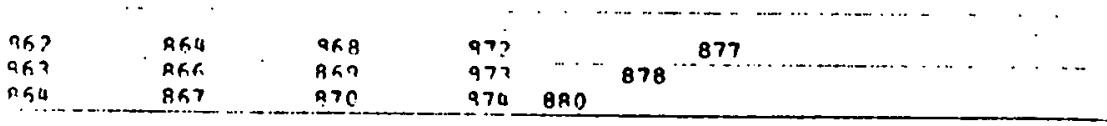

non $\cdots$ A95 B78 $\cdots$ "म63 -

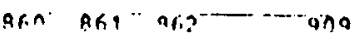

$123-7.90$

975

$861-880 \quad 847-896$

952

956

925

890

863

AR2 AF 3 R64

$977 \cdots \quad \cdots 952$

$974-\cdots 29$

$862^{835} 895^{-009}$

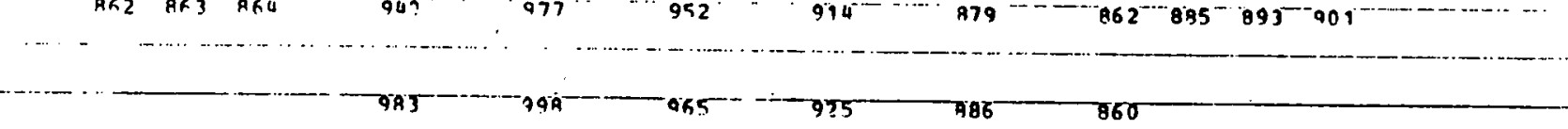

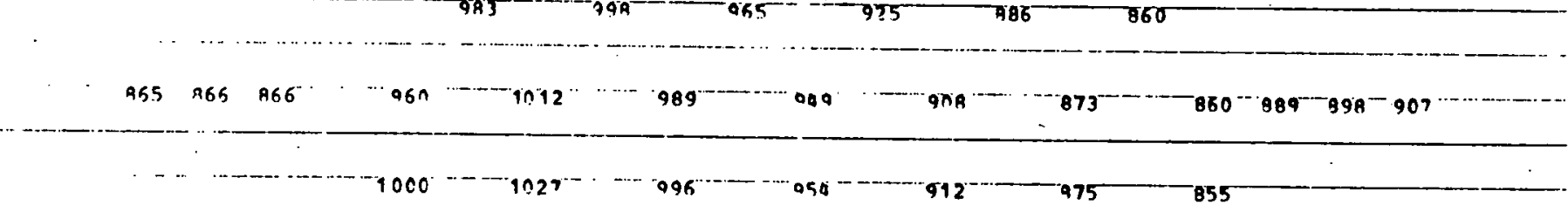

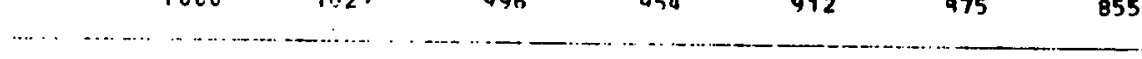

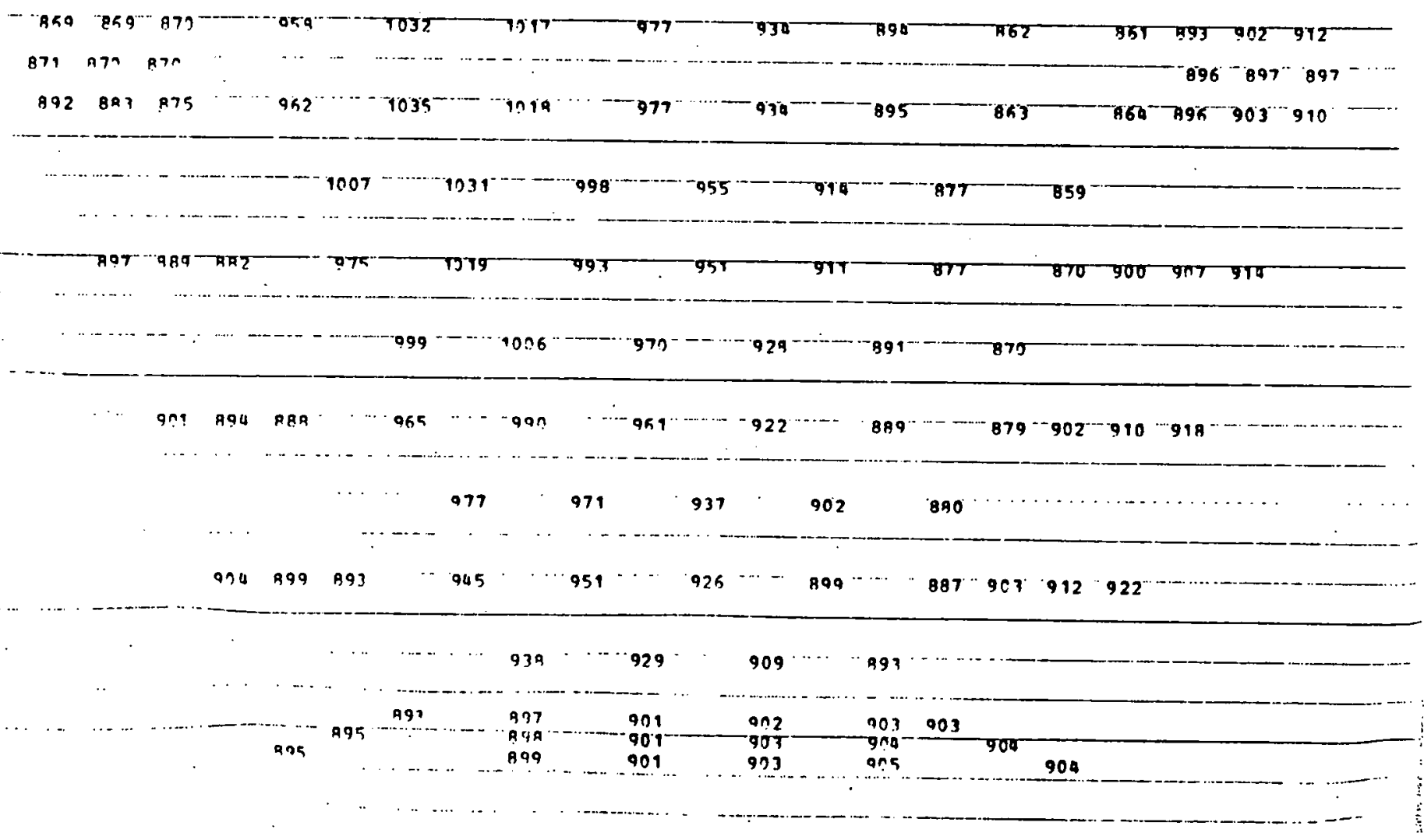




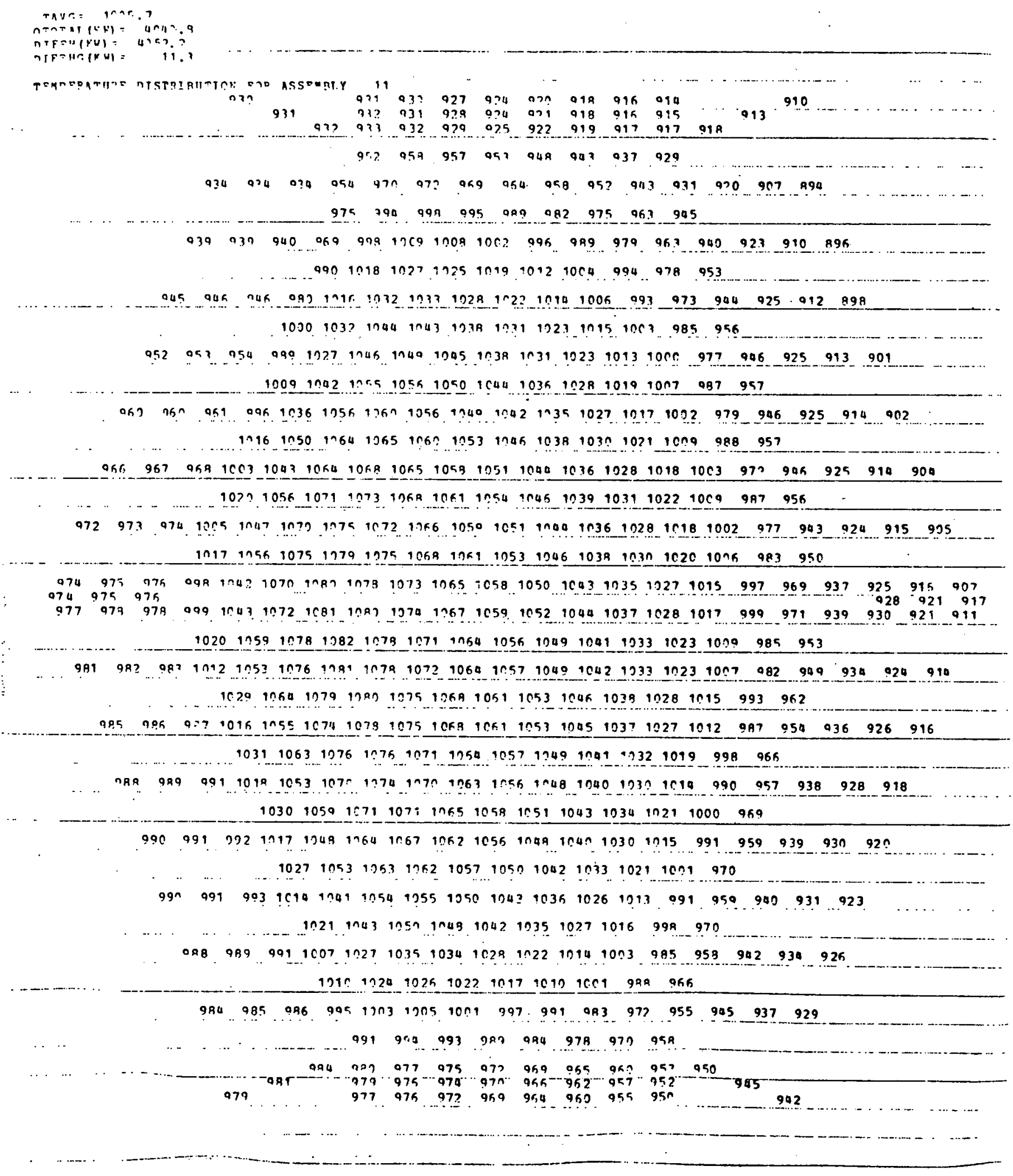




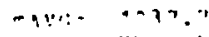

Tाली1.1021:

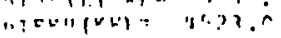

nTHHr: $(k \omega)=12.7$

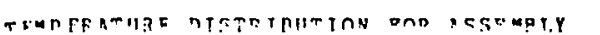

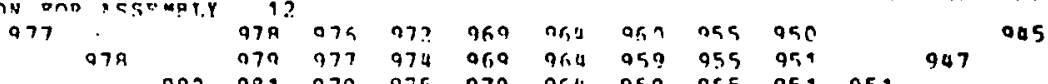

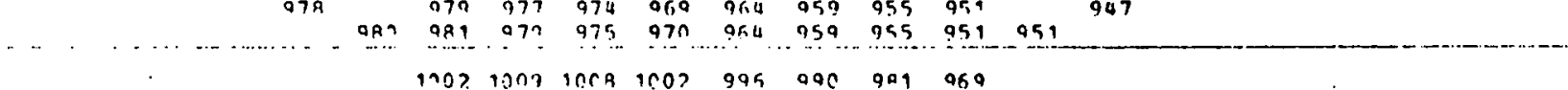

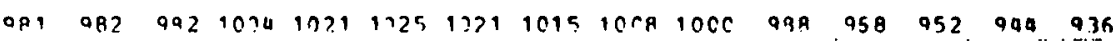

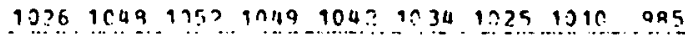

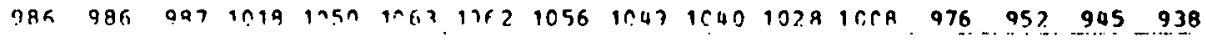

$$
\begin{aligned}
& 1038 \quad 1350 \quad 1079 \quad 1079 \quad 1071 \quad 1054 \quad 1055 \quad 1043 \quad 1022 \quad 989
\end{aligned}
$$

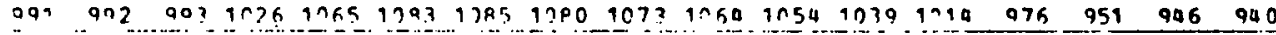

$$
\begin{aligned}
& \text { 1045 1079 1002 1992 1986 1079 1070.1061 1947 1r20 } 988
\end{aligned}
$$

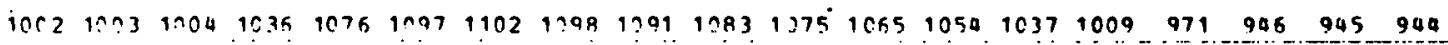

1953 Inge $1103119419901991 \quad 108310751066195610411017982$

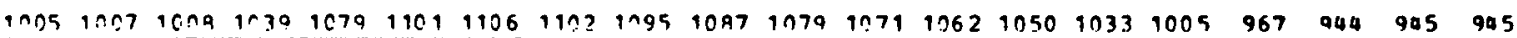

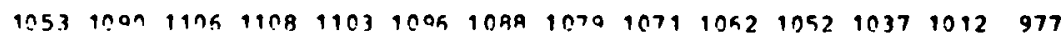

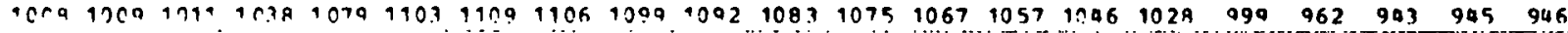

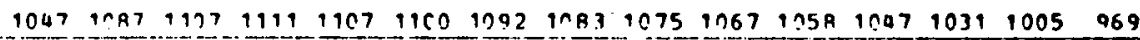

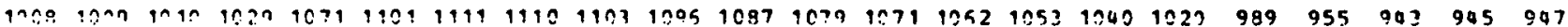

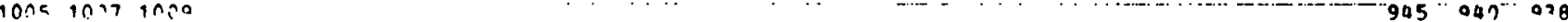

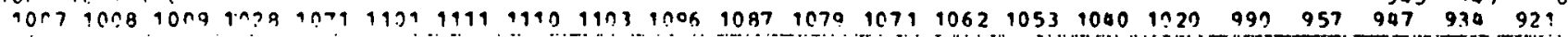

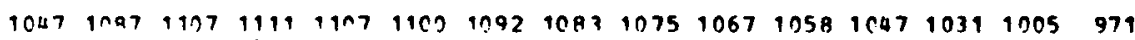

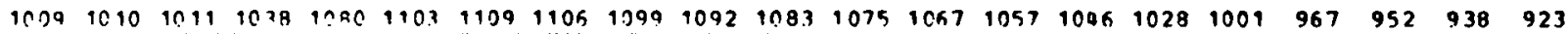

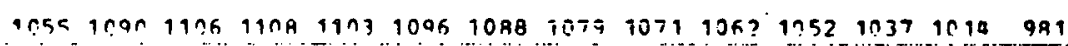

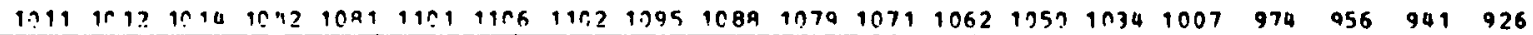

$1956 \quad 1999 \quad 1193 \quad 1194 \quad 1999^{\circ} 1991 \quad 1997 \quad 1075 \quad 1066 \quad 105619421019986$

$1913191410961942 \quad 10791099 \quad 1102 \quad 1098 \quad 1991 \quad 1093 \quad 1075 \quad 1066 \quad 1054 \quad 1039 \quad 1012 \quad 977 \quad 958 \quad 943 \quad 920$

$105490851799110 ? 109410871078107010601945102399 ?$

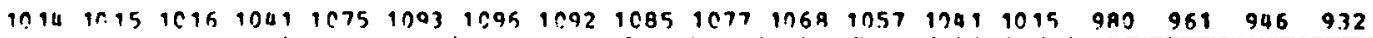

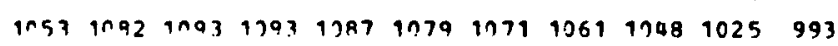

$101310151316 \quad 1 \times 3919791095199510811074106510551041016983963949935$

104A 1973 InB1 $1979 \quad 1073 \quad 1065 \quad 1956 \quad 1044 \quad 1025 \quad 994$

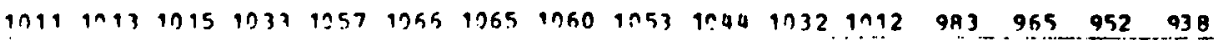

$1937 \quad 10.53 \quad 1957 \quad 1053 \quad 1047 \quad 10491031 \quad 1016 \quad 992$

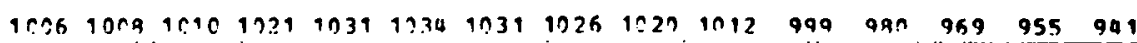

$\begin{array}{llllll}1997 & 1021 & 1920 \quad 1097 \quad 1012 & 1906 \quad 997 \quad 984\end{array}$

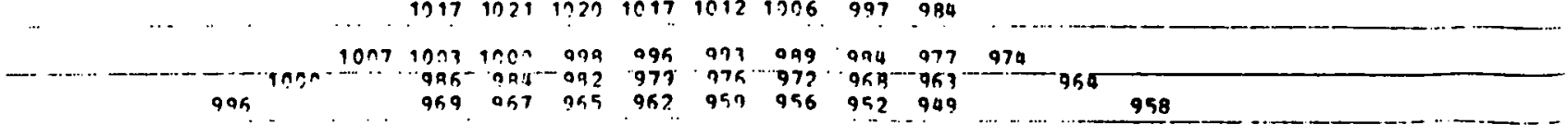


Tavi- 1 Tr.

ก⿻上丨)

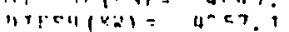

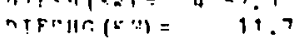

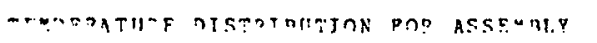

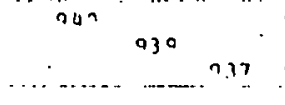

17
965 o.
945 of

$\begin{array}{lllll}0.9 & 95 & 05 & 049 & 345\end{array}$

936 97 972927 424 9?2 92

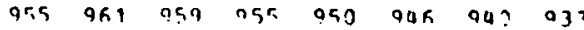

0? ด 0?

$$
9 \% 9965960 \quad 954 \quad 946 \quad 934 \quad 925 \quad 926 \quad 926
$$

$976 \quad 999$ nan a95 09? 989 076 $964 \quad 947$

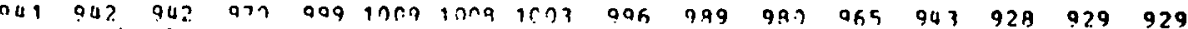

$901 \quad 1018 \quad 1027 \quad 1025 \quad 1197 \quad 1012 \quad 1304 \quad 995 \quad 979 \quad 055$

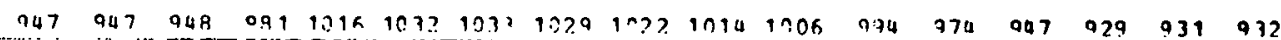

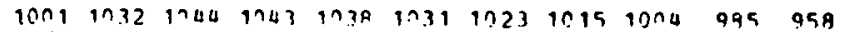

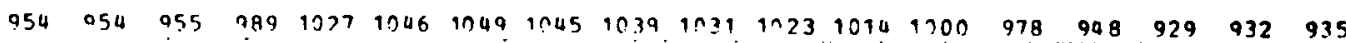

$1009 \quad 10421055 \quad 1056 \quad 1050 \quad 1044 \quad 1036 \quad 1928^{\circ} 1020 \quad 19 n 7 \quad 998 \quad 059$

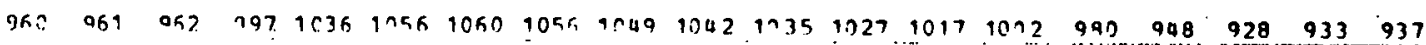

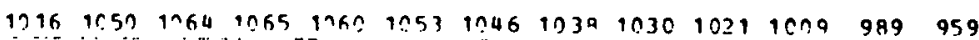

$967 \quad 969 \quad 069 \quad 9093 \quad 1043 \quad 1064 \quad 1968 \quad 1065 \quad 1958 \quad 1051 \quad 1044 \quad 1136 \quad 1029 \quad 1018 \quad 1053 \quad 979 \quad 947 \quad 927 \quad 933 \quad 939$

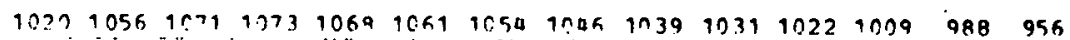

$977.97 ? .974 \quad 1075,1947 \quad 1070 \quad 1375 \quad 1072 \quad 1066 \quad 1159 \quad 1094 \quad 1344 \quad 1036 \quad 1928 \quad 1098 \quad 1002 \quad 977 \quad 948 \quad 925 \quad 932 \quad 939$

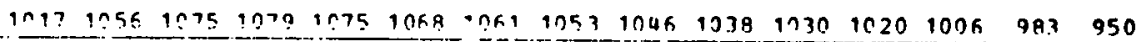

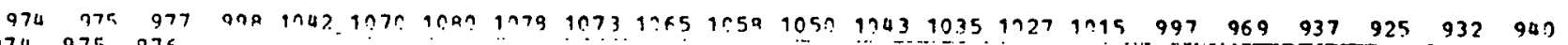

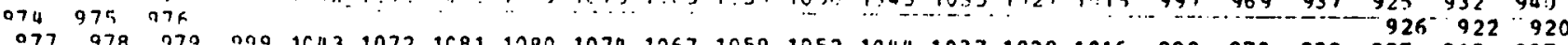

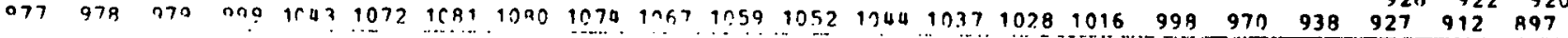

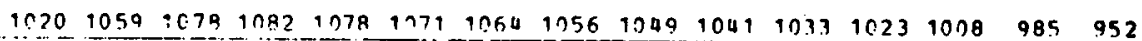

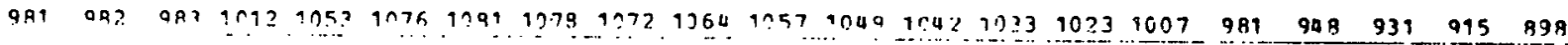

$1029 \quad 054 \quad 1079 \quad 109 ? 1075 \quad 1059 \quad 10691053 \quad 1046 \quad 10391028 \quad 1015 \quad 993 \quad 961$

$999 \quad 995 \quad 987 \quad 1016 \quad 1555 \quad 1974 \quad 1078 \quad 1075 \quad 1068 \quad 1051 \quad 1053 \quad 1045 \quad 1037 \quad 1027 \quad 1019 \quad 985 \quad 953 \quad 933 \quad 916 \quad 899$

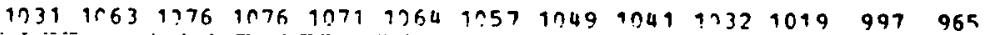

$089990991 \quad 1018 \quad 15531070 \quad 1074 \quad 1970 \quad 1063 \quad 1056 \quad 1048 \quad 1840 \quad 1230 \quad 10149999559959918900$

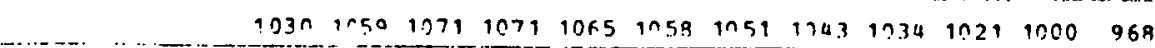

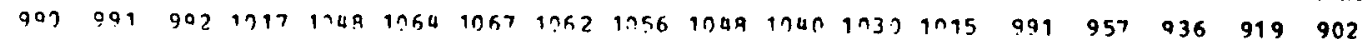

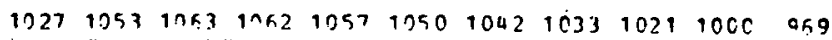

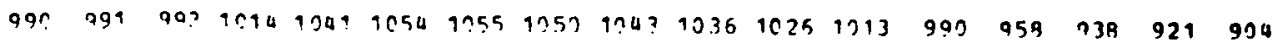

10211243 in $1949 \quad 194210351027$ 1915 997 968

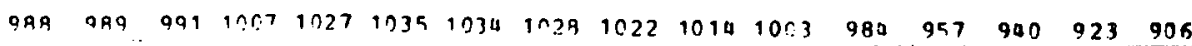

191? 19?3 1925. 102? 1916 1010 19!9 947 065

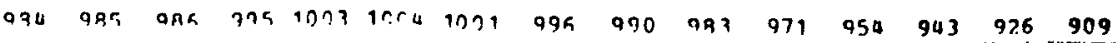

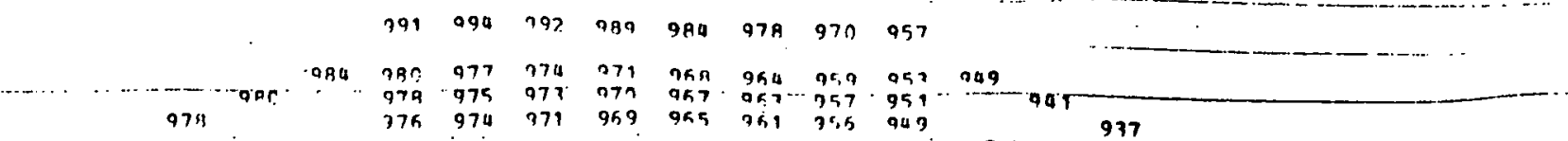




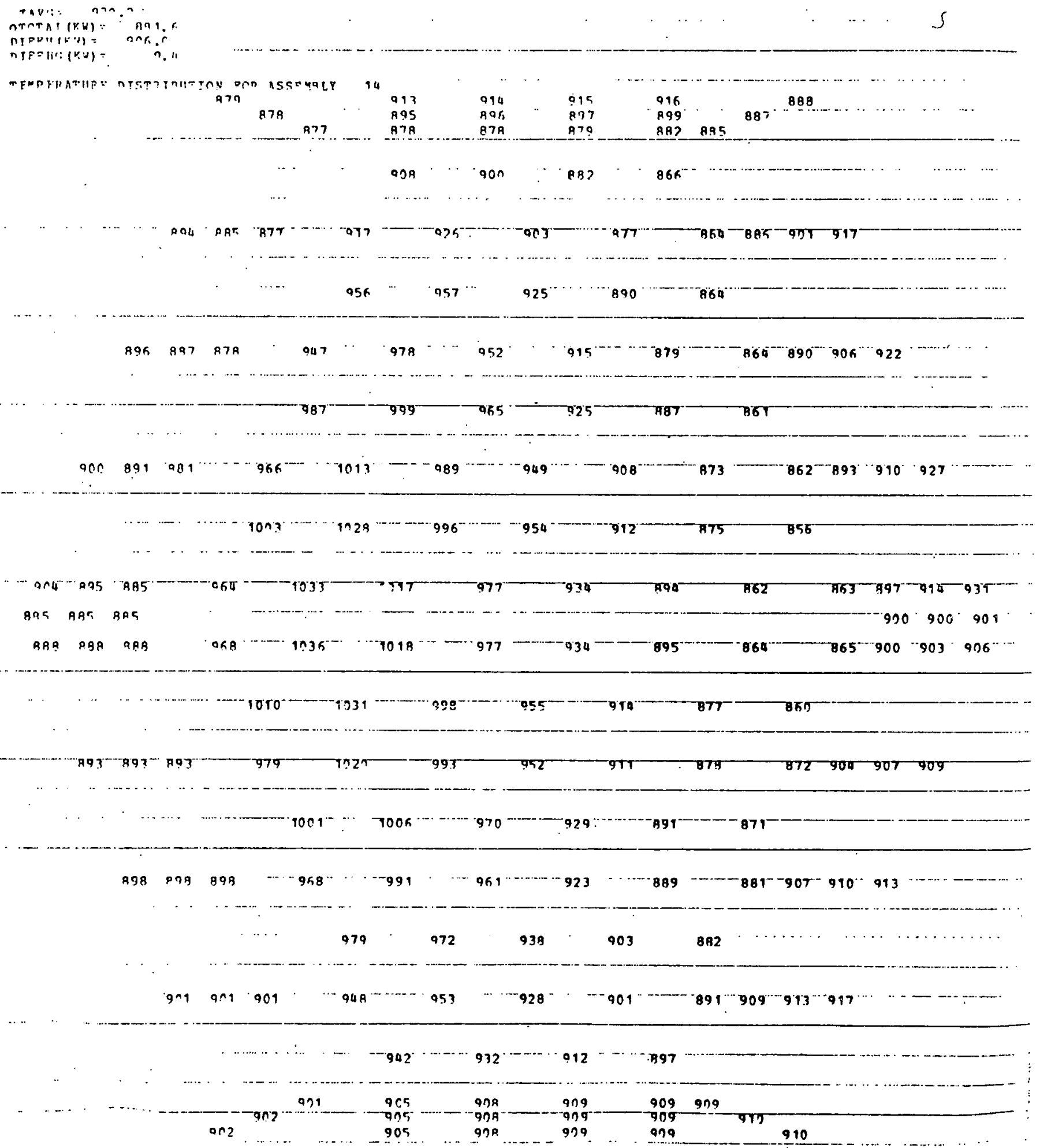




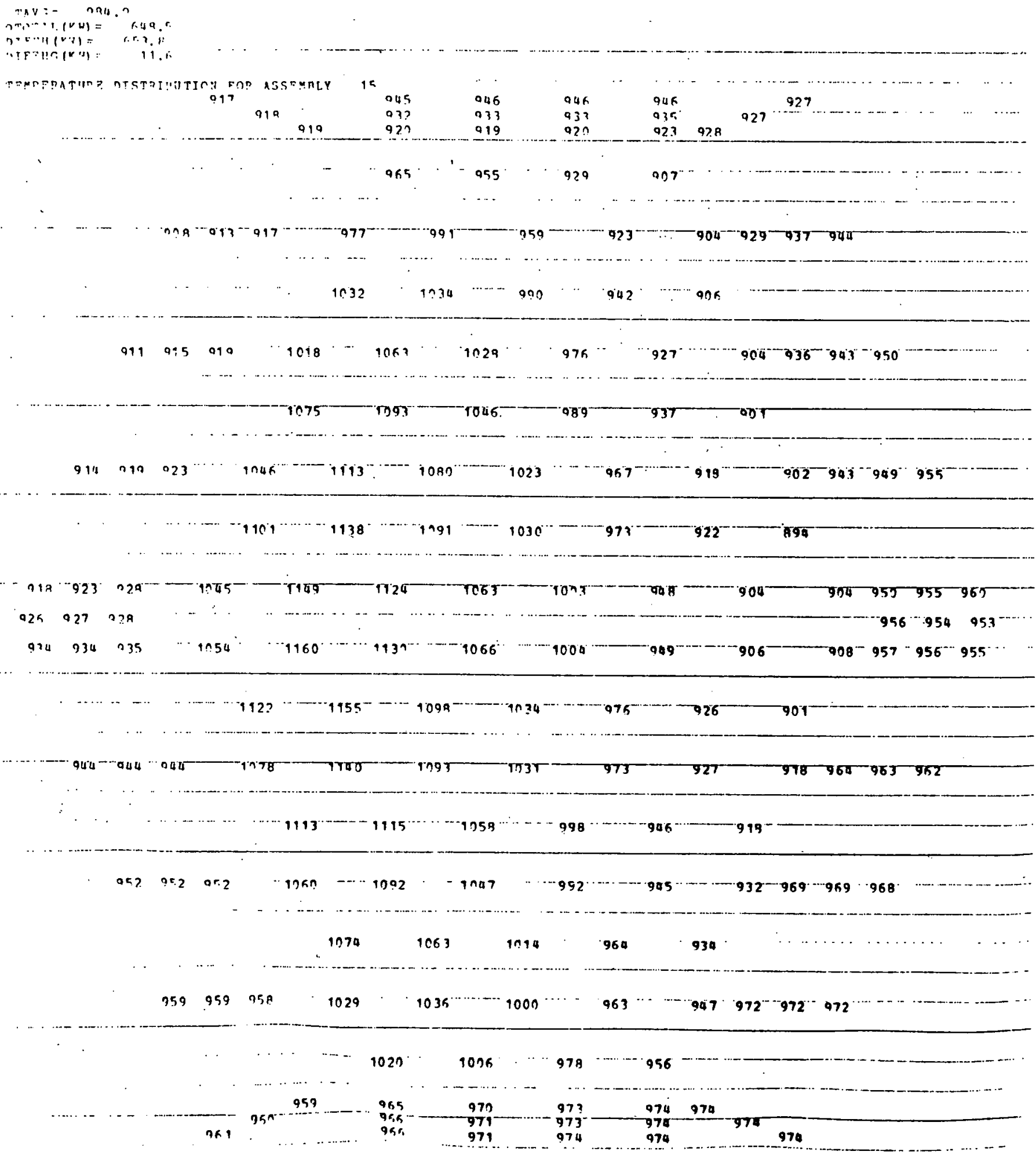




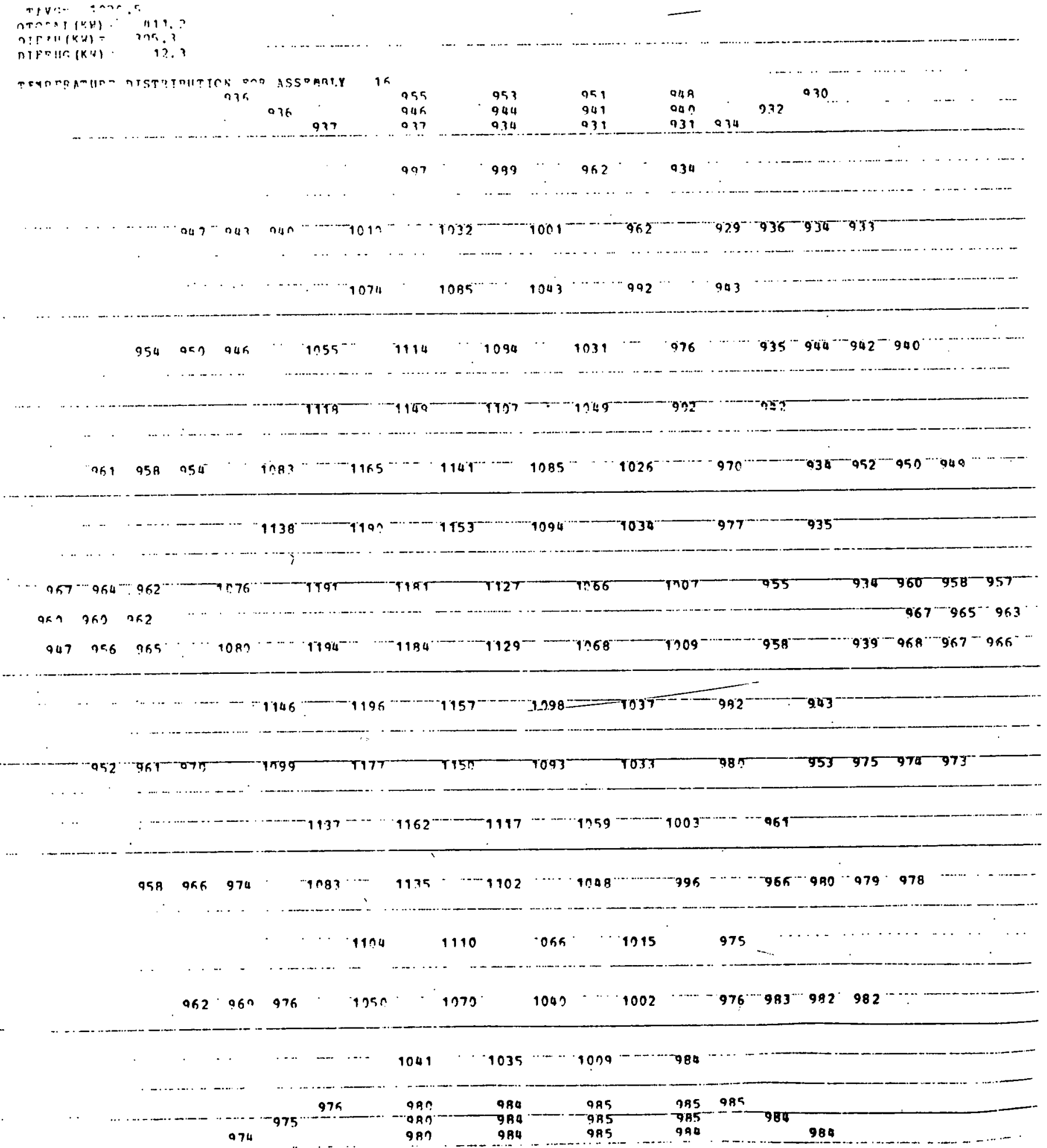

